\title{
SPATIAL AND TEMPORAL ASSESSMENT OF SOIL NITROGEN AVAILABILITY AND RELATIONSHIPS TO BIOPHYSICAL VARIABLES IN A HIGH ARCTIC WETLAND
}

By

\author{
Jacqueline K.Y. Hung
}

Honours B.A., University of Western Ontario, London, Ontario, Canada, 2015

\author{
A thesis presented to Ryerson University \\ in partial fulfillment of the requirements for the degree of \\ Master of Applied Science \\ in the Program of \\ Environmental Applied Science and Management
}

Toronto, Ontario, Canada, 2017

(C) Jacqueline Kit-Ying Hung 2017 


\section{Author's Declaration}

I hereby declare that I am the sole author of this thesis. This is a true copy of the thesis, including any required final revisions, as accepted by my examiners.

I authorize Ryerson University to lend this thesis to other institutions or individuals for the purpose of scholarly research.

I further authorize Ryerson University to reproduce this thesis by photocopying or by other

means, in total or in part, at the request of other institutions or individuals for the purpose of scholarly research.

I understand that my thesis may be made electronically available to the public. 


\begin{abstract}
SPATIAL AND TEMPORAL ASSESSMENT OF SOIL NITROGEN AVAILABILITY AND

RELATIONSHIPS TO BIOPHYSICAL VARIABLES IN A HIGH ARCTIC WETLAND
\end{abstract}

\author{
Jacqueline K.Y. Hung \\ Master of Applied Science, 2017 \\ Environmental Applied Science and Management \\ Ryerson University
}

Increased soil nutrient availability, and associated increase in ecosystem productivity, could create a negative feedback between Arctic ecosystem and the climate system, reducing the contribution of Arctic ecosystems to future climate change. This study explores the environmental controls over spatial patterns of soil nitrogen availability in a High Arctic wet sedge meadow and how they influence carbon exchange processes to predict whether this feedback will develop. Ion exchange resin membranes measured available inorganic nitrogen throughout the growing season at a high spatial resolution, while environmental variables and carbon flux measurements were taken at frequent intervals during the 2016 field season. Environmental measures correlated highly with total and late season nitrate with soil temperatures having the greatest effect. The results suggest that finer scale processes altering nitrogen availability may influence the $C$ balance of wet sedge meadows in the High Arctic and how these ecosystems may respond to changes in climate. 


\section{Co-Authorship}

The following list provides the names and institutions of the people who contributed to the manuscript that is the basis for this thesis:

Hung, J.K.Y. ${ }^{1}$, Atkinson, D.M. ${ }^{2}$, Scott, N.A. ${ }^{3}$ (2017). Spatial and temporal assessment of soil nitrogen availability and relationships to biophysical variables in a High Arctic wetland.

${ }^{1}$ Jacqueline K.Y. Hung: Candidate

${ }^{2}$ David M. Atkinson: Associate Professor, Department of Geography and Environmental Studies, Ryerson University

${ }^{3}$ Neal A. Scott: Associate Professor, Department of Geography and Planning, Queen’s University

Authorship of anticipated publications is as follows:

Hung, J.K.Y., Atkinson, D.M., and Scott, N.A. Spatial and temporal patterns of soil nitrogen availability and carbon exchange in a High Arctic wetland. (To be submitted).

The candidate is the primary author of the thesis and manuscript. Author 2 is the candidate's supervisor who contributed to the experimental design development, assisted with data collection, provided guidance on analysis methods, and reviewed and edited the manuscript. Author 3 also reviewed the manuscript and provided comments. 


\section{Acknowledgements}

I would like to thank my supervisor, Dr. David Atkinson, for his guidance and support throughout the research and writing process. This thesis would have taken a completely different turn and might not have happened had he not welcomed me into the Polar SEAL lab. Dr. Atkinson provided mentorship in the field and the lab and instilled in me a love for Arctic research.

Dr. Neal Scott of Queen's University was also invaluable in the sample analysis and thesis revision process. His support in providing access to necessary lab equipment to conduct much of the analysis played a huge role in the success of this research project. Dr. Andrew Laursen provided access to the shaker table that enabled for analysis of the soil nitrogen extracts. I would also like to thank Steve Koziar, Amanda Schevers, Matthew Gilman, and Gillian Thiel for their lab assistance, Sean Arruda, Robbie MacTavish, Jessica Peters, Maddie Harasyn, and Gillian Thiel for their help in the field, and Casey Beel for manuscript comments. Many thanks are owed to Dr. Scott Lamoureux of Queen's University for allowing me to join the research team at the Cape Bounty Arctic Watershed Observatory for the 2016 field season. Thank you to my defence committee members - Dr. Andrew Laursen (Department of Biology) and Dr. Claire Oswald (Department of Geography and Environmental Studies) - for providing your comments and insight on the manuscript. Logistical and equipment support was provided by Polar Continental Shelf Program (Natural Resources Canada). Funding from Ryerson University's Geography and Environmental Studies department, the Yeates School of Graduate Studies, and ArcticNet made this research possible. 
Behind the scenes, I owe many thanks to my parents, Derek, and Eva for your support and cheerleading along the way. Thank you for all your encouragement throughout my Master's degree and for your continued support as I further my education. 


\section{Table of Contents}

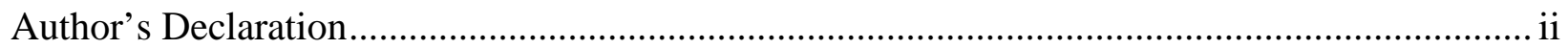

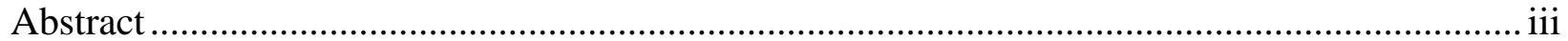

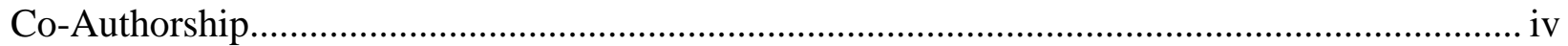

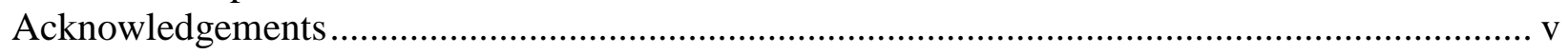

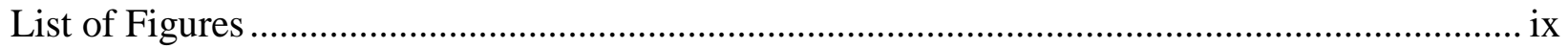

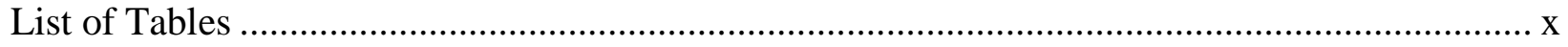

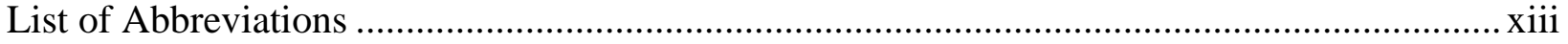

Chapter 1: Introduction ............................................................................................. 1

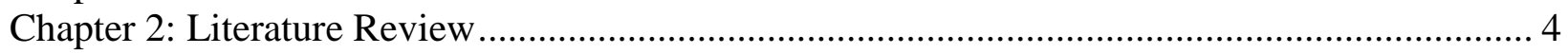

$2.1 \quad$ High Arctic Wetlands.................................................................................................... 4

2.1.1 Climate Warming and High Arctic Wetlands ............................................................ 5

2.2 Climate Warming and Carbon Shifts ............................................................................. 6

2.2.1 Arctic Carbon Fluxes ......................................................................................... 7

2.2.2 Environmental Controls of Arctic Carbon Fluxes ............................................... 8

2.3 High Arctic Soils .................................................................................................... 10

2.4 Nutrient Cycling in High Arctic Ecosystems ............................................................... 11

2.4.1 Arctic Nitrogen Cycling..................................................................................... 12

2.4.1.1 Biotic Nitrogen Fixation in High Arctic Wetlands........................................... 14

2.4.2 Environmental Factors Affecting Nitrogen Availability ……………………….... 15

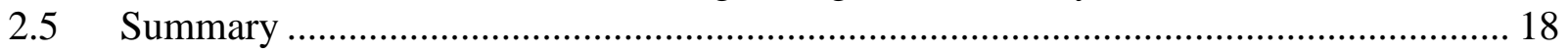

Chapter 3: Spatial and temporal patterns of soil nitrogen availability and carbon exchange in a

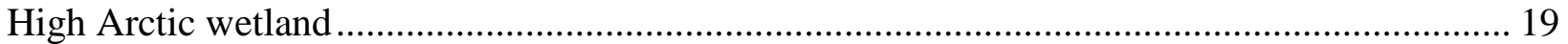

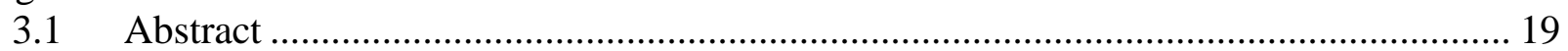

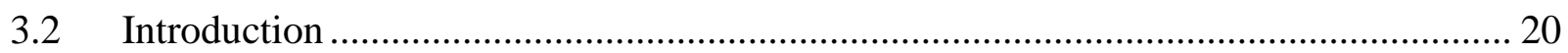

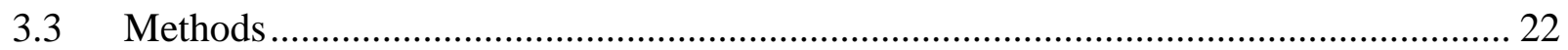

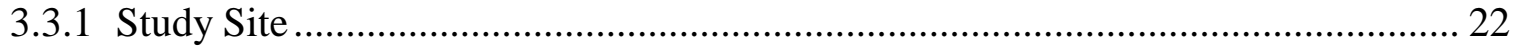

3.3.2 Experimental Design........................................................................................ 26

3.3.3 Soil Nutrient Availability Evaluation .................................................................... 28

3.3.4 Carbon Flux Sampling ..................................................................................... 30

3.3.5 Environmental Measurements .............................................................................. 31

3.3.6 Post-Field Processing............................................................................................... 32

3.3.6.1 Ion Exchange Resin Sample Processing........................................................ 32

3.3.6.2 Carbon Flux Calculation........................................................................... 33

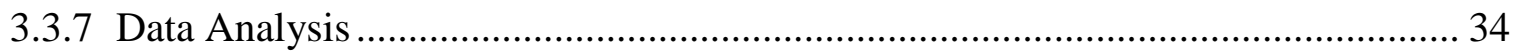

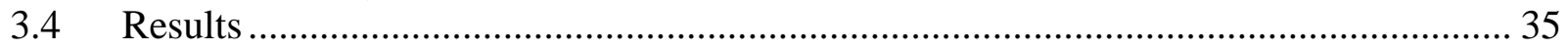

3.4.1 2016 Growing Season Air Temperature and Precipitation ...................................... 35

3.4.2 Environmental Variables ................................................................................... 37

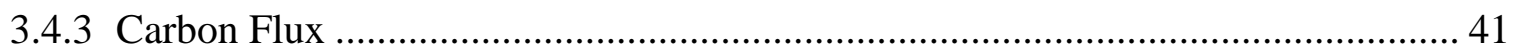

3.4.4 Quantitative Relationships Between Carbon Flux and Environmental Variables.. 44

3.4.5 Available Soil Nitrogen ................................................................................... 46

3.4.5.1 Seasonal Trends .......................................................................................... 46

3.4.5.2 Spatial Patterns ................................................................................................ 47

3.4.6 Relationships Between Available Nitrogen, Carbon Fluxes, and Environmental

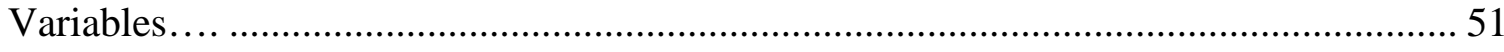




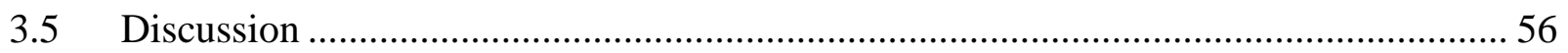

3.5.1 Carbon Flux and Environmental Trends ........................................................ 56

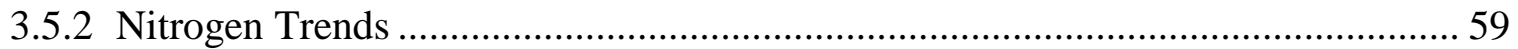

3.5.3 Implications of Lack of Statistical Significance ........................................................ 61

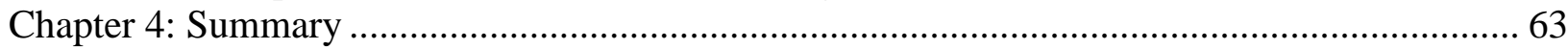

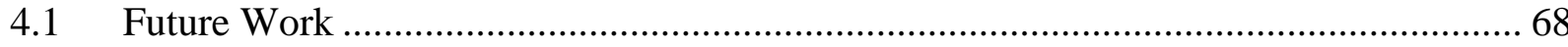

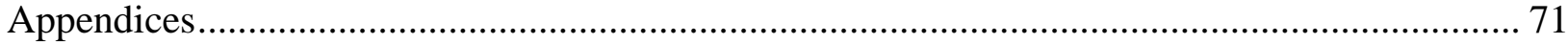

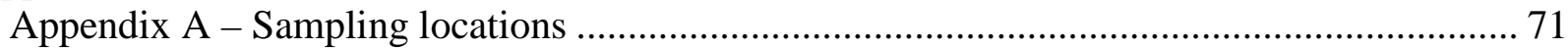

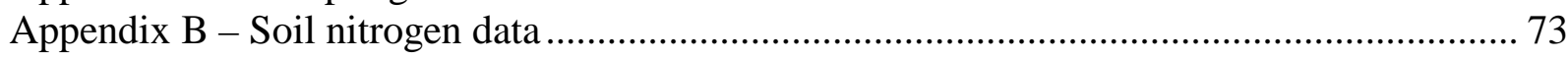

Appendix C - Carbon dioxide exchange data......................................................................... 76

Appendix D - Soil moisture, soil temperature, and active layer depth data .............................. 82

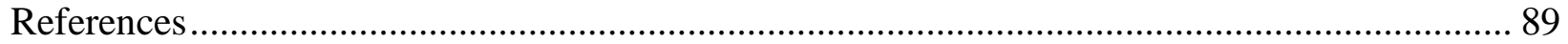




\section{List of Figures}

Figure 1: Positive and negative feedback loops between carbon fluxes and environmental variables

Figure 2: A conceptual diagram of the terrestrial nitrogen cycle, with red portions representing microbial processes and blue portions representing plant available $\mathrm{N}$ forms. 13 Figure 3: Map showing Melville Island with the Cape Bounty Arctic Watershed Observatory (red star). 23

Figure 4: WorldView-2 imagery of the Cape Bounty Arctic Watershed Observatory in July 2016 23

Figure 5: Topographic map of the Cape Bounty Arctic Watershed Observatory, highlighting the study area "Muskox" .................................................................................................... 25

Figure 6: North-facing image of the wet sedge meadow study area "Muskox"......................... 25

Figure 7: Wet sedge meadow vegetation type .................................................................... 26

Figure 8: Conceptual diagram of the sampling plot, with wet tracks represented in red and dry tracks represented in green. Elevations of the snowpack, northern-most sampling plots, and southern-most sampling plots are displayed as metres above mean sea level (AMSL).............. 27

Figure 9: Topographic map depicting the layout of the experimental design ........................... 28

Figure 10: $\mathrm{CO}_{2}$ flux static chamber light measurement and ion exchange resin strips in situ ..... 31 Figure 11: Hourly air temperature and precipitation measurements at the "West Met" meteorological station at CBAWO from June 29 to July 27, 2016. Rectangles represent the partitioning of the study period into weeks for analysis: Week 1 (blue), Week 2 (orange), Week 3 (grey), and Week 4 (yellow) .......................................................................................... 36 Figure 12: Mean June and July temperatures and cumulative June and July rainfall since

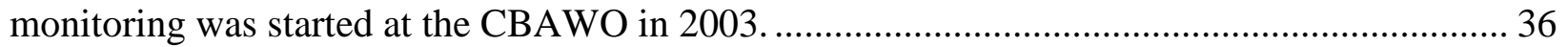

Figure 13: Mean ( \pm 1 SE) ST change across the growing season within the tracks.................... 38

Figure 14: Mean ( \pm 1 SE) SM change across the growing season. .......................................... 39

Figure 15: Mean ( $\pm 1 \mathrm{SE})$ AL change across the growing season.......................................... 40

Figure 16: Mean $( \pm 1$ SE) NEE change across the growing season. ....................................... 42

Figure 17: Mean ( \pm 1 SE) ER change across the growing season. ............................................ 43

Figure 18: Mean ( \pm 1 SE) GPP change across the growing season......................................... 44

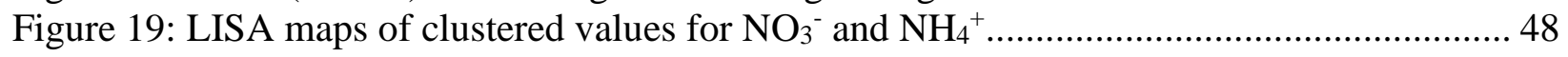

Figure 20: Ordinary kriging maps for total season adsorption of $\mathrm{NO}_{3}{ }^{-}$and $\mathrm{NH}_{4}+$. Red dots represent wet tracks and green dots represent dry tracks................................................... 49 Figure 21: Ordinary kriging maps for early season adsorption of $\mathrm{NO}_{3}{ }^{-}$and $\mathrm{NH}_{4}{ }^{+}$. Red dots represent wet tracks and green dots represent dry tracks..................................................... 50 Figure 22: Ordinary kriging maps for late season adsorption of $\mathrm{NO}_{3}{ }^{-}$and $\mathrm{NH}_{4}{ }^{+}$. Red dots represent wet tracks and green dots represent dry tracks................................................... 51 Figure 23: NEE, ER, and GPP change throughout the growing season across moisture tracks.

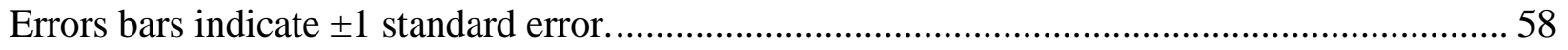




\section{List of Tables}

Table 1: Mean environmental variables across the moisture tracks over the growing season. Standard deviations are indicated in brackets................................................................... 37 Table 2: Two-way ANOVA p-values for environmental variables across the growing season in different moisture tracks across the plot. Bolded values indicate significance at $\mathrm{p}<0.05$........ 37 Table 3: Mean carbon exchange measurements across the moisture tracks over the growing season. Standard deviations are indicated in brackets. .................................................... 41 Table 4: Two-way ANOVA p-values for carbon flux measurements across the growing season in different moisture tracks across the plot. Bolded values indicate significance at $\mathrm{p}<0.05$........ 41 Table 5: Pearson's bivariate correlation coefficients for carbon flux measurements and environmental variables across the entire growing season. Bolded values indicate significance at $\mathrm{p}<0.05$.

Table 6: Pearson's bivariate correlation coefficients for carbon flux measurements and environmental variables across the early season. Bolded values indicate significance at $\mathrm{p}<0.05$.

Table 7: $\mathrm{r}^{2}$ values for environmental variable regression analysis during the late growing season.

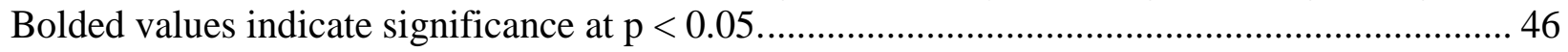
Table 8: Mean and standard error values for $\mathrm{NO}_{3}{ }^{-}$and $\mathrm{NH}_{4}{ }^{+}$across moisture tracks, expressed as $\mu \mathrm{g}$ of nutrient adsorbed per $10 \mathrm{~cm}^{2}$ per two-week period................................................... 46

Table 9: Univariate local Moran's I values for $\mathrm{NO}_{3}{ }^{-}$and $\mathrm{NH}_{4}{ }^{+}$........................................... 48 Table 10: Bivariate regression $\mathrm{R}^{2}$ coefficients for nitrogen (dependent variable) against environmental variables (independent variable) across dry tracks. Bolded values indicate

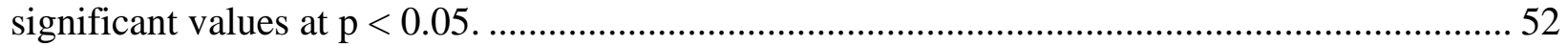
Table 11: Bivariate regression $\mathrm{R}^{2}$ coefficients for nitrogen (independent variable) against environmental variables (dependent variable) across dry tracks. Bolded values indicate

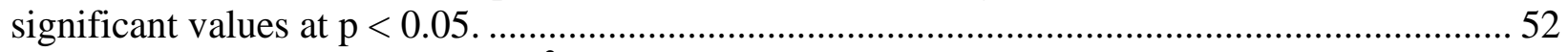
Table 12: Bivariate regression $\mathrm{R}^{2}$ coefficients for nitrogen against environmental variables and carbon flux across wet tracks. Bolded values indicate significant values at $\mathrm{p}<0.05 \ldots \ldots \ldots \ldots . . . . .52$ Table 13: Bivariate regression $\mathrm{R}^{2}$ coefficients for nitrogen (independent variable) against environmental variables (dependent variable) across wet tracks. Bolded values indicate

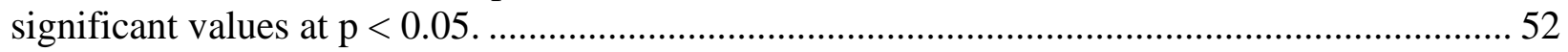
Table 14: Multiple regression statistics for total season $\mathrm{NH}_{4}{ }^{+}$across wet and dry tracks. Bolded

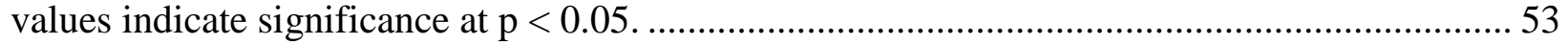
Table 15: Multiple regression statistics for early season $\mathrm{NH}_{4}{ }^{+}$across wet and dry tracks. Bolded

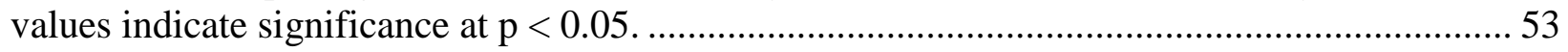
Table 16: Multiple regression statistics for late season $\mathrm{NH}_{4}$ across wet and dry tracks. Bolded

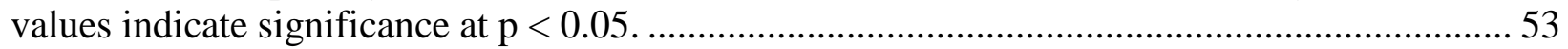
Table 17: Multiple regression statistics for total season $\mathrm{NO}_{3}{ }^{-}$across wet and dry tracks. Bolded

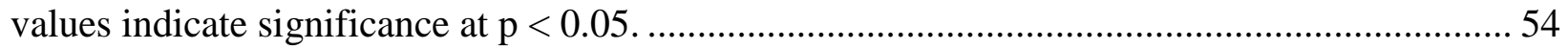
Table 18: Multiple regression statistics for early season $\mathrm{NO}_{3}{ }^{-}$across wet and dry tracks. Bolded

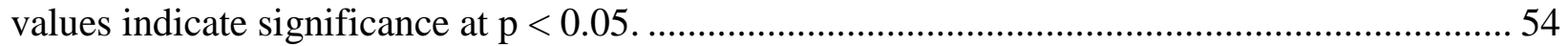
Table 19: Multiple regression statistics for late season $\mathrm{NO}_{3}{ }^{-}$across wet and dry tracks. Bolded

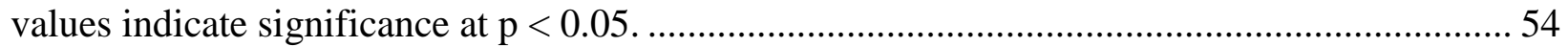
Table 20: Multiple regression statistics for total season ER across wet and dry tracks. Bolded

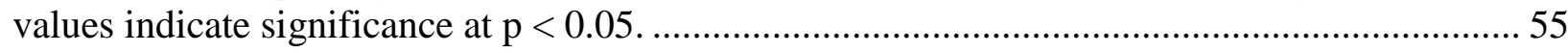


Table 21: Multiple regression statistics for early season ER across wet and dry tracks. Bolded

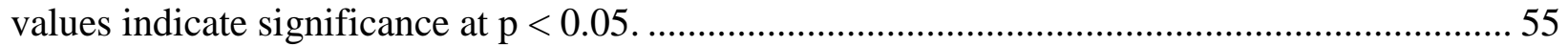
Table 22: Multiple regression statistics for late season ER across wet and dry tracks. Bolded

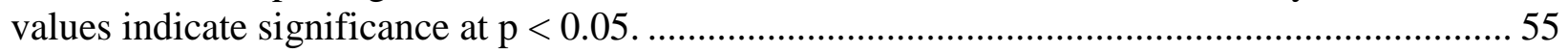
Table 23: Multiple regression statistics for total season GPP across wet and dry tracks. Bolded

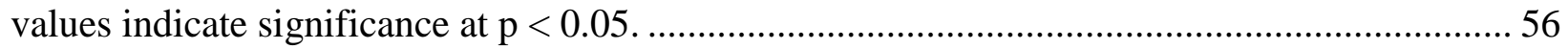
Table 24: Multiple regression statistics for early season GPP across wet and dry tracks. Bolded

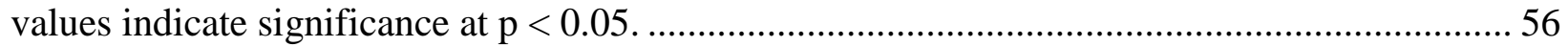
Table 25: Multiple regression statistics for late season GPP across wet and dry tracks. Bolded

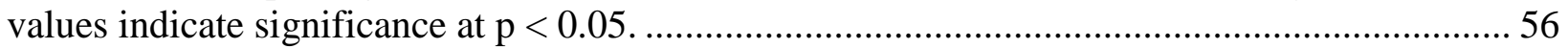
Table 26: Summary of environmental variables and carbon flux trends across the growing

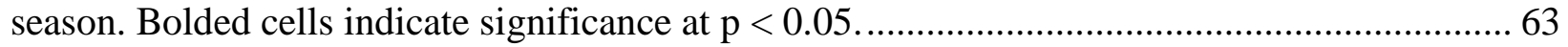
Table 27: UTM coordinates (WGS 84, Zone 12N) of all sampling sites in the Muskox wet sedge meadow at the Cape Bounty Arctic Watershed Observatory ................................................. 71 Table 28: Resin A (June 30 to July 27) $\mathrm{NO}_{3}{ }^{-}$(orange) and $\mathrm{NH}_{4}^{+}$(green) adsorbed using ion exchange membranes, expressed as $\mu$ g of nutrient adsorbed per $10 \mathrm{~cm}^{2}$ over a four-week period

Table 29: Resin B1 (June 30 to July 13) $\mathrm{NO}_{3}{ }^{-}$(orange) and $\mathrm{NH}_{4}{ }^{+}$(green) adsorbed using ion exchange membranes, expressed as $\mu \mathrm{g}$ of nutrient adsorbed per $10 \mathrm{~cm}^{2}$ over a two-week period

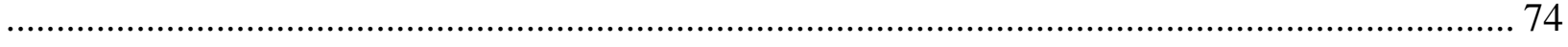
Table 30: Resin B2 (July 13 to July 27) $\mathrm{NO}_{3}{ }^{-}$(orange) and $\mathrm{NH}_{4}{ }^{+}$(green) adsorbed using ion exchange membranes, expressed as $\mu \mathrm{g}$ of nutrient adsorbed per $10 \mathrm{~cm}^{2}$ over a two-week period

Table 31: Net ecosystem exchange (NEE) throughout the growing season expressed as

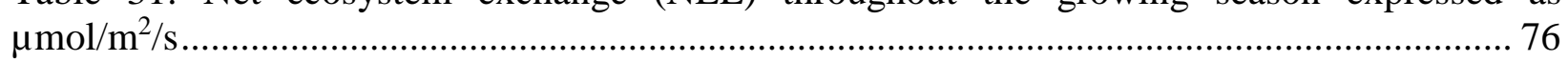

Table 32: Mean NEE measurements standard deviation across the dry tracks over the growing

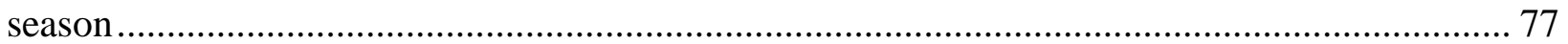

Table 33: Mean NEE measurements standard deviation across the wet tracks over the growing

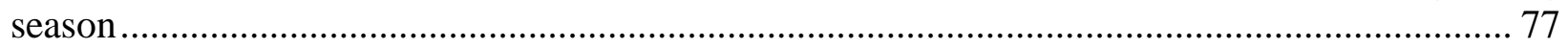

Table 34: Ecosystem respiration (ER) throughout the growing season expressed as $\mu \mathrm{mol} / \mathrm{m}^{2} / \mathrm{s} .78$ Table 35: Mean ER measurements standard deviation across the dry tracks over the growing season..... 79

Table 36: Mean ER measurements standard deviation across the wet tracks over the growing season .......................................................................................................... 79 Table 37: Gross primary production (GPP) throughout the growing season expressed as

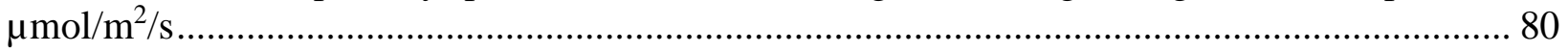

Table 38: Mean GPP measurements standard deviation across the dry tracks over the growing season. 81

Table 39: Mean GPP measurements standard deviation across the wet tracks over the growing

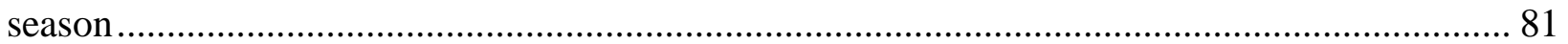

Table 40: Soil temperature data collected throughout the growing season, expressed in Celsius 82 Table 41: Mean ST measurements standard deviation across the dry tracks over the growing season. 83 Table 42: Mean ST measurements standard deviation across the wet tracks over the growing season. 83 
Table 43: Soil moisture data collected throughout the growing season, expressed as a percentage

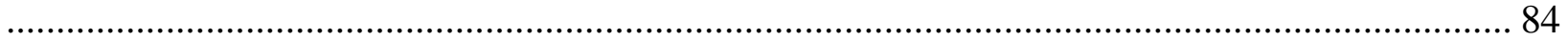

Table 44: Mean SM measurements standard deviation across the dry tracks over the growing

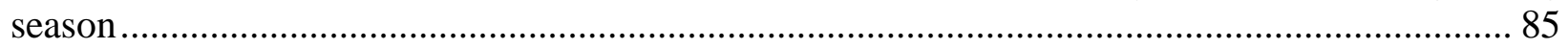
Table 45: Mean SM measurements standard deviation across the wet tracks over the growing

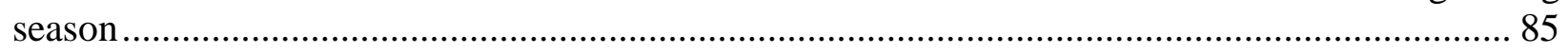
Table 46: Active layer depth collected throughout the growing season, expressed in centimetres

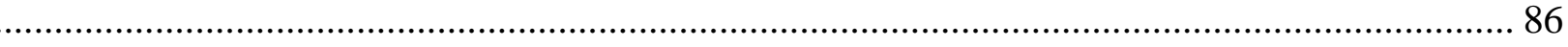

Table 47: Mean AL measurements standard deviation across the dry tracks over the growing

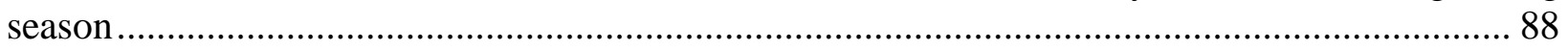
Table 48: Mean AL measurements standard deviation across the wet tracks over the growing

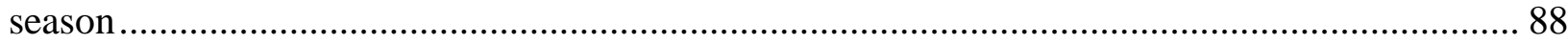




\section{List of Abbreviations}

ACIA

AL

ANOVA

AT

C

CBAWO

CNNRO

$\mathrm{CH}_{4}$

$\mathrm{CO}_{2}$

ER

GPP

IER

IPCC

IRGA

M

NEE

$\mathbf{N}$

$\mathrm{NH}_{4}^{+}$

$\mathrm{NO}_{3}{ }^{-}$

$\mathrm{N}_{2} \mathrm{O}$

OLS

$\mathbf{P}$

PAR

ppm

PRS

SD

SE

SOM

SM

ST

SZ
Arctic Climate Impact Assessment

Active Layer

Analysis of Variance

Air Temperature

Carbon

Cape Bounty Arctic Watershed Observatory

Canadian Network of Northern Research Operators

Methane

Carbon Dioxide

Ecosystem Respiration

Gross Primary Production

Ion Exchange Resin

Intergovernmental Panel on Climate Change

Infrared Gas Analyzer

Mean

Net Ecosystem Exchange

Nitrogen

Ammonium

Nitrate

Nitrous Oxide

Ordinary Least Squares

Phosphorus

Photosynthetic Active Radiation

Parts Per Million

Plant Root Simulator

Standard Deviation

Standard Error

Soil Organic Matter

Soil Moisture

Soil Temperature

Saturation Zone 


\section{Chapter 1: Introduction}

The onset of climate warming has been introducing numerous problems to our environment, and in recent decades, Arctic regions have been most notably affected (IPCC, 2013; Stocker et al., 2013). The last three years - 2014, 2015, and 2016 - have been the warmest years on record (NASA, 2017). In 2016, global temperatures were $0.99^{\circ} \mathrm{C}$ above the $1951-1980$ average, with the region north of $60^{\circ} \mathrm{N}$ warming by $0.94^{\circ} \mathrm{C}$ alone in the past year (NASA, 2017). Changes in the High Arctic regions include decreasing sea ice extents and the melting of perennial snowpacks as a result of warming temperatures (IPCC, 2013; Woo and Young, 2014). Ecosystems adjacent to these snowpacks therefore experience changes in patterns of water inputs (Callaghan et al., 2011b). With increased snowmelt contributing greater amounts of runoff to wetland areas of Arctic environments (e.g. wet sedge meadows), changes to the spatial and temporal patterns of microbial activity and soil nutrient availability could occur (Biederbeck and Campbell, 1973; Jonasson and Shaver, 1999). These wet sedge meadows can have a significant impact on landscape-scale carbon (C) exchange. Environmental responses of higher ecosystem respiration (ER) will release more carbon dioxide $\left(\mathrm{CO}_{2}\right)$ into the atmosphere, contributing to the positive feedback loop of global warming, while increased nutrient availability could increase plant growth, storing more C and creating a negative feedback (Elberling et al., 2008; Chae et al., 2015; Christiansen, 2016). In this climate change narrative, Arctic ecosystems play a large role in its contribution or sequestration of $\mathrm{CO}_{2}$ into the atmosphere (Grogan and Jonasson, 2005). As such, understanding controls on soil nutrient availability in these ecosystems can provide insight into their future contribution to C storage rates in the High Arctic (Grogan and Chapin, 2000). 
At the Cape Bounty Arctic Watershed Observatory (CBAWO), scientists have been studying hydrological, biogeochemical, and permafrost dynamics since 2003 (CNNRO, 2015). There is extensive literature published on the findings from research conducted on the processes occurring across different environments at the CBAWO. While the controls on C dynamics in wet sedge meadows have been studied (Gregory, 2011; Atkinson, 2012; Beamish et al., 2014; Ramsay, 2015; Blaser, 2016; Luce, 2016), the nutrient availability as a control on C dynamics has not been investigated in this setting. A knowledge gap still exists within some of the individual micro-environments within the watersheds, specifically in relation to High Arctic wetlands.

At Ryerson University, the Polar Regions Spatial and Environmental Analysis Laboratory (Polar SEAL) has been examining the biophysical variables within Low, Mid, and High Arctic ecosystems. Specific studies in the High Arctic out of Polar SEAL have looked at modelling environmental variables (e.g. active layer depth, soil moisture, soil temperature, and snowmelt) in High Arctic wetlands (Ramsay, 2015) and the examination of the relationship between C cycling and environmental variables (Luce, 2016). Building on this previous research and existing knowledge, the objective of this study is to examine and evaluate the spatial and temporal distribution of available soil nitrogen (N) in a High Arctic wetland.

The following three research questions were investigated in this study:

1. How does active layer depth, soil moisture, and soil temperature affect nitrogen availability of a High Arctic wetland throughout the growing season?

With the known changes that are occurring in High Arctic environments (IPCC, 2013), it is expected that as the growing season progresses, the active layer will thaw and deepen, resulting in an increase in the mean soil temperature within the High Arctic wet sedge tundra 
(Grogan and Chapin, 2000; Hill and Henry, 2011). Prior research has shown that increases in soil temperature will promote microbial activities like net $\mathrm{N}$ mineralization (Biederbeck and Campbell, 1973; Jonasson and Shaver, 1999).

2. What relationships exist between carbon flux and the concentration of available nitrogen in a High Arctic wetland throughout the growing season?

If $\mathrm{N}$ limits net primary production, increased $\mathrm{N}$ availability could increase photosynthesis and, therefore, net ecosystem exchange (NEE). Previous research has found that that an increase in soil $\mathrm{N}$ significantly increased net $\mathrm{CO}_{2}$ uptake (Billings et al., 1984; Shaver et al., 2000). This reverse relationship of increased net $\mathrm{CO}_{2}$ uptake promoting soil available $\mathrm{N}$ will likely be seen in the wetland as the growing season progresses; however, this will depend on whether respiration or production is the dominant process in flux at the time of the season.

3. What effect does proximity to the perennial snowpacks have on spatial patterns of nitrogen availability of a High Arctic wetland as the growing season progresses?

The melt of the perennial snowpack adjacent to many wet sedge meadows will alter the water availability and microbial activity within the wetland (Nobrega and Grogan, 2008; Christiansen, 2016). As productivity within the meadow is directly linked with moisture (Reynolds and Tenhunen, 1996), it can be hypothesized that areas with higher water content in wet sedge meadows will display higher NEE, greater ER, and more photosynthetic activity compared to dry tracks. As the snowpack disappears, areas beyond the lateral extent of the snowpack will likely see the rates of the linked processes slow down. 


\section{Chapter 2: Literature Review}

\subsection{High Arctic Wetlands}

High Arctic wetlands play an important role in the hydrological and C dynamics of Arctic environments (Grogan and Jonasson, 2005). Wetlands require a constant, sufficient water supply and are found where water gains exceed losses (Woo, 2011). Consequently, the availability of water in the arid, desert environment of the Arctic is a determining factor in the location and productivity of these wetlands (Woo and Young, 2006; Woo and Young, 2012). Wetlands consist of hydric soils characterized by saturated surfaces promoting hydrophyte growth (National Wetlands Working Group, 1988). In the Arctic, their growing season is limited to a maximum of three months each year, during which an adequate supply of water is needed to sustain them as wetlands. These areas of significant moisture within the otherwise dry polar desert provide sustenance for Arctic fauna and play an important role in ecological function (Woo and Young, 2006; Woo and Young, 2012). Their role in the global climate system is often understated: covering 346-500 Mha of the Earth’s surface, northern wetlands play an important role in regulating dynamic processes that affect the entire planet (Gorham, 1991; Zoltai and Martikainen, 1996; Sullivan et al., 2008).

In the Canadian Arctic, wetlands cover 3.4\% of the northern land area (Environment and Climate Change Canada, 2016). Arctic wetlands currently act as important regions of long-term C storage and sequestration. These wetlands contain a disproportionate amount of subterraneous C (Post et al., 1982; Grogan and Chapin, 1999) and will contribute significantly to global C changes. For example, it is expected that increased C losses from the terrestrial environment into the atmosphere will result from increased permafrost degradation as a result of a changing global climate (Tarnocai et al., 2009). Land cover in the High Arctic is typically classified as being dry, 
mesic, or wet (Gregory, 2011; Atkinson, 2012). Within the wet land cover class in the CBAWO, wet sedge meadows are the most productive and photosynthetically active environments (Henry et al., 1990; Henry, 1998; Atkinson, 2012; Atkinson and Treitz, 2013). Seasonal and perennial snowpacks, which are frozen for 9-10 months throughout the year, provide runoff during the short growing season, resulting in nival-driven wetlands (Woo and Young, 2006). Thawing of the active layer in these environments is promoted by the clay substrate that underlies the organic layer, which helps decrease the amount of moisture loss through vertical percolation (Woo and Young, 2006). Preliminary research has predicted that the wetland cover in Arctic regions have the potential to increase with increased temperatures and precipitation inputs (Nobrega and Grogan, 2008; Hill and Henry, 2011). These increases in wet sedge meadow biomass can help offset the projected increases in C losses through C uptake during photosynthesis. However, global climate models by Avis et al. (2011) have also projected the opposite, with permafrost degradation leading to a decrease in the areal extent of wetlands. As such, more research is needed to understand the relationship between climatic warming and Arctic wetlands to determine the reaction these regions will have with increased temperatures.

\subsubsection{Climate Warming and High Arctic Wetlands}

An earlier onset of snowmelt and consequent vegetation growth is expected to increase water storage in the subsurface (Young, 2006; Woo and Young, 2012; Lafrenière et al., 2013). Warmer climate years can quickly diminish the extents of permanent snowpacks that feed into wetlands, but to accumulate a snowpack back up to its former extent takes a considerable time and winter precipitation (Woo and Young, 2006). Consequently, the water supply to High Arctic wetlands in the latter part of the growing season will see a shift in its water source in years to come due to the declining extent of permanent snowpacks. Global climate models project 
significant regional temperature increases in the High Arctic, with precipitation inputs expecting to increase in response (IPCC, 2013; Bintanja and Andry, 2017). Subsequent changes in the water balance and expected degradation of permafrost will help maintain a high water table but may lead to a decrease in the extent of wetlands that are fed by meltwater (Woo and Young, 2006). Similarly, permafrost thaw is also thought to decrease wetland extent due to drainage (Avis et al., 2011; Grosse et al., 2011; Beermann, 2016). Thus, the effects of changes in environmental variables on these ecosystems needs to be further investigated to project the future reactions of northern wetlands to warming.

Within the permafrost and frozen soil layers of Arctic wetlands are thousands of years of stored C that can be released through melt. In saturated environments like wetlands, the anaerobic conditions (oxygen limited) are favourable for methane $\left(\mathrm{CH}_{4}\right)$ and nitrous oxide $\left(\mathrm{N}_{2} \mathrm{O}\right)$ production and release over $\mathrm{CO}_{2}$ (Elberling et al., 2008; Schuur et al., 2009). The impact of $\mathrm{CH}_{4}$ and $\mathrm{N}_{2} \mathrm{O}$ release in the atmosphere is much more detrimental than $\mathrm{CO}_{2}$ release, as the global warming potential of $\mathrm{CH}_{4}$ is 28-36 over 100 years and $\mathrm{N}_{2} \mathrm{O}$ has a GWP of 265-298 (US EPA, 2017). Because these trace gases are favoured in anoxic conditions like High Arctic wetlands, there is a need to understand the dynamics in these wetlands that warrant their potential release in warming conditions.

\subsection{Climate Warming and Carbon Shifts}

There has been a $40 \%$ increase in atmospheric $\mathrm{CO}_{2}$ concentrations since pre-industrial times (1920-2017), and concentrations continue to increase more rapidly each year (IPCC, 2013; Stocker et al., 2013). Atmospheric $\mathrm{CO}_{2}$ concentrations were measured at greater than $400 \mathrm{ppm}$ at the National Oceanic and Atmospheric Administration's (NOAA) Mauna Loa in September 2016, at a time when $\mathrm{CO}_{2}$ concentrations are typically at their lowest of the year (Kahn, 2016). 
Comprehensive data from NOAA's Barrow station indicated that early winter $\mathrm{CO}_{2}$ emissions have risen 75\% since 1975 (Commane et al., 2017). Arctic tundra soils contains 14\% of the global C pool (Post et al., 1982; Grogan and Chapin, 1999) and their potential release into the atmosphere could be detrimental to terrestrial and hydrological systems. Nobrega and Grogan (2008) have found in their study of mid-Arctic wetlands that net $C$ gain was largest in an Arctic wetland setting when compared to other Arctic ecosystems. Short-term studies of Arctic tundra environments are suggesting that Arctic permafrost regions currently act as sinks of atmospheric and terrestrial C (Nobrega and Grogan, 2008; Lafleur et al., 2012; McGuire et al., 2012); however, the comprehensive C study by McGuire et al. (2012) also determined that the tundra has been neutral in recent decades. Generally, long-term C studies are still lacking across the High Arctic tundra (Euskirchen et al., 2016). A long-term study by Euskirchen et al. (2016) found that increases in air and soil temperatures at multiple depths may trigger a new trajectory of $\mathrm{CO}_{2}$ release. As such, the need to understand both the physical processes as well as the environmental variables that influence these processes is necessary, particularly in ecosystems like wetlands that can have the most dramatic change and impact on global systems.

\subsubsection{Arctic Carbon Fluxes}

The terrestrial C cycle is composed of two dynamic components - gross primary production (GPP) and ER - that together make up NEE. GPP accounts for C gained through processes like photosynthesis, while ER is the C lost through respiration in plants and soils. Several variables influence C exchange processes: Sullivan et al. (2008) found that in Greenland fen environments, the terrestrial $\mathrm{C}$ balance is dependent on the surrounding microtopography. Natali et al. (2011) found that a $1.5^{\circ} \mathrm{C}$ increase in soil temperature resulted in a $10 \%$ increase in thaw depth. Additionally, the water table depth can have an influence on ER through higher 
evapotranspiration resulting in drier soils (Billings et al., 1982; Weller et al., 1995; Welker et al., 2004).
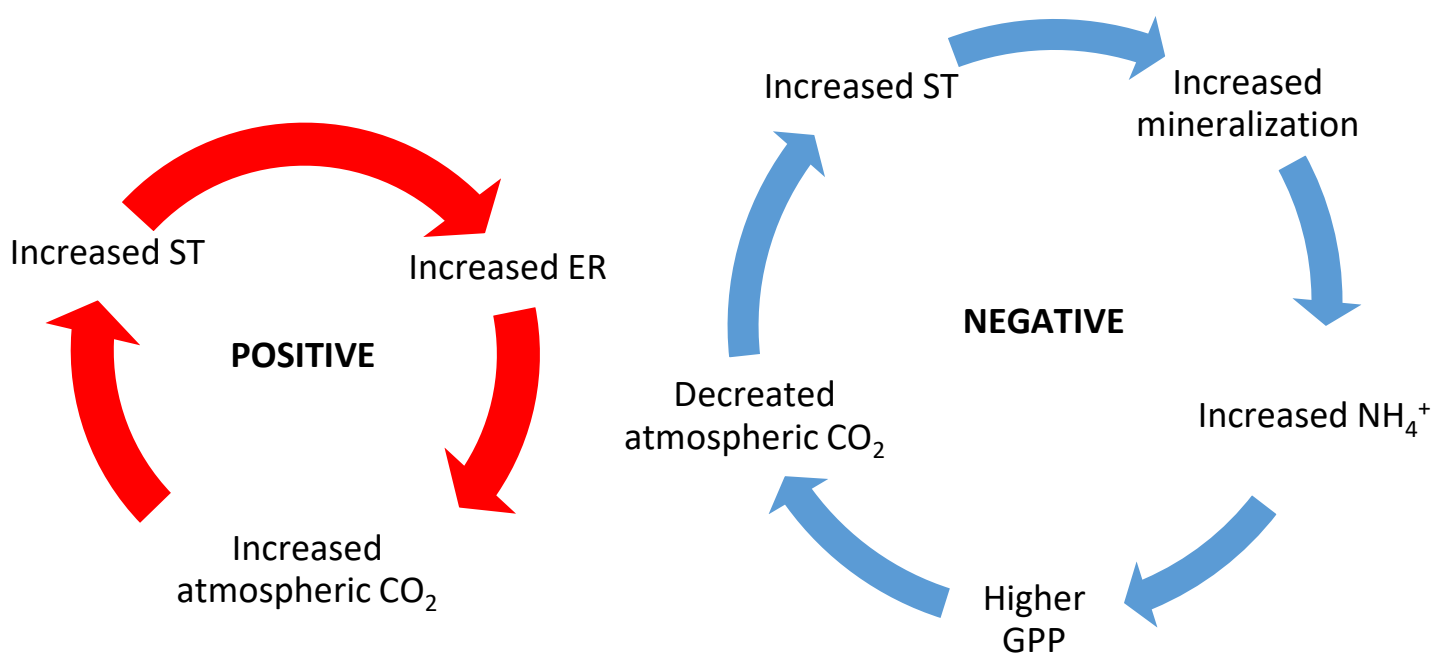

Figure 1: Positive and negative feedback loops between carbon fluxes and environmental variables

The balance between ER and GPP is an important determinant of net C storage. High Arctic wetlands have long been regarded as C sinks due to the dominance of GPP over ER (Mikan, et al., 2002; Nobrega and Grogan, 2008; Lafleur et al., 2012; McGuire et al., 2012; Blaser, 2016). However, experimental warming research near the Alaska Range has shown that organic C near the surface of these Arctic environments is very vulnerable and susceptible to release, contributing to a positive feedback loop (Figure 1) (Post et al., 1982; Natali et al., 2011; Commane et al., 2017). Warming temperatures are expected to increase ER in the Arctic regions, which could lead to a shift in the C balance depending on the response of GPP. This could lead to decreased net $\mathrm{C}$ storage and make permafrost regions long-term net $\mathrm{C}$ sources (Welker et al., 2004; Commane et al., 2017).

\subsubsection{Environmental Controls of Arctic Carbon Fluxes}

The northern circumpolar permafrost region accounts for approximately $16 \%$ of the global soil area with 1672 Pg of organic C stored (Tarnocai et al., 2009). Belowground $\mathrm{CO}_{2}$ 
release is season-dependent and strongly influenced by climate (Grogan and Chapin, 1999). Historically, the Arctic's frozen soils were considered strong C sinks due to low temperatures and poor drainage (Grogan and Chapin, 1999; Mikan, et al., 2002). However, some Arctic areas like the Alaskan North Slope have consistently been acting as $\mathrm{C}$ sources during the growing season (Oechel et al., 1993). More recently, studies have determined that the Alaskan Arctic has been a net $\mathrm{CO}_{2}$ source from 2012 to 2014, with particularly high emissions in the early winter months (Commane et al., 2017). Similarly, a study that included a Canadian High Arctic wetland at Alexandra Fiord on Ellesmere Island showed that the wet sedge was a net $\mathrm{CO}_{2}$ source until switching to a sink closer to the end of the growing season (Welker et al., 2004). Studies at Toolik Lake, Alaska found that simulated warmer climate made wet sedge tundra plots a weak sink for $\mathrm{CO}_{2}$ at the peak of the growing season but only for a short period of time (Johnson et al., 2000). The study of C cycling in Arctic wetlands by Sullivan et al. (2008) found C fluxes to be temperature-sensitive, concluding that with future warming trajectories. High Arctic wetlands may respond more rapidly due to their smaller temperature ranges.

Bunnell et al. (1977) quantified the temperature response of microbial respiration $\left(Q_{10}\right)$ in the Arctic as 3.7 for soils between 0 and $10^{\circ} \mathrm{C}$ (Robinson, 2002), which is the average temperature range of wet sedge soils in the growing season. When Billings et al. (1984) increased soil $\mathrm{N}$ through fertilization, a significant increase in $\mathrm{CO}_{2}$ uptake was recorded in the harvested tundra soil cores. Past research has shown that a relationship exists between available soil $\mathrm{N}$ and measured environmental variables; this study aims to determine the spatial and temporal extents of these relationships in the CBAWO wetlands. 


\subsection{High Arctic Soils}

In Canada, High Arctic soils are generally cryoturbated and permafrost-affected, therefore classifying them as cryosols. Cryosols in Canada’s High Arctic account for 35\% of soil area in the country (Tarnocai et al., 2009; Jones et al., 2010). High Arctic soils fall under the hypergelic soil temperature regime (Jones et al., 2010), meaning their mean annual soil temperature falls below $-10^{\circ} \mathrm{C}$. Processes like cryoturbation explain irregular soil horizons or lack of definitive horizontal soil layers; the thorough mixing of soil material is frost-induced, and as such, below the organic layer, High Arctic soils see a perennially frozen layer known as the I horizon (Jones et al., 2010). According to the Soil Atlas of the Northern Circumpolar Region, compiled as an initiative under the International Polar Year, CBAWO soils are turbic cryosols (Jones et al., 2010). Arctic cryosols have a high quantity of recalcitrant organic material because of thousands of years of accumulation (Stark, 2007).

Arctic soils store large quantities of organic matter due to the frozen storage of decayed matter. In soils, competition for nutrients between microorganisms and plants is expected to shift with the changing climate; for example, reductions in soil microbes could greatly increase the amount of plant-available nutrients for uptake (Schmidt et al., 1997; Stark, 2007). As the climate warms, environments like the High Arctic are susceptible to increased ground ice thaw and the subsequent degradation of permafrost through the formation of ground slumps and thermokarst depressions (Woo et al., 2013). In 2007, which was an unseasonably warm year at the CBAWO, active layer detachments occurred that have direct disturbances on the watersheds (Lamoureux and Lafrenière, 2009); these permafrost disturbances are only expected to increase as warming is amplified (Jorgenson et al., 2006; Fortier et al. 2007; Isaksen et al., 2007). Because Arctic soils are particularly sensitive to climatic changes (Oechel et al., 1993), Arctic permafrost 
environments are expected to be some of the largest $\mathrm{C}$ contributors through $\mathrm{CO}_{2}$ and $\mathrm{CH}_{4}$ release as the climate warms (Oechel et al., 1993; Euskirchen et al., 2016). These permafrost environments are also expected to contribute large quantities of $\mathrm{N}_{2} \mathrm{O}$. An experiment in the High Arctic research facility in Zackenberg, Greenland by Elberling et al. (2010) found that after thaw and rewetting, $31 \%$ of the $\mathrm{N}_{2} \mathrm{O}$ in a 10 -cm permafrost core was released into the atmosphere. Another study in Northern European Russia found the first evidence of increasing $\mathrm{N}_{2} \mathrm{O}$ emissions with warmed temperatures (Voigt et al., 2016). Relevant to this study of Arctic wetlands is that saturation is expected to increase $\mathrm{N}_{2} \mathrm{O}$ emissions (Callaghan et al., 2011a; Chen et al., 2016); as such, the saturated nature of High Arctic wet sedge meadows and the forecast of increased precipitation with temperature increases the potential for greenhouse gasemissions of $\mathrm{CH}_{4}$ and $\mathrm{N}_{2} \mathrm{O}$.

\subsection{Nutrient Cycling in High Arctic Ecosystems}

The nutrient regime in Arctic plant growth is typically characterized by slow growth rates that are $\mathrm{N}$ and P-dependent (Shaver and Jonasson, 1999). However, relative to more active, nutrient-rich temperate environments, tundra environments are more responsive to short-term (110 year) changes in nutrient availability (Shaver et al., 2000). Due to the interconnected nature of the physical and microbial processes of Arctic wetlands, it is expected that changes in nutrient availability will be reflected in processes such as $C$ flux. In a tundra microcosm experiment by Billings et al. (1984), authors found that an increase in soil $\mathrm{N}$ significantly increased $\mathrm{CO}_{2}$ uptake. With the ongoing changes to climate that are affecting the High Arctic regions, it is expected that the increased soil temperatures will deepen active layers, lowering the water table to allow for nutrient release from decomposing organic matter (Biederbeck and Campbell, 1973; Billings et

al., 1982; Nadelhoffer et al., 1991; Johnson et al., 2000; Natali et al., 2011). Environmental 
variables that have influence on the distribution of nutrients include soil temperature (ST), water availability and flow pathways, topography, and precipitation (Stewart et al., 2014). All these factors in turn affect abiotic characteristics such as ST, soil moisture (SM), and pH.

\subsubsection{Arctic Nitrogen Cycling}

The $\mathrm{N}$ cycle involves the steps of fixation, mineralization, nitrification, and denitrification to convert $\mathrm{N}$ into various chemical forms (Figure 2). Terrestrial inputs of $\mathrm{N}$ occur through fixation, which is the conversion of atmospheric $\mathrm{N}$ into ammonium $\left(\mathrm{NH}_{4}^{+}\right)$or reduced $\mathrm{N}$ through microorganisms like cyanobacteria. There is a large quantity of atmospheric N, however this form is unavailable to plants (Chapin et al., 2002). The input of $\mathrm{N}$ into the soils through $\mathrm{N}_{2}$ fixation plays a large role in accounting for half of the external annual input into Arctic soils, with atmospheric deposition contributing the remainder (Chapin and Bledsoe, 1992).

Mineralization is the conversion of organic $\mathrm{N}$ into $\mathrm{NH}_{4}^{+}$for uptake by plants. This process is heavily dependent on the $\mathrm{C}$ to $\mathrm{N}$ balance of the decomposing material in the soil (Chapin et al., 2002; Stark, 2007). Net mineralization encompasses gross $\mathrm{N}$ mineralization, soil adsorption, and immobilization (Robinson, 2002) and ranges from 0.1 to $0.6 \mathrm{~g} \mathrm{~m}^{-2}$ year ${ }^{-1}$ in Arctic soils (Van Cleve and Alexander, 1981; Robinson, 2002), although it is highly variable across different soil types and plant groups. Soil organic matter and decomposing litter fuel mineralization, and as the process is reliant on enzymes and bacteria, the presence of $\mathrm{NH}_{4}{ }^{+}$can be indicative of microbial activity. Furthermore, it is hypothesized that with climate change and warming temperatures, higher rates of ecosystem respiration will decrease C storage, creating more favourable conditions for mineralization to occur in the High Arctic (Shaver et al., 2000; Schmidt et al., 2002). 
$\mathrm{NO}_{3}{ }^{-}$is another form of inorganic $\mathrm{N}$ that is available for plants. Nitrification converts $\mathrm{NH}_{3}{ }^{+}$or $\mathrm{NH}_{4}{ }^{+}$to $\mathrm{NO}_{2}{ }^{-}$, which can then be oxidized to form nitrate that plants can take up through assimilation. The rate at which microbial processes like the $\mathrm{N}$ cycle operate depends on several factors within the specific environment (Stark, 2007). The low temperature and acidic nature of tundra soils slows processes like nitrification (Giblin et al., 1991), which can only occur when nitrifying microorganisms are present (Stark, 2007). Mineral N forms can be lost to soil through leaching, as shown in Figure 2.

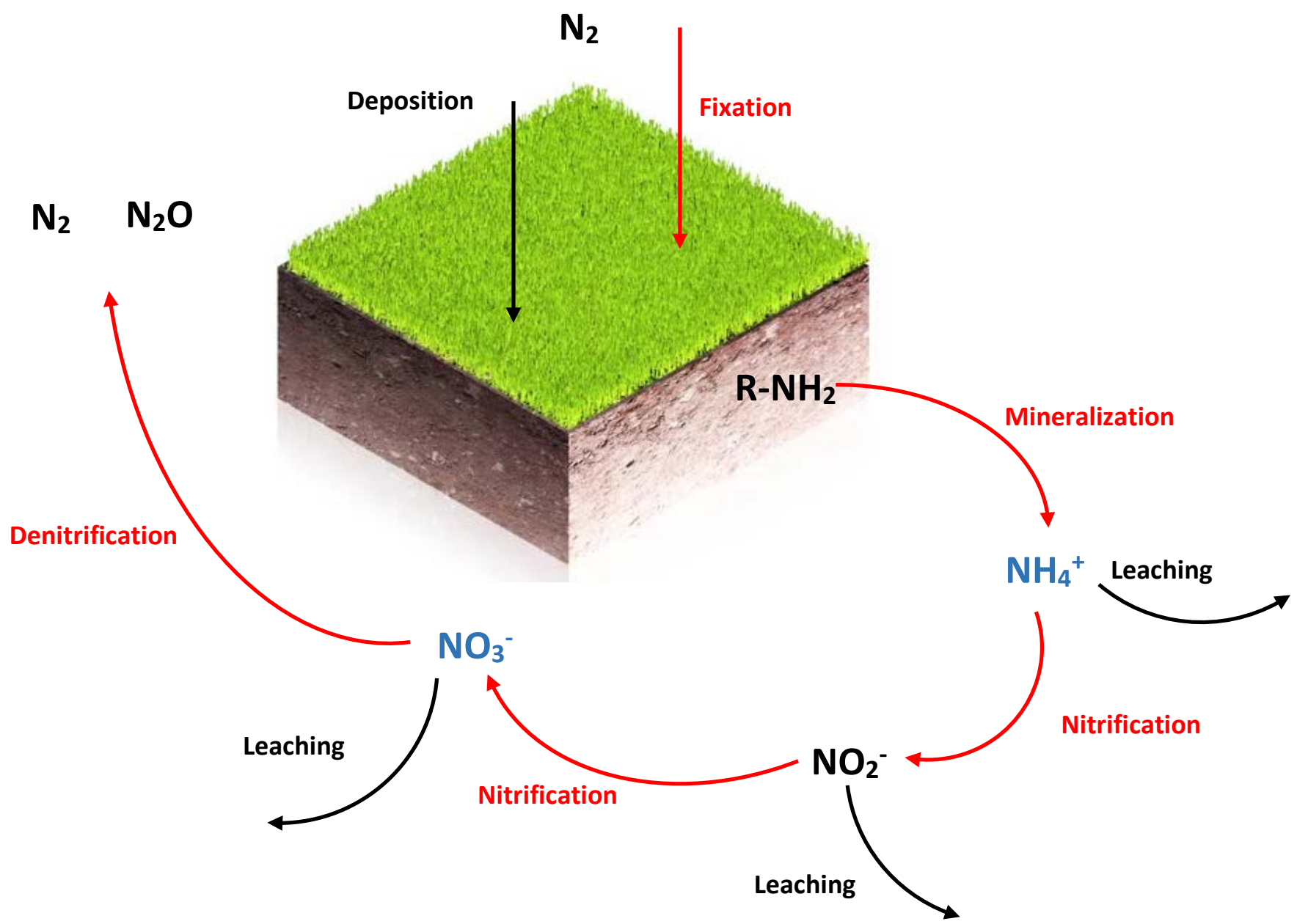

Figure 2: A conceptual diagram of the terrestrial nitrogen cycle, with red portions representing microbial processes and blue portions representing plant available $\mathrm{N}$ forms. 
Denitrification is the last step of the $\mathrm{N}$ cycle when $\mathrm{NO}_{3}{ }^{-}$is converted back into $\mathrm{N}_{2}$ for release into the atmosphere. Low oxygen, high $\mathrm{NO}_{3}{ }^{-}$concentration, and a labile organic $\mathrm{C}$ supply are required for high denitrification (Del Grosso et al., 2000); as such, denitrification is a dominant process in anoxic environments like wetlands, since the high water availability limits oxygen (Chapin et al., 2002). Larose et al. (2013) found N cycling to be sustainable in waterlimited environments like the base of snowpacks through the work of microorganisms; the microbial communities were able to shift their functional potential to allow for several pathways of the $\mathrm{N}$ cycle to continue despite the low temperatures and limited water. These processes may be important in the wet sedge meadow of the study presented here, which is located at the base of a perennial snowpack. Research from field studies has also shown soil decomposition by microbes may be limited by $\mathrm{N}$ (Mack et al., 2004; Lavoie et al., 2011). Understanding the role $\mathrm{N}$ plays in Arctic ecosystems will help in future predictions of decreasing soil C storage and microbial decomposition as the environments continue to change (Chapin et al., 2002; Mack et al., 2004).

\subsubsection{Biotic Nitrogen Fixation in High Arctic Wetlands}

$\mathrm{N}$ sources in Arctic wetlands are largely brought in through fixation (Chapin and Bledsoe, 1992), much of which comes from biotic sources like cyanobacteria and mosses (Lennihan et al., 1994; Griffith, 2014; Leppänen et al., 2015). These organisms fix atmospheric $\mathrm{N}$, transforming it into plant-available $\mathrm{N}$ forms. Cyanobacteria in terrestrial High Arctic ecosystems play an important role in $\mathrm{N}$ cycling. One genus, Nostoc, are associative phototrophic $\mathrm{N}$ fixers (Chapin et al., 2002), and while their role in the wetland environment is known to be important, the relationship between fixation from Nostoc and consequent uptake into plants in the High Arctic has never been quantified (Griffith, 2014). In the CBAWO, Nostoc commune 
cover is quite high in undisturbed, exposed soil (Atkinson, 2012). In response to elevated temperature, Griffith (2014) found boreal N fixation by Nostoc to be decreased. Furthermore, with higher levels of plant-available $\mathrm{N}$ in the soils, Nostoc slowed down or ceased $\mathrm{N}$ fixation (Griffith, 2014). While these findings represent the response of Nostoc in a non-tundra environment, their role in nutrient cycles are the same, which could warrant similar responses in tundra environments.

Sphagnum is a genus of moss that has high water retention associated with $\mathrm{N}_{2}$ fixation in Arctic environments (Leppänen et al., 2015). This genus is typically found in fens and bogs with low-pH soils (Verhoeven et al., 1990; Jonasson and Shaver, 1999); a variety of Sphagnum species are present in the CBAWO (Atkinson, 2012). In a warming treatment study, Chapin et al. (1995) found Sphagnum species to respond positively (increased height growth) to increased light exposure. As such, one can expect that with increased temperature leading to increased $\mathrm{N}$ availability, species richness may shift to favour more suitable $\mathrm{N}$ fixers in these wetland environments (Mellinger and McNaughton, 1975; Tilman, 1982; Jonasson and Shaver, 1999)

\subsubsection{Environmental Factors Affecting Nitrogen Availability}

Several factors explain the limitation of nutrient cycling in the Arctic; the short growing season with low temperatures and harsh climactic conditions are the main factors accounting for the limited microbial processes of the Arctic as compared to boreal environments. Plant decomposition rates are limited by temperature (Nadelhoffer et al., 1991), as the nature of the climate in the Arctic regions allows decay to be slowed down by the cold temperatures (Woo and Young, 2006). These decomposition rates are directly related to nutrient release rates and their subsequent availability to plants (Jonasson and Shaver, 1999). With the changing climate, it is expected that the rate of microbial processes will change in response to higher soil temperatures. 
However, the magnitude of this change is unknown, as the effect that warmer air temperatures will have on soil temperatures is uncertain (Robinson, 2002). An incubation study by Clein and Schimel (1995) did find that a wet sedge soil from Arctic Alaska showed a shift from net mineralization to immobilization of $\mathrm{N}$ as temperatures decreased.

Nutrient deposition into soil can occur through several pathways. Atmospheric C and N inputs can be deposited into soils through precipitation (Chapin et al., 2002). Dry deposition delivers compounds like nitric acid by sedimentation, while cloud-water deposition leaves compounds onto plant surfaces as water droplets in fog (Chapin et al., 2002). Generally, atmospheric $\mathrm{N}$ deposition in the Arctic regions tends to be low as compared to southern ecosystems, but can be highly variable. Studies have placed this number anywhere from 0.03 to $0.56 \mathrm{~kg} \mathrm{~N} \mathrm{ha}^{-1}$ year ${ }^{-1}$ (Gunther, 1989; Shaver et al., 1992; Woodin, 1997; Hodson et al., 2005; Aren et al., 2008), to 1 to $10 \mathrm{~kg} \mathrm{ha}^{-1}$ year $^{-1}$ (Lagerström et al., 2007), to as high as $50 \mathrm{~kg} \mathrm{ha}^{-1}$ year $^{-1}$ (NADP, 2002). Leaching through groundwater from surrounding watersheds also provide an input for loading of nutrients (Jonasson and Shaver, 1999). However, N gained through this process is generally low; for example the nature of the topography of the wet sedge meadow of interest at the CBAWO generally prevents groundwater input and promotes groundwater output.

Water availability is high in High Arctic wetlands due to the soil composition and its water supply (Chapin et al., 2002). The CBAWO is underlain by steeply dipping sandstone and siltstone of the Devonian Weatherall and Griper Bay Formations; the weathered material is fine sand, silt, and clay mixed with gravel (Hodgson et al., 1984; Atkinson and Treitz, 2013). As clay substrate soils have a high surface area-to-volume ratio, the relatively high soil moisture of the CBAWO promotes nutrient availability. Topography is also important in influencing the direction of flow and areas of deposition for nutrients. Spring snowmelt run off and a heavy rain 
after a drier season can introduce pulses of nutrients into an environment (Chapin et al., 2002; Thompson and Woo, 2009); the flow pathways and input of these nutrients are dependent on elevation.

Microbial controls on nutrient cycling are important processes to consider in High Arctic environments. Mikan et al. (2002) found that warming in laboratory incubation studies stimulated microbial activity and increased nutrient turnover in thawed soils. Microbial activity is known to remain active throughout the winter season and can have significant contributions to nutrient budgets during spring thaw (Hobbie and Chapin, 1996; Schmidt and Lipson, 2004; Edwards et al., 2006). Because the insulating snow layer prevents Arctic mid-winter soils from falling below $-10^{\circ} \mathrm{C}$ (Clein and Schimel, 1995), the occurrence of freeze-thaw events allows microorganisms to remain active as long as pockets of liquid water are still present as a result of the snow insulation (Edwards et al., 2006). The activity of these microorganisms will mobilize $\mathrm{N}$ stores that can help mitigate the current nutrient limitation in High Arctic ecosystems (Beermann, 2016). This conforms to Mikan et al.'s (2002) findings that thawed soils display increased microbial activity. In High Arctic wetlands where microbial metabolism is primarily anaerobic due to the anoxic conditions, changes to drainage, precipitation, or evapotranspiration patterns will be the primary driver of microbial activity changes in the future (Mikan et al., 2002).

While soil nutrient availability in High Arctic wetlands can be associated with C flux, C flux cannot necessarily be used as an indicator of nutrient stores as plants metabolize nutrients at different rates (Jonasson and Shaver, 1999). More available nutrients to plants promotes plant metabolism and subsequent respiration and photosynthetic activity. These mineralization and metabolic rates of plants are heavily dependent on variables such as temperature and moisture; 
Schmidt et al. (2002) found that increases in soil temperature (ST) by $2^{\circ} \mathrm{C}$ increased net $\mathrm{N}$ mineralization in Low Arctic dwarf shrubs.

\subsection{Summary}

In the High Arctic, wetlands are the most productive ecosystems with high rates of $\mathrm{C}$ storage (Henry et al., 1990; Henry, 1998; Blaser, 2016) and will have great influence on the C balance of the northern regions as the climate warms. These ecosystems have a large quantity of stored subterraneous carbon (Post et al., 1982; Grogan and Chapin, 1999, Tarnocai et al., 2009). As such changes to wetlands can drive changes in the fluxes of $\mathrm{CO}_{2}$ and trace gases in these systems. Changes to environmental variables like ST, SM, and active layer (AL) depths will affect the processes and dynamics within Arctic soils, including key processes like $\mathrm{N}$ cycling. Available $\mathrm{N}$ in the forms of $\mathrm{NH}_{4}{ }^{+}$and $\mathrm{NO}_{3}{ }^{-}$is a major limiting factor for plant growth in the High Arctic (Nadelhoffer et al., 1992; Shaver and Chapin, 1995) and concentrations are usually relatively low. However, the factors causing this shortage of plant-available $\mathrm{N}$ are not fully understood (Beermann, 2016) and the circumpolar N pool needs to be further investigated. Biotic $\mathrm{N}$ fixers like cyanobacteria and moss play important roles in the Arctic tundra environments (Lennihan et al., 1994), and their role in response to environmental change is expected to increase (Griffith, 2014). Many factors determine the levels of plant-available $\mathrm{N}$ that fuel $\mathrm{N}$

cycling and C flux (Nadelhoffer et al., 1991; Clein and Schimel, 1995; Chapin et al., 2002), and the need to understand the relationship between the environmental variables and these processes is more important than ever in this climate change narrative. 


\section{Chapter 3: Spatial and temporal patterns of soil nitrogen availability and carbon exchange in a High Arctic wetland}

\subsection{Abstract}

Increased soil nutrient availability, and associated increase in ecosystem productivity, could create a negative feedback between Arctic ecosystem and the climate system, reducing the contribution of Arctic ecosystems to future climate change. To predict whether this feedback will develop, it is important to understand the environmental controls over nutrient cycling in High Arctic ecosystem, and how they vary over space and time. This study explores the environmental controls over spatial patterns of soil nitrogen availability in a High Arctic wet sedge meadow and how they influence carbon exchange processes. Ion exchange resin membranes measured available inorganic nitrogen throughout the growing season at a high spatial resolution, while environmental variables (e.g. active layer depth, soil temperature, and

soil moisture) and carbon flux measurements were taken at frequent intervals during the 2016 field season. Environmental measures correlated highly with total and late season nitrate (total season dry tracks $\mathrm{NO}_{3}{ }^{-} \mathrm{R}^{2}=0.533$, total season wet tracks $\mathrm{NO}_{3}{ }^{-} \mathrm{R}^{2}=0.803$, late season $\mathrm{NO}_{3}{ }^{-} \mathrm{R}^{2}$ $=0.622$ ), with soil temperatures at $10 \mathrm{~cm}$ depth having the greatest effect. Soil available nitrogen correlated highly with total and early season gross primary productivity (total season wet tracks $\mathrm{R}^{2}=0.685$, early season dry tracks $\mathrm{R}^{2}=0.788$, early season wet tracks $\mathrm{R}^{2}=0.785$ ). Higher ammonium concentrations coincided with greater $\mathrm{CO}_{2}$ uptake. Nitrate concentrations correlated strongly to soil moisture, but nitrate levels were much lower than ammonium concentrations, suggesting low rates of nitrification vs. mineralization. Similar patterns were observed regardless of whether the wet-sedge meadow was classified as wet vs. dry, but the relationships were always stronger in areas classified as wet, indicating the importance of moisture and water availability on abiotic processes in High Arctic wet sedge meadows. Topography played an 
important role in the movement and transport of water, which influenced how nutrients were cycled and moved within the wetland. Generally, the low-lying areas had the highest inorganic nitrogen concentrations. These results suggest that finer scale processes altering nitrogen availability may influence the $C$ balance of wet sedge meadows in the High Arctic, and how these ecosystems may respond to changes in climate.

\subsection{Introduction}

Warming temperatures in the High Arctic are expected to exceed global rates by $40 \%$ (IPCC, 2013). Changes to seasonal weather patterns may also influence ecosystem-level abiotic factors, which in turn will influence biogeochemical processes (e.g. C and N cycles) in complex ways. The IPCC (2013) projects a 10-28\% increase in mean Arctic precipitation by the end of the $21^{\text {st }}$ century. Some of the changes to Arctic regions are already being seen with amplified warming (Bintanja and Andry, 2017) and further changes are expected. These changes could lead to the development of negative feedbacks, potentially stabilizing the climate system.

Some of the consequences of Arctic warming include increased air temperatures leading to earlier snowmelt onset (Young, 2006) and precipitation increase leading to permafrost degradation and the release of previously unavailable soil C (Oechel et al., 1993; Schuur et al., 2009). Warming is expected to accelerate the decomposition of soil organic matter (SOM) (Chapin et al., 1995; Aerts et al., 2005; Bell et al., 2013), potentially altering rates of nutrient cycling. N fixation by key ecosystem species like Nostoc commune and Sphagnum spp. will also change with air temperature increases (Chapin et al., 1995; Schmidt and Lipson, 2004; Griffith, 2016), potentially altering available nutrient pools. In turn, higher nutrient availability could alter species composition within High Arctic ecosystems (Aerts et al., 2005), plant productivity (Shaver et al., 2000), and the net C balance (Welker et al., 2004). Given the number of changes 
and potential responses, an ecosystem-level understanding of these interactions is critical to understand how they will respond to future changes in climate.

High Arctic plant growth is typically limited by N availability (Nadelhoffer et al., 1992; Shaver and Chapin, 1995; Shaver et al., 2000). As such, this study looked at the spatial patterns of plant-available inorganic $\mathrm{N}$ to see how these patterns shift as the growing season progressed. A wetland was selected as the study site for its characteristics as the most productive and photosynthetically active ecosystem in the High Arctic environment. $\mathrm{N}$ fixing organisms in wet Arctic environments like wet sedge meadows are primarily mosses and lichens (Robinson and Wookey, 1997; Stark, 2007), which are dominant in wet sedge meadows in the Cape Bounty Arctic Watershed Observatory (CBAWO). With changes anticipated in the High Arctic regions, land classes such as wet sedge meadows will likely respond dramatically, and changes in these wetlands will have cascading effects on terrestrial and hydrological features around them.

This study explores the spatial and temporal patterns of available soil $\mathrm{N}$ in a wet sedge meadow in the Cape Bounty Arctic Watershed Observatory of the Canadian High Arctic, and how they relate to $\mathrm{C}$ exchange processes. In the High Arctic, the wet sedge meadows are generally saturated year round, resulting in relatively high net primary production (NPP), but productivity is limited by the harsh polar environment and poor drainage (Gebauer et al., 1995; Hill and Henry, 2011). Wet sedge meadows at CBAWO occupy slightly less than $10 \%$ of the land area at CBAWO and have the highest rates of net ecosystem exchange (NEE) compared to the other dominant plant communities at CBAWO (Gregory, 2011). Previous studies in this wet sedge meadow have looked at the seasonal variability of $\mathrm{C}$ flux and environmental variables (Ramsay, 2015; Luce, 2016) and C fluxes across wet and dry areas within wet-sedge meadows (Blaser 2016). To date, however, no one has assessed the relationships between available $\mathrm{N}$ and 
C exchange and never assessed the spatial patterns of these interactions. While nutrients have been examined in CBAWO wetlands (Gregory, 2011), spatial and temporal extent of the sampling was much more limited than used in this study.

\subsection{Methods}

\subsubsection{Study Site}

The CBAWO (Figure 3) is located on the southern coast of Melville Island, Nunavut $\left(74^{\circ} 54^{\prime} \mathrm{N}, 109^{\circ} 35^{\prime} \mathrm{W}\right)$, near the Nunavut-Northwest Territories border. The area contains two watersheds (East and West Lake), and the entire area covers approximately $150 \mathrm{~km}^{2}$. The area is continuous permafrost with a 0.5 to 1-metre thick active layer (Atkinson and Treitz, 2013). The climate in the area is cold throughout the year with the summer melt and growing season running from June to August (Atkinson and Treitz, 2013). Strong winds are typical during the growing season, clocked at up to $80 \mathrm{~km} / \mathrm{h}$ in 2008 (Gregory, 2011). January 2016 minimum and maximum temperatures were $-33.7^{\circ} \mathrm{C}$ and $-21.5^{\circ} \mathrm{C}$ respectively, while July 2016 minimum and maximum temperatures were $1.7^{\circ} \mathrm{C}$ and $10.9^{\circ} \mathrm{C}$ respectively. 

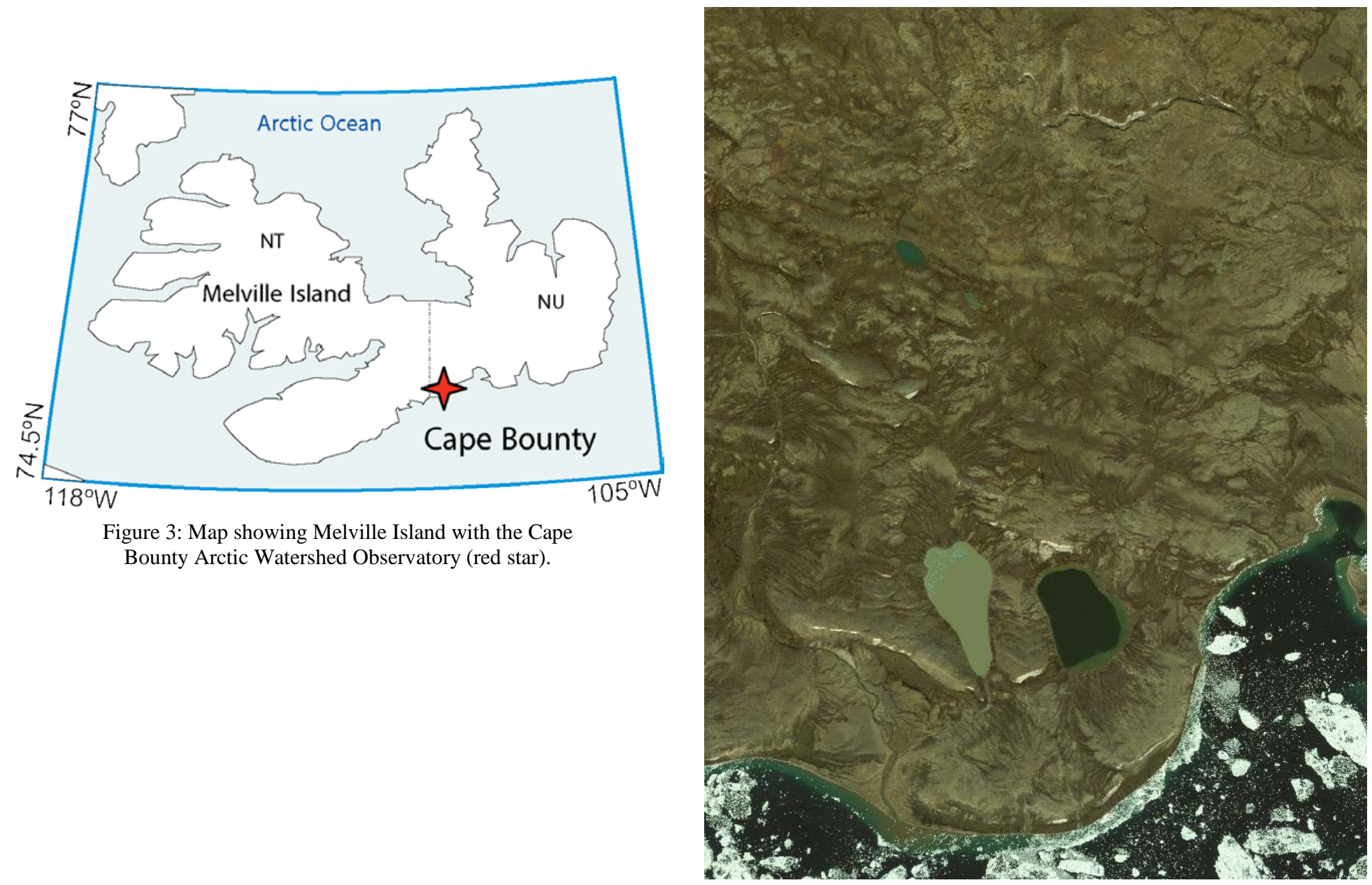

Figure 3: Map showing Melville Island with the Cape Bounty Arctic Watershed Observatory (red star).

Figure 4: WorldView-2 imagery of the Cape Bounty Arctic Watershed Observatory in July 2016.

The CBAWO (Figure 4) was selected as the area of interest due to its availability as a High Arctic research area and the longevity of hydrological and biogeochemical research that has been conducted. This study was carried out from June 25 to July 28. Sampling regimes were established once on site and depended to some extent on equipment availability and weather.

The CBAWO is dominated by three land cover classes: polar semi-desert, mesic tundra, and wet sedge meadows (Gregory, 2011; Atkinson, 2012; Atkinson and Treitz, 2013). The polar semi-desert often occur on upland sites and contains patches of vegetation interspersed with dry, rocky ground. These vegetation patches are characterized by a mix of dwarf shrub, forbs, grasses, and mosses (Gregory, 2011; Atkinson, 2012). The mesic tundra is characterized by a 
thin vegetation layer interspersed by exposed mineral soil (Gregory, 2011; Atkinson, 2012). Wet sedge meadows are the least abundant cover type in the CBAWO (Atkinson and Treitz, 2013). These areas tend to be in lower-lying locales near a continuous water supply during the growing season (Woo and Young, 2006; Thompson and Woo, 2009; Woo, 2011).

The wet sedge meadow of interest within the CBAWO, "Muskox", is a 200 metre by 200 metre plot that is saturated year round (Figure 5). Water is provided to the site from a perennial snowpack located at the north end of the area (Figure 6). Walker et al. (2005) give the Cape Bounty area a G2 vegetation classification of moist tundra covered with low-growing forbs, grasses, mosses, and lichens. The Muskox site slopes downward away from the snowpack from north to south as well as from east to west and has a south-facing aspect. Within Muskox, there are variations in dryness and wetness across the sites (Atkinson, 2016; Blaser, 2016). Wet tracks are characterized by standing water in some areas and higher soil moisture, while dry tracks are still wet but lack pools of standing water (Blaser, 2016). The partitions for these moisture tracks are small longitudinal hummocks that were likely formed from cryogenic events (Hodgson et al., 1984). 


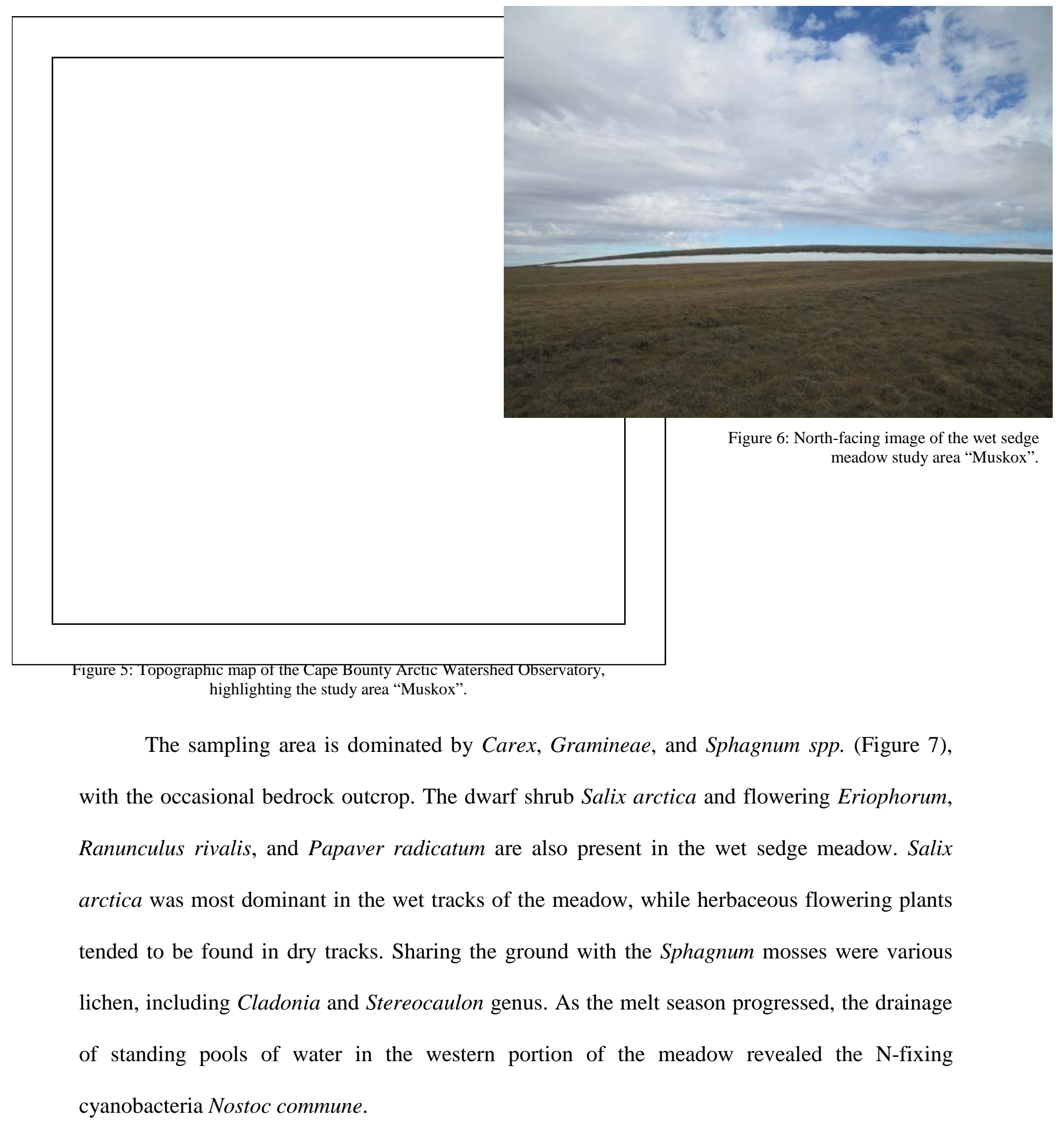




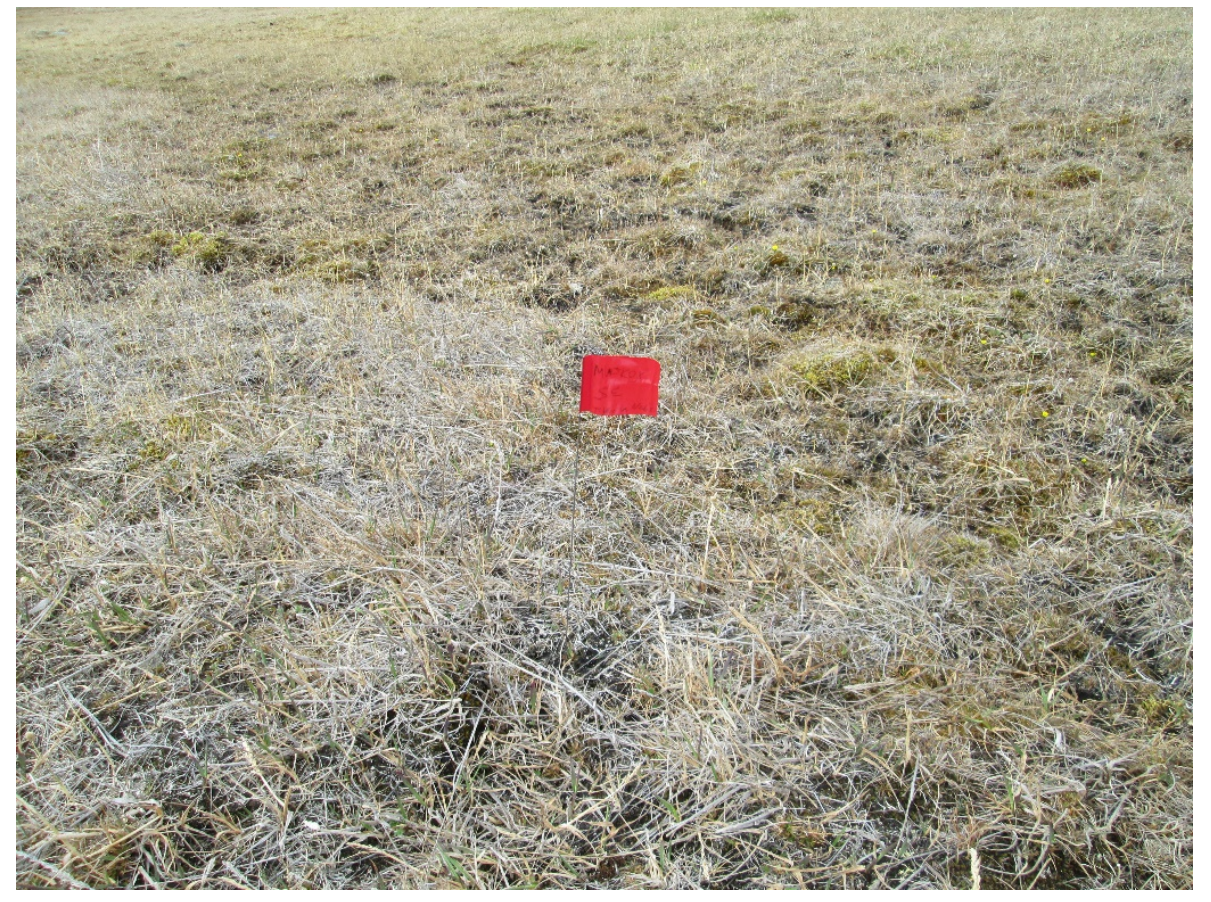

Figure 7: Wet sedge meadow vegetation type.

\subsubsection{Experimental Design}

The sampling methodology was designed to sample the variations in soil moisture within the meadow. The actual sampling sites were determined using in situ site reconnaissance with the aid of satellite imagery to discern between moisture tracks. 


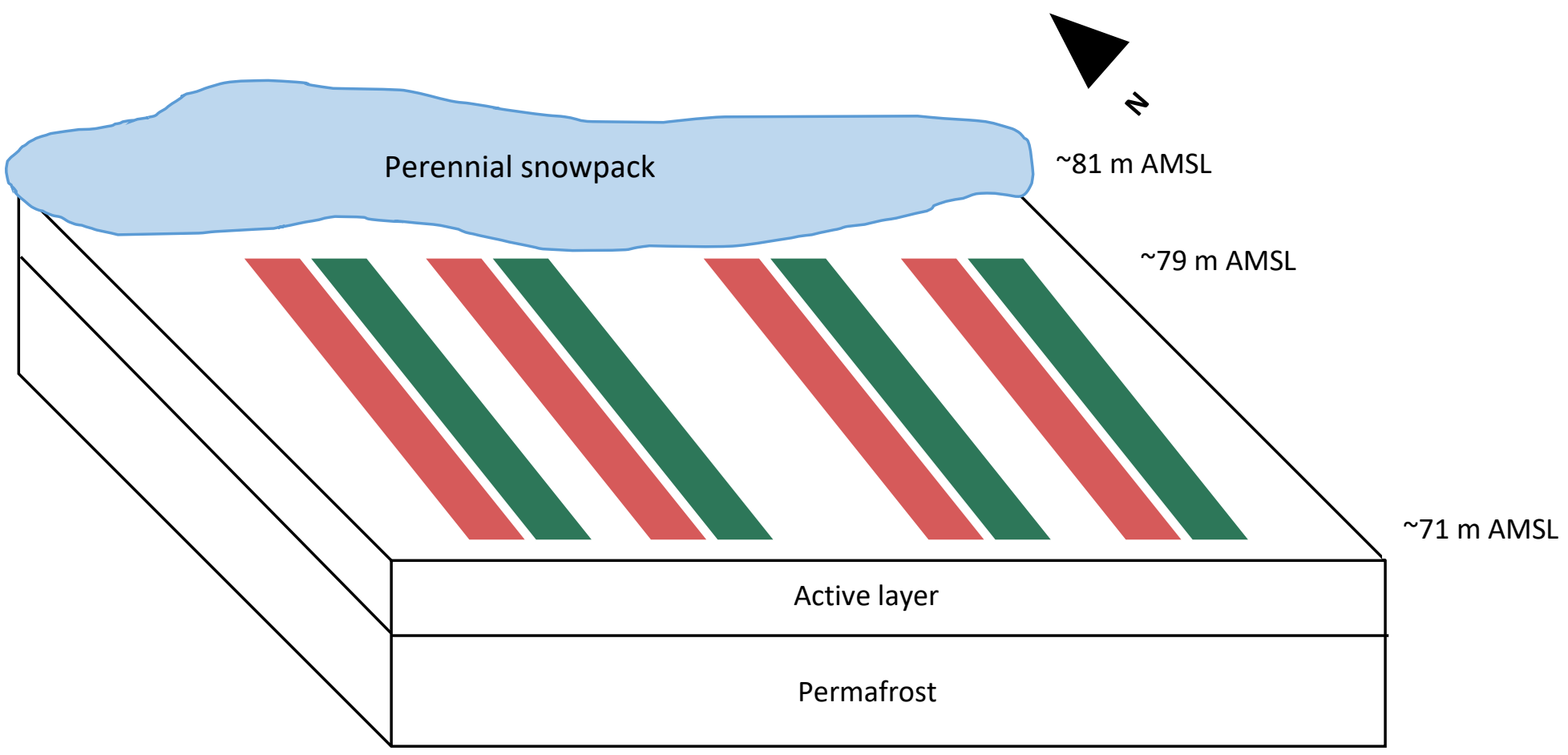

Figure 8: Conceptual diagram of the sampling plot, with wet tracks represented in red and dry tracks represented in green. Elevations of the snowpack, northern-most sampling plots, and southern-most sampling plots are displayed as metres above mean sea level (AMSL).

A total of 64 sites were established on alternative wet and dry strips sampled using ion exchange resin strips (Figure 8 and Figure 9); these sites represent an 8 row by 8 column grid that encompasses 4 wet and 4 dry transects within the meadow. The aim with this sampling design is to test the effects of proximity to snowpack and its water input (e.g. differences in soil moisture) on nutrient availability within the wet sedge meadow. A prior study at CBAWO sampled soil nutrients randomly in wet-sedge meadows, and did not account for soil moisture variability (Gregory, 2011). The results from this design give insight into the spatial variability within the meadow. 


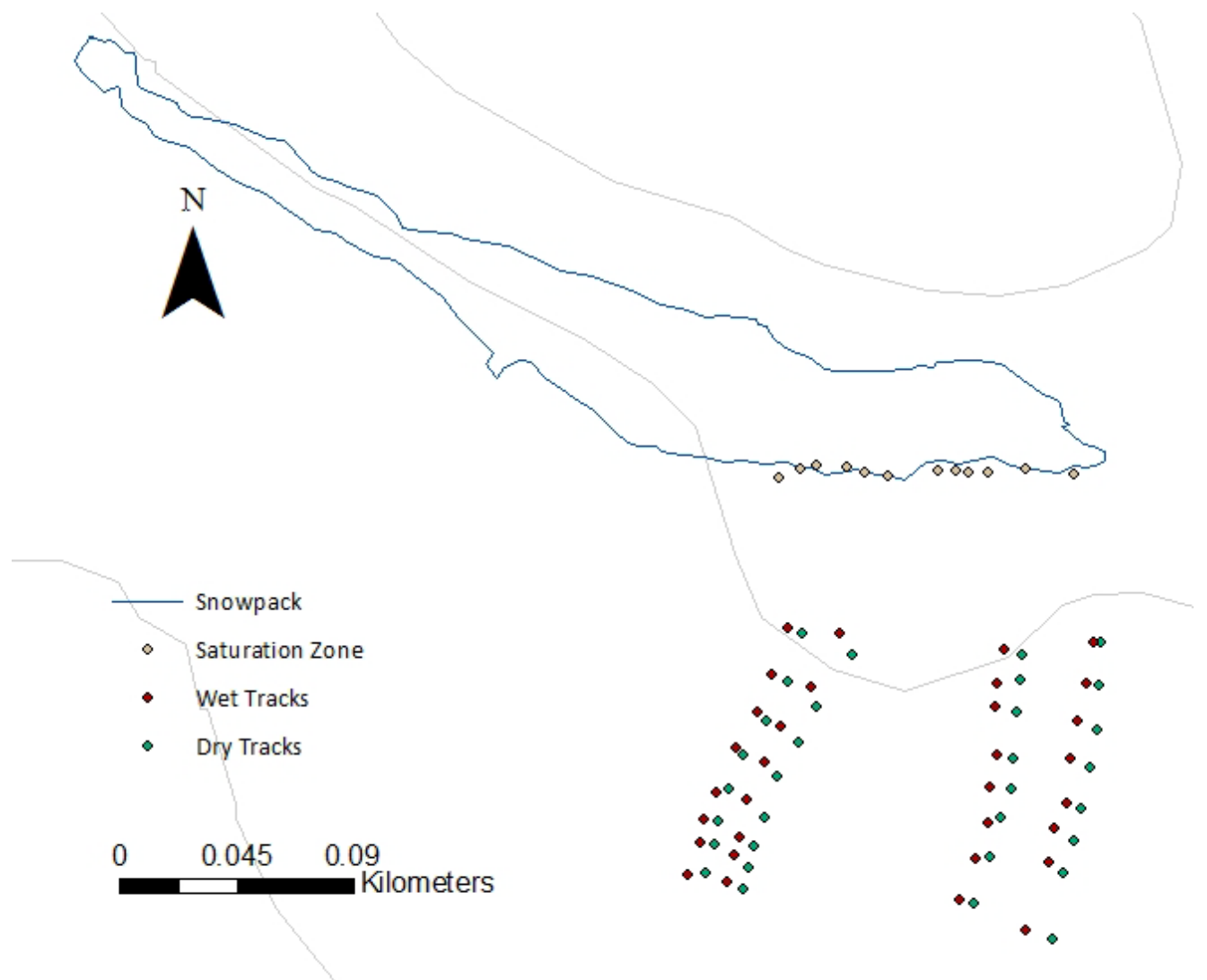

Figure 9: Topographic map depicting the layout of the experimental design

Directly south of the snowpack, a saturation zone (SZ) exists that is characterized by standing water above the vegetation in some areas (Atkinson, 2016). The SZ exists as the snowpack retreats due to the melt, exposing an area that is not quite developed as a wetland due to a lack of exposure from under the snowpack that has a very high moisture content. Consequently, vegetation in this area does not develop as it is typically limited in nutrients (Woo and Young, 2006). This area was also sampled with 12 sites of ion exchange resins to determine the effects of the perennial snowpack on soil characteristics. Overall, 76 sampling sites were staked out in the wetland.

\subsubsection{Soil Nutrient Availability Evaluation}

Ion exchange resin (IER) membranes (Qian and Schoenau, 2005; Milligan, 2010) were employed to determine soil $\mathrm{N}$ availability within the Muskox meadow at CBAWO. The 
methodology for soil nutrient assessment in the watershed were determined from literature, as soil nutrients have never been examined or quantified in the watershed wet sedge. Traditionally, soil nutrient assessment studies in literature have employed the use of the soil sample collection and wet chemical analysis to determine the nutrient availability on site (Binkley and Matson, 1983). However, these traditional methods can be costly and time consuming, depending on the environment of interest. A method of assessing soil nutrient availability that can complement traditional methods of soil sampling is the use of resin strips (Qian and Schoenau, 2005). These resin membranes work by adsorbing nutrients that are attracted to the resident ions on the resin membranes, which are placed onto the resins through pre-burial preparation techniques (Jasrotia and McSwiney, 2009).

IER membranes are polymers that have charged sites that can exchange ions with other substances; bicarbonate-form anion resins were selected as they are preferable to hydroxyl-form resins (Lajtha, 1988). Resin membranes were prepared using the ion exchange resin protocols created at the Kellogg Biological Station at Michigan State University (Jasrotia and McSwiney, 2009). Cation and anion exchange resins measuring $2.5 \mathrm{~cm}$ by $10 \mathrm{~cm}$ were made from membrane sheets obtained from Membranes International Incorporated (Membranes International Inc., Ringwood, New Jersey, United States). Cation and anion resins were pre-loaded with a $0.5 \mathrm{M}$ hydrochloric acid $(\mathrm{HCl})$ solution for 24 hours with agitation to allow for the acid to strip the resin of any ions currently present, after which they were soaked in $0.5 \mathrm{M} \mathrm{NaHCO}_{3}$ for 5 hours with agitation to saturate sites for sodium and bicarbonate ions (Qian and Schoenau, 2005; Western Ag, 2012). The anion probes were also soaked in a $0.01 \mathrm{M}$ ethylenediaminetetraacetic acid (EDTA) solution for one hour with agitation to help increase its adsorption of phosphorus (Western Ag, 2012). The resins were deployed at $10 \mathrm{~cm}$ soil depth remained in the field for the 
allotted burial time of either 2 weeks or 4 weeks. When removed from site, the resins from each experimental plot were cleaned and rinsed with deionized water, bagged, refrigerated, kept dark, and brought back for analysis. In each sampling plot, 5 anions and 5 cations were deployed and eluted concurrently to obtain one concentration value of the nutrients of interest. Batch elutions were done for each sampling plot do to the nutrient-limited nature of the study area that may be below detection limits if eluted individually and averaged. Resin extracts were then run through an Astoria2 Analyzer automated colourimetric system (Astoria-Pacific, Clackamus, Oregon, United States) to quantify nitrate and ammonium concentrations.

Two sampling regimes were employed: in one method, the resins were deployed for the duration of the study period for nutrient adsorption from June 30 to July 27 (Resin A). In the second method, resins were deployed at the beginning of the study period from June 30 to July 13 (Resin B1) and switched out for new resins halfway through from July 13 to July 27 (Resin B2) to test for the robustness of the resins when comparing the total nutrients adsorbed to the resins deployed for the entire season. This sampling methodology also helps account for the seasonal variation of soil nutrient availability.

\subsubsection{Carbon Flux Sampling}

NEE and ER measurements were conducted using closed, static chambers, according to methods in Beamish et al. (2014). A PVC collar (20 cm diameter) was inserted into the ground (at roughly $5 \mathrm{~cm}$ depth) at half of the resin sampling sites and transparent chambers (Figure 10) were attached to the collars using a rubber gasket to create a seal. Instantaneous $\mathrm{CO}_{2}$ concentration was measured using a portable infrared gas analyzer (IRGA) (Vaisala GMP343 Carbon Dioxide Probe; \pm 3ppm) (Vaisala, Vaanta, Finland) in sites adjacent to the resin sampling area. A relative humidity (RH) and temperature probe (Vaisala HMP75 Relative Humidity and 
Temperature Probe; $\pm 1 \% \mathrm{RH}, \pm 0.2^{\circ} \mathrm{C}$ ) in the chamber measured these parameters simultaneously. Changes to $\mathrm{CO}_{2}$ concentrations were measured in the chamber at five second intervals for five minutes. After the light measurement, the chambers were removed from the collars and aired out return to ambient conditions, after which an opaque shrowd was used to cover the chamber and prevent photosynthesis for the ER measurement. A Kestrel 3500 weather metre was used to determine atmospheric pressure which was needed for the gas flux calculations (Kestrel, Birmingham, Michigan, United States).

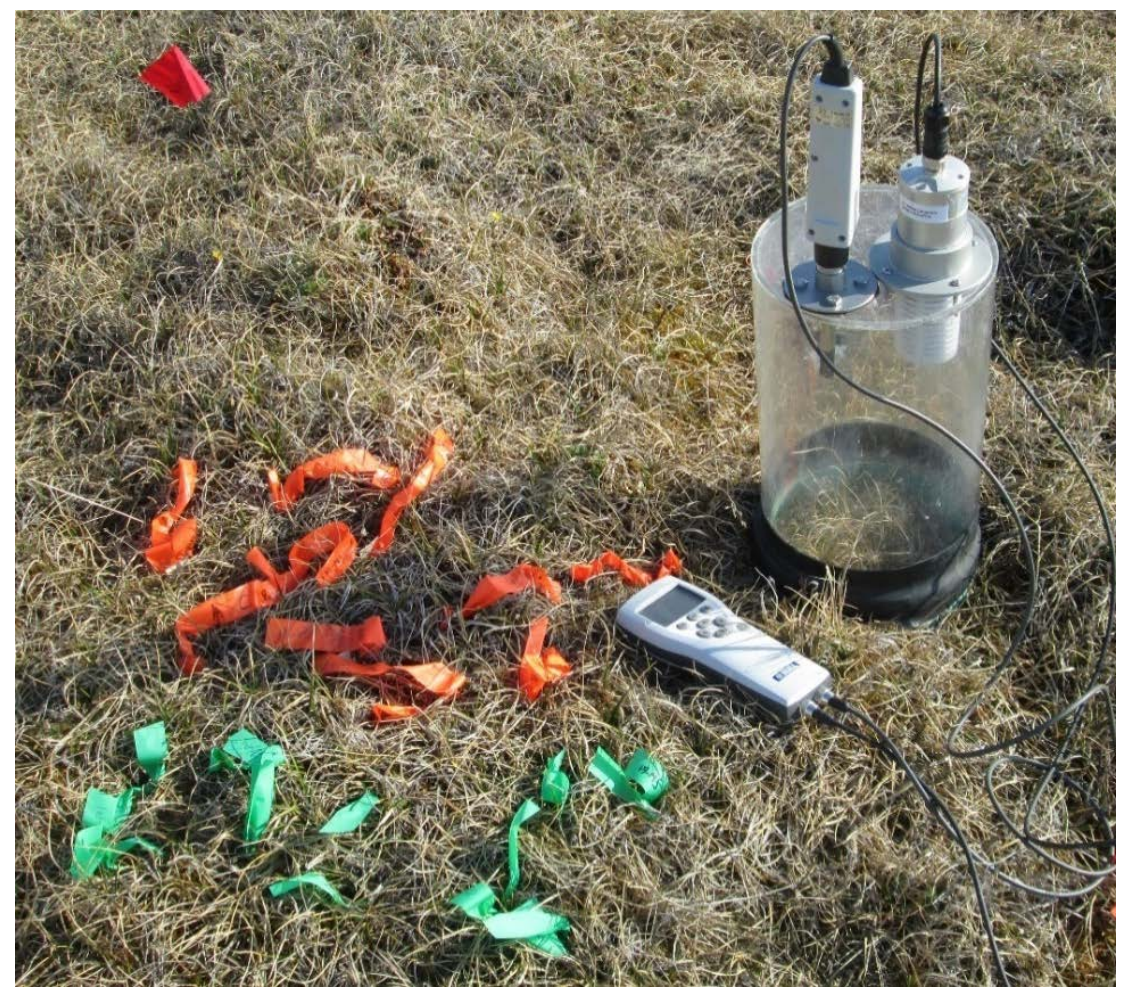

Figure 10: $\mathrm{CO}_{2}$ flux static chamber light measurement and ion exchange resin strips in situ

\subsubsection{Environmental Measurements}

Environmental measurements (soil moisture, soil temperature, and active layer depth) were taken twice per week. Sampling sites were adjacent to the locations of the ion exchange resins. SM was measured at $0-5 \mathrm{~cm}$ depth using a ML-3 Theta probe with data stored in a data logger. ST was measured at $10 \mathrm{~cm}$ depths using a standard soil temperature probe. AL depth was 
measured using a steel rod that was inserted into the ground until reaching frozen ground. A local meteorological station set up by Queen’s University, “West Met” provided hourly on temperature and precipitation.

\subsubsection{Post-Field Processing}

\subsubsection{Ion Exchange Resin Sample Processing}

The ion exchange resins were eluted in groups of 10 strips (5 per cation and anion) to analyze each sampling plot; consequently, single values for each ion of interest were generated for each of the 76 sampling areas. The concurrent elutions to produce one sample for analysis was done to avoid nutrient readings below the detection limit, as Arctic environments are nutrient-limited to begin with. The eluates were extracted by soaking the resins in a $400 \mathrm{~mL}$ 0.5M HCl solution for one hour with 40 rotations per minute (RPM) agitation. The elution for each sampling site were down-sampled into two sets of $50 \mathrm{~mL}$ centrifuge tubes for transportation and storage prior to colourimetric analysis.

The Astoria2 Analyzer automated colourimetric system is a segmented flow analyzer (Astoria Pacific, 2011) that automates the wet chemistry processes in determining nutrient concentrations of interest. In this study, as plant-available $\mathrm{N}$ was of interest, the colourimeter was set up to analyze for $\mathrm{NH}_{4}{ }^{+}$and $\mathrm{NO}_{3}{ }^{-}$. The phenate method was used in the determination of $\mathrm{NH}_{4}{ }^{+}$concentrations and the cadmium reduction method was employed for determining $\mathrm{NO}_{3}{ }^{-}$ concentrations (Pansu and Gautheyrou, 2006). The samples were downsampled to $4 \mathrm{~mL}$ cuvettes to be run for analysis and three quality assurance and quality control steps were taken to assess for error: 1 in 10 samples was run in duplicate, 1 in 30 samples was a blank (MilliQ), and 1 in 45 samples was run using blanks to account for instrumentation drift. Overall, all samples were run twice and averaged where valid. 


\subsubsection{Carbon Flux Calculation}

A custom Matlab script was created to calculate $\mathrm{CO}_{2}$ fluxes and GPP from the $\mathrm{CO}_{2}$ concentration data gathered by the IRGA (Atkinson, 2012). $\mathrm{CO}_{2}$ concentrations were converted to fluxes by converting ppm values to moles of $\mathrm{CO}_{2}$ using the ideal gas law and temperature and pressure data collected during field data acquisition. Gas concentrations $\left(\mu \mathrm{mol} / \mathrm{m}^{3} / \mathrm{s}\right)$ were calculated from the inputted air pressure $(\mathrm{hPa})$, relative humidity $(\%)$, temperature $\left({ }^{\circ} \mathrm{C}\right)$, and gas concentrations in parts per million (Equation 1):

$$
n=C\left(\frac{\rho}{R \tau}\right)\left(\frac{v}{A}\right)
$$

$n$ : converted gas concentration $\left(\mu \mathrm{mol} \mathrm{m} \mathrm{m}^{-3}\right)$

$C$ : original measured gas concentration (ppm)

$\rho$ : air pressure (hPa)

$R$ : ideal gas constant $\left(8.314 \mathrm{~J} \mathrm{~K}^{-1} \mathrm{~mol}^{-1}\right)$

$\tau$ : temperature $(\mathrm{K})$

$v$ : combined volume of chamber attached to the collar minus the volume of the sensors $\left(\mathrm{m}^{3}\right)$ A: projected horizontal surface area of the chamber $\left(\mathrm{m}^{2}\right)$

Once converted to moles, an iterative linear regression algorithm went through the inputted data to determine the rate of change during the 5-minute measurement period. The algorithm searches through the data and finds the best subset of points that yields the highest $\mathrm{R}^{2}$ value (minimum of 12 points). The slopes of these regression lines represent the flux rate $\left(\mu \mathrm{mol} \mathrm{m}{ }^{-2}\right)$ GPP (total photosynthesis) was calculated using Equation 2:

$$
G P P=N E E-E R
$$

NEE (e.g. overall $\mathrm{CO}_{2}$ exchange) is equal to what the atmosphere gains through respiration (positive values) minus what the terrestrial system sequesters with respect to productivity (negative values) (Chapin et al., 2006). Negative NEE is indicative of C coming into the system, while a positive number represent $C$ being outputted into the atmosphere. 


\subsubsection{Data Analysis}

A variety of spatial and non-spatial statistical analysis techniques were used to analyze the data. The IBM SPSS 22 statistical analysis package was used to conduct descriptive statistical analysis. Two-way repeated measures analysis of variance (ANOVA) was conducted to compare environmental variables, $\mathrm{C}$ fluxes, and available soil $\mathrm{N}$ in the different moisture regimes. When analysing these variables, studentized residuals were examined for values greater than \pm 3 and outliers were removed (Laerd Statistics, 2013). All the variables were assessed for normality using the Shapiro-Wilk's test on the studentized residuals and for homogeneity. Mauchly's test of sphericity was indicative of any within-subjects effects that violated the assumption of sphericity; as such, the Greenhouse-Geisser correction (Maxwell and Delaney, 2004) was used for any necessary variables. A second two-way repeated measures ANOVA was conducted to explore spatial differences within a single moisture regime (e.g. dry vs. dry, wet vs. wet). For these analyses, Tukey’s post-hoc test was run and individual tracks were compared temporally to determine the areas of greatest variance.

Bivariate and multiple regression was run with available $\mathrm{N}$ as the dependent variable to determine relationships between environmental variables with early, late, and total season $\mathrm{NO}_{3}{ }^{-}$ and $\mathrm{NH}_{4}{ }^{+}$. N was used as the independent variable when analyzed against early, late, and total season GPP and ER. The Durbin-Watson statistic determined that there was independence of residuals for all resin regimes. The data were checked for homoscedasticity, multicollinearity, and normality and outliers were removed prior to analysis.

To explore spatial patterns, local indicators of spatial association (LISA) maps were created in GeoDa and analyzed to determine clusters of areas with high and low $\mathrm{NO}_{3}{ }^{-}$and $\mathrm{NH}_{4}{ }^{+}$ tended to gather within Muskox. Ordinary Kriging in ArcGIS 10.3.1 was conducted on total, 
early, and late season $\mathrm{NO}_{3}{ }^{-}$and $\mathrm{NH}_{4}{ }^{+}$concentrations to interpolate concentrations across the wet sedge meadow and confirm the spatial autocorrelation results. This method was selected as kriging is considered an unbiased interpolation method with the least estimation variance (Siska and Hung, 2001; Yang et al., 2011). Furthermore, as there is hypothesized to be some directional bias or spatial correlation in the data, kriging can be useful in visualizing those biases (Childs, 2004).

\subsection{Results}

\subsubsection{Growing Season Air Temperature and Precipitation}

The 2016 growing season exhibited temperature and precipitation patterns, collected at the meteorological stations at CBAWO (Figure 11) consistent with 2014 patterns. When comparing the last three growing seasons, 2016 exhibited significantly higher cumulative rainfall and warmer June temperatures, while 2015 had the highest June temperatures of the three years (Figure 12). Maximum air temperature (AT) of $17.4^{\circ} \mathrm{C}$ was reached on July 5, 2016, which was preceded by a precipitation high of $2.2 \mathrm{~mm}$ the day before. The early season was characterized by little to no precipitation with constant temperature increases, while the later part of the season had more occurrences of precipitation with decreasing AT. 


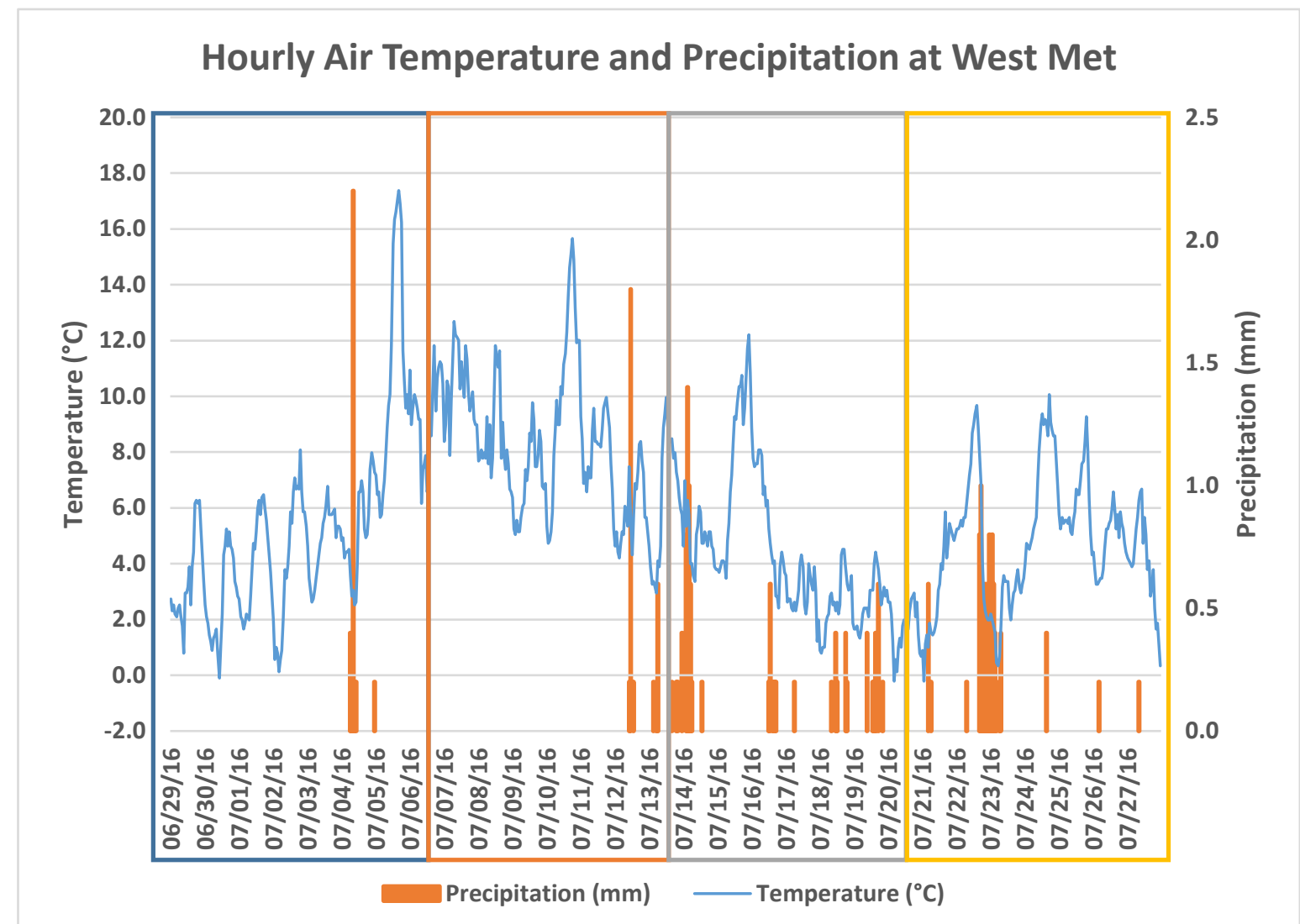

Figure 11: Hourly air temperature and precipitation measurements at the "West Met" meteorological station at CBAWO from June 29 to July 27, 2016. Rectangles represent the partitioning of the study period into weeks for analysis: Week 1 (blue), Week 2 (orange), Week 3 (grey), and Week 4 (yellow).

\section{Mean June/July Temperatures and Cumulative June/July Rainfall Since 2003}

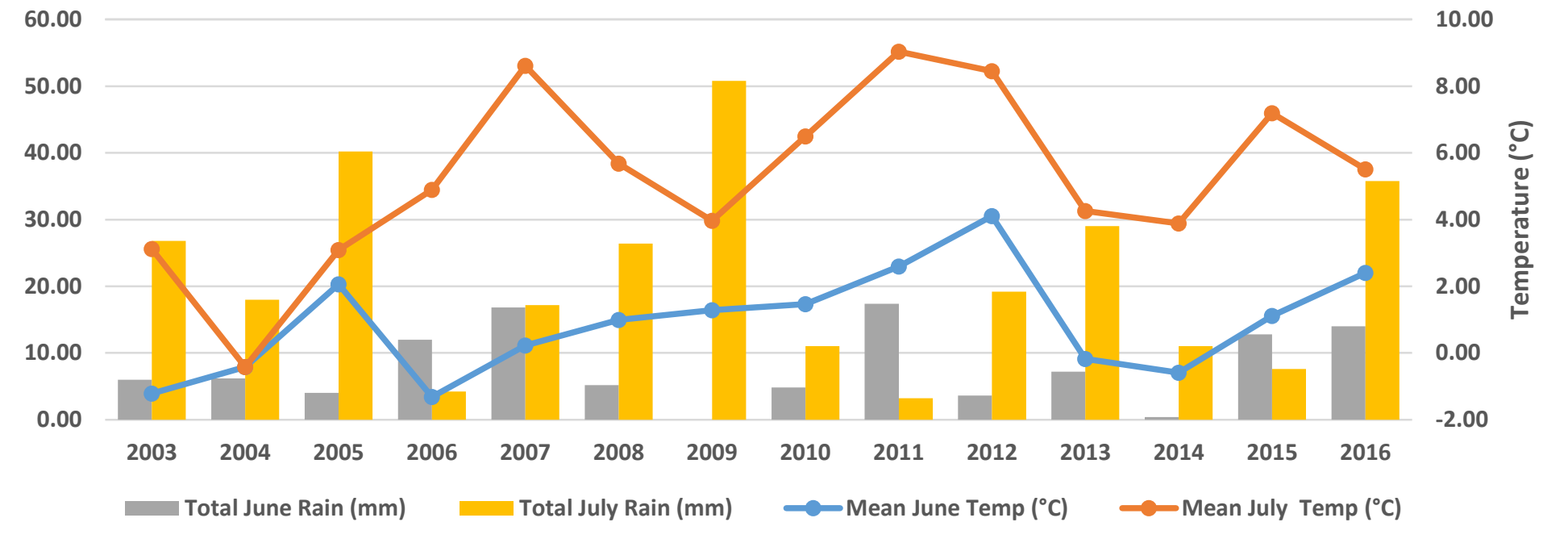

Figure 12: Mean June and July temperatures and cumulative June and July rainfall since monitoring was started at the CBAWO in 2003. 


\subsubsection{Environmental Variables}

Table 1: Mean environmental variables across the moisture tracks over the growing season. Standard deviations are indicated in brackets.

\begin{tabular}{|l|c|c|c|c|}
\hline & Week 1 & Week 2 & Week 3 & Week 4 \\
\hline ST Dry $\left({ }^{\circ} \mathrm{C}\right)$ & $0.9(0.8)$ & $2.0(1.1)$ & $1.3(0.85)$ & $2.0(0.87)$ \\
\hline ST Wet $\left({ }^{\circ} \mathrm{C}\right)$ & $2.4(1.4)$ & $3.8(1.3)$ & $2.9(0.94)$ & $3.6(0.76)$ \\
\hline SM Dry (\%) & $45.7(12.2)$ & $55.4(11.4)$ & $69.5(12.2)$ & $62.7(9.24)$ \\
\hline SM Wet (\%) & $80.7(15.7)$ & $76.8(13.8)$ & $86.5(13.4)$ & $88.4(12.5)$ \\
\hline AL Dry (cm) & $25.3(6.03)$ & $28.7(7.16)$ & $29.8(8.25)$ & $30.8(7.87)$ \\
\hline AL Wet $(\mathbf{c m})$ & $33.9(6.99)$ & $41.7(6.55)$ & $43.6(7.09)$ & $43.9(6.18)$ \\
\hline
\end{tabular}

Table 2: Two-way ANOVA p-values for environmental variables across the growing season in different moisture tracks across the plot. Bolded values indicate significance at $\mathrm{p}<0.05$.

\begin{tabular}{|l|c|c|c|}
\hline \multicolumn{1}{|c|}{ Interaction } & ST & SM & AL \\
\hline Time & $\mathbf{0 . 0 0 0}$ & $\mathbf{0 . 0 0 0}$ & 0.000 \\
\hline Moisture track & $\mathbf{0 . 0 0 0}$ & $\mathbf{0 . 0 0 0}$ & $\mathbf{0 . 0 0 0}$ \\
\hline Time x Moisture track & 0.286 & $\mathbf{0 . 0 0 0}$ & 0.000 \\
\hline $\begin{array}{l}\text { Time x Moisture track } \mathbf{x} \\
\text { Spatial location (W vs. E) }\end{array}$ & $\mathbf{0 . 0 0 0}$ & $\mathbf{0 . 0 0 1}$ & 0.005 \\
\hline
\end{tabular}

Soil temperature was measured ten times during the growing season, and was significantly higher for between-subjects effects in the wet vs. dry tracks $\left(1.5\right.$ vs. $\left.3.2^{\circ} \mathrm{C}\right), \mathrm{F}(1,28)$ $=19.8, \mathrm{p}<0.05$ (Table 2). There was also a statistically significant within-subjects effects across the four-week growing season, $\mathrm{F}(1.77,49.4)=97.5, \mathrm{p}<0.05, \varepsilon=0.59$, with the wetter track means increasing from Week 1 to Week 4 (Figure 13). However, there was no statistically significant three-way interaction between ST within the moisture tracks over the growing season, $\mathrm{F}(1.765,49.418)=1.281, \mathrm{p}=0.284$. When the tracks were compared within a moisture regime (to test spatial variability), the dry tracks differed significantly for within-subjects effects, $\mathrm{F}(3,33)=106.817, \mathrm{p}<0.05$, but there was not statistical difference for between-subjects effect across individual dry tracks across the season, $\mathrm{F}(9,33)=1.51, \mathrm{p}=0.186$ (Table 41). In the wet tracks, the measurements were statistically significant across weeks, $F(3,33)=106.1, p<0.05$, 
and between individual wet tracks across the growing season, $\mathrm{F}(9,33)=10.1$, $\mathrm{p}<0.05$ (Table 42). The post-hoc results indicated the greatest difference between Wet 1 and Wet 5, which was statistically significant $(\mathrm{p}<0.05)$ (Figure 13).

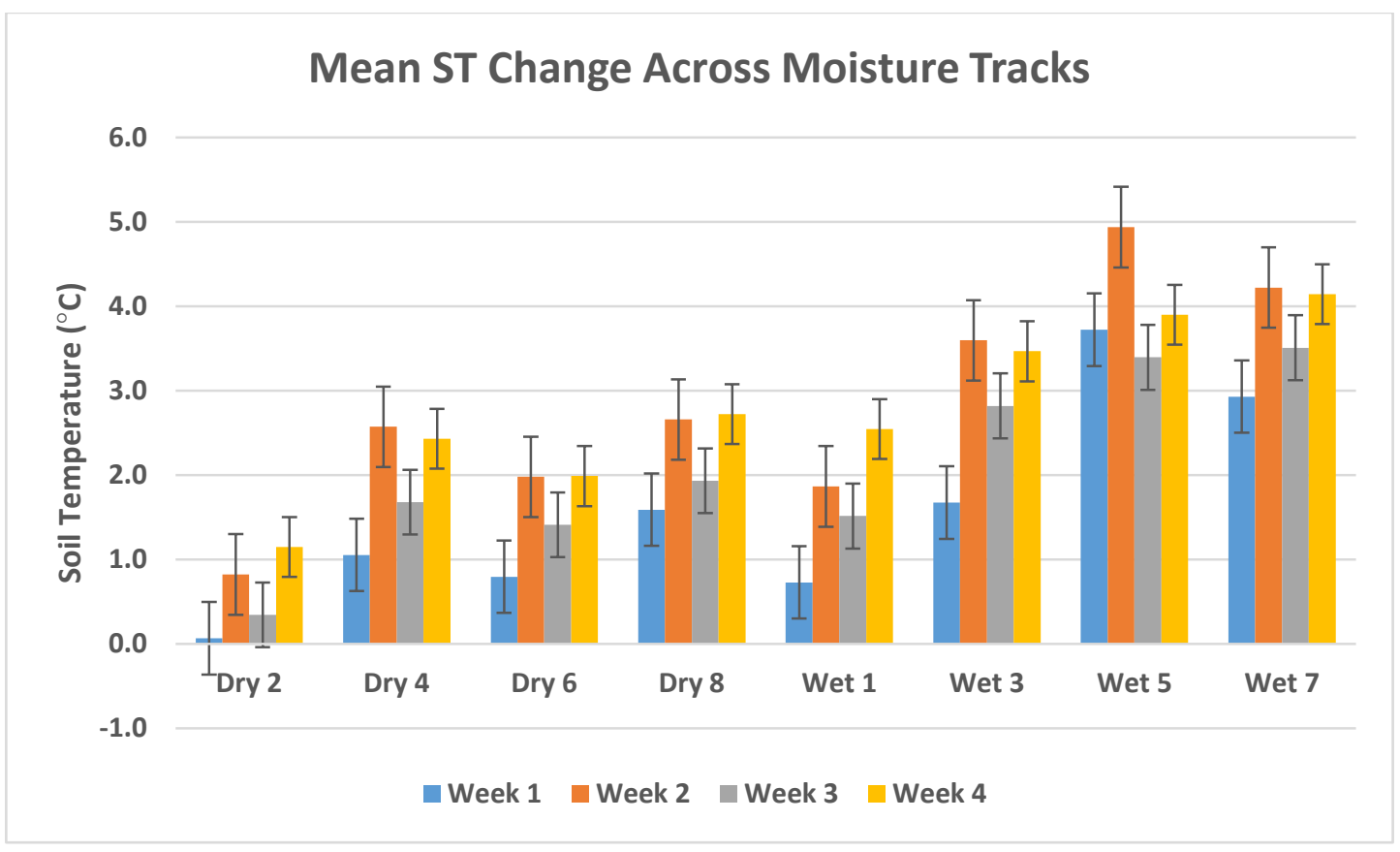

Figure 13: Mean ( \pm 1 SE) ST change across the growing season within the tracks.

SM differed significantly between wet and dry tracks, $F(1,28)=39.4$, $p<0.001$ (Table 2). There was a statistically significant within-subjects interaction between SM across weeks over the growing season, $\mathrm{F}(2.10,58.7)=26.1, \mathrm{p}<0.05, \varepsilon=0.70$; as with ST, SM also steadily increased from week to week and measurements were greater in the wet tracks than the dry tracks (Figure 14). When the tracks were compared within moisture regimes, the dry tracks were still statistically significant across weeks, $F(1.65,18.2)=24.4, p<0.05$, but not across the season, $\mathrm{F}(4.96,18.2)=1.33, \mathrm{p}=0.297$ (Table 44). In the wet tracks, the measurements were statistically significant across weeks, $\mathrm{F}(1.73,19.1)=10.8, \mathrm{p}<0.05, \varepsilon=0.551$, but not between individual wet tracks across the growing season, $\mathrm{F}(5.20,19.1)=2.54, \mathrm{p}=0.062, \varepsilon=0.551$ (Table 
45). The post-hoc results indicated that wet and dry tracks exhibited the greatest within track differences in the western portion of the plot, while the eastern tracks were more similar to each other.

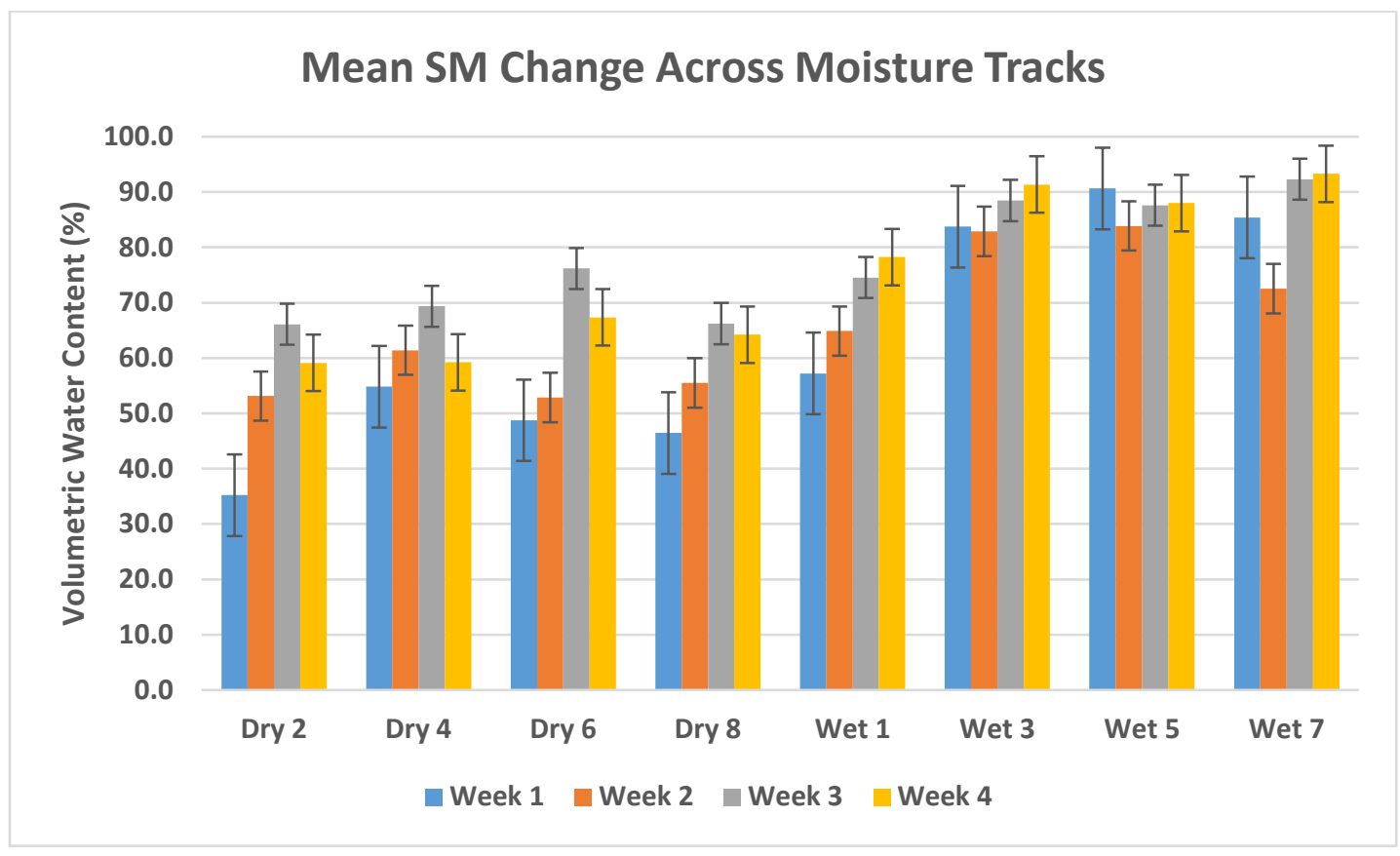

Figure 14: Mean ( \pm 1 SE) SM change across the growing season.

Between-subject effects of active layer depth was higher in the wet compared to the dry tracks, $\mathrm{F}(1,28)=24.0, \mathrm{p}<0.05$ (Table 2 ). There was a statistically significant within-subjects effect between AL between weeks throughout the growing season, $\mathrm{F}(2.31,64.6)=74.0, \mathrm{p}<0.05$, $\varepsilon=0.769$. In both the wet and dry tracks, the AL increased from week to week, with the biggest increased in AL happening in the first half of the growing season (Figure 15). A statistically significant interaction was found between $\mathrm{AL}$ across the moisture track-week treatment, $\mathrm{F}(2.31$, $64.6)=8.36, \mathrm{p}<0.05$. When the tracks were investigated individually against each other, the dry tracks were still statistically significant across weeks, $\mathrm{F}(3,33)=17.0, \mathrm{p}<0.05$, but there was not statistical difference between individual dry tracks across the season, $F(9,33)=1.67, p=0.137$ (Table 47). In the wet tracks, the measurements were statistically significant across weeks, 
$\mathrm{F}(3,33)=74.1, \mathrm{p}<0.05$, but not between individual wet tracks across the growing season, $\mathrm{F}(9,33)=0.736, \mathrm{p}=0.673$ (Table 48). The post-hoc results indicated the greatest difference between Wet 1 and Wet $5(\mathrm{p}<0.05)$ as well as Wet 1 and Wet $7(\mathrm{p}=0.067)$. As with SM, the post-hoc results indicated that the greatest within-track differences were in the western portion of Muskox for both wet and dry tracks.

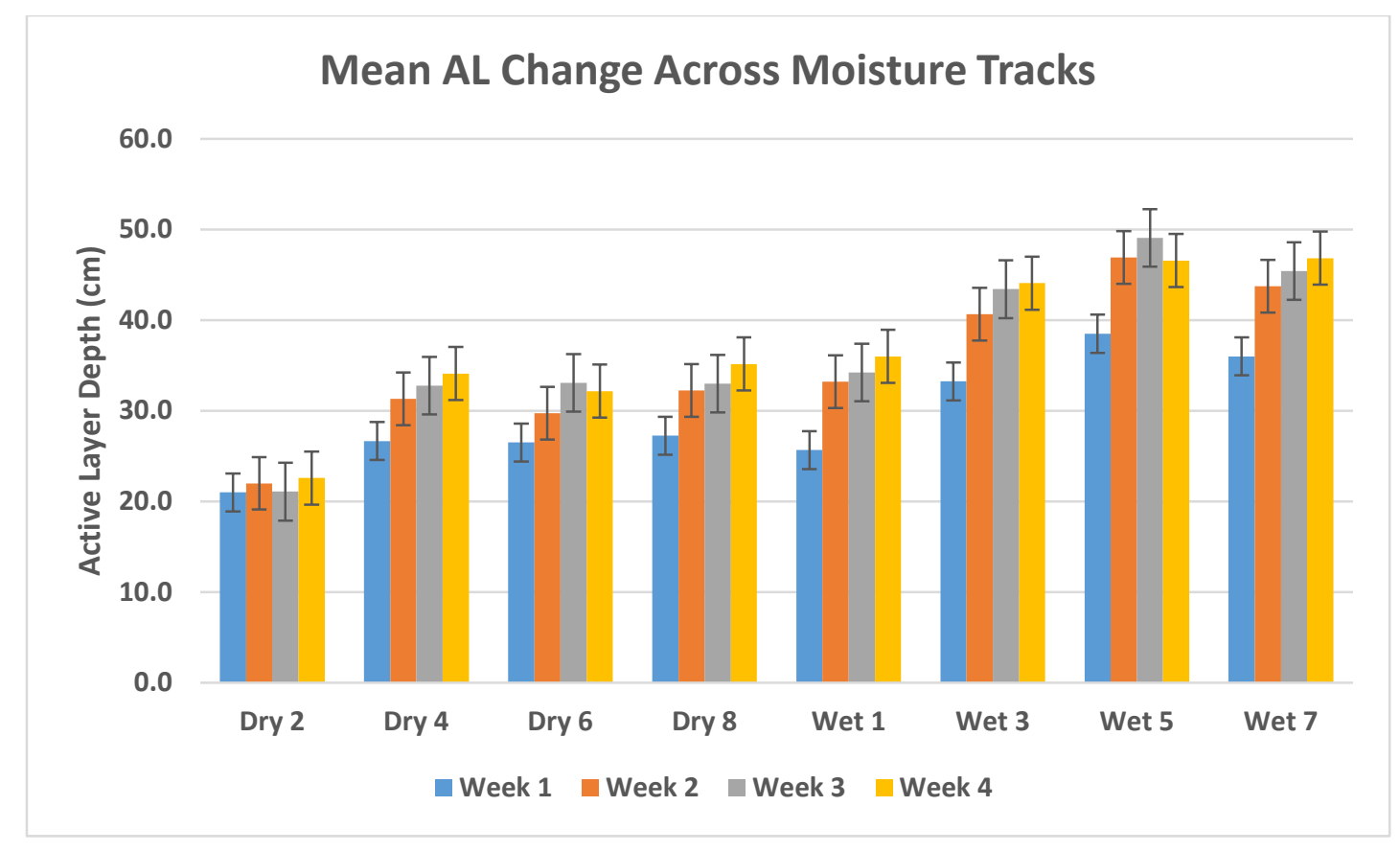

Figure 15: Mean ( \pm 1 SE) AL change across the growing season. 


\subsubsection{Carbon Flux}

Table 3: Mean carbon exchange measurements across the moisture tracks over the growing season. Standard deviations are indicated in brackets.

\begin{tabular}{|c|c|c|c|c|}
\hline & Week 1 & Week 2 & Week 3 & Week 4 \\
\hline $\begin{array}{c}\mathrm{NEE} \mathrm{Dry} \\
\left(\mu \mathrm{mol} / \mathrm{m}^{2} / \mathrm{s}\right)\end{array}$ & $1.13(0.900)$ & $0.590(0.811)$ & $-0.709(0.720)$ & $-0.324(0.802)$ \\
\hline $\begin{array}{c}\mathrm{NEE} \mathrm{Wet} \\
\left(\mu \mathrm{mol} / \mathrm{m}^{2} / \mathrm{s}\right)\end{array}$ & $-0.320(-0.767)$ & $-0.876(1.01)$ & $-1.83(0.698)$ & $-1.43(0.853)$ \\
\hline $\begin{array}{c}\mathrm{ER} \mathrm{Dry} \\
\left(\mu \mathrm{mol} / \mathrm{m}^{2} / \mathrm{s}\right)\end{array}$ & $2.06(0.780)$ & $1.85(0.803)$ & $1.02(0.207)$ & $1.12(0.336)$ \\
\hline $\begin{array}{c}\mathrm{ER} \mathrm{Wet} \\
\left(\mu \mathrm{mol} / \mathrm{m}^{2} / \mathrm{s}\right)\end{array}$ & $2.62(0.807)$ & $2.87(1.02)$ & $1.09(0.301)$ & $1.02(0.407)$ \\
\hline $\begin{array}{c}\mathrm{GPP} \mathrm{Dry} \\
\left(\mu \mathrm{mol} / \mathrm{m}^{2} / \mathrm{s}\right)\end{array}$ & $-0.935(0.941)$ & $-1.26(1.10)$ & $-1.73(0.812)$ & $-1.44(0.899)$ \\
\hline $\begin{array}{c}\mathrm{GPP} \mathrm{Wet} \\
\left(\mu \mathrm{mol} / \mathrm{m}^{2} / \mathrm{s}\right)\end{array}$ & $-2.94(1.07)$ & $-3.75(1.44)$ & $-2.91(0.653)$ & $-2.44(1.09)$ \\
\hline
\end{tabular}

Table 4: Two-way ANOVA p-values for carbon flux measurements across the growing season in different moisture tracks across

\begin{tabular}{|l|c|c|c|}
\multicolumn{1}{|c|}{ the plot. Bolded values indicate significance at $\mathrm{p}<0.05}$. & GPP \\
\hline Interaction & NEE & ER & $\mathbf{0 . 0 0 0}$ \\
\hline Moime & $\mathbf{0 . 0 0 0}$ & $\mathbf{0 . 0 0 0}$ & $\mathbf{0 . 0 0 0}$ \\
\hline Time x Moisture track & $\mathbf{0 . 0 0 0}$ & $\mathbf{0 . 0 2 7}$ & $\mathbf{0 . 0 0 0}$ \\
\hline $\begin{array}{l}\text { Time } \text { X Moisture track } \mathbf{x} \\
\text { Spatial location (W vs. E) }\end{array}$ & 0.452 & $\mathbf{0 . 0 0 7}$ & $\mathbf{0 . 0 0 0}$ \\
\hline
\end{tabular}

NEE differed significantly between tracks, being greatest (most negative) in the wet tracks), $\mathrm{F}(1,28)=29.8, \mathrm{p}<0.05$ (Table 3). Dry tracks were $\mathrm{C}$ sources in the early season (atmospheric C gain), transitioning into a late season sink, while wet tracks were net C sinks throughout the entire season (terrestrial C uptake). There was also a statistically significant within-subject effect for NEE across the four-week growing season, $\mathrm{F}(2.41,67.6)=46.6, \mathrm{p}<$ $0.05, \varepsilon=0.804$, but no statistically significant interaction between-subjects effect of NEE across the moisture tracks over the growing season, $\mathrm{F}(2.41,67.6)=0.847, \mathrm{p}=0.452$. The wet tracks were also a net sink, while dry tracks shifted from being an early season source to late season 
sink, as shown in Figure 16. When the tracks were investigated individually against each other, the within-subjects effects of dry tracks were still statistically significant across weeks, $F(3,33)=$ 29.4, p $<0.05$, but there was no statistical between-subject effect between individual dry tracks across the season, $\mathrm{F}(9,33)=1.46, \mathrm{p}=0.203$ (Table 32). In the wet tracks, results suggest greatest differences in the western end of the plot. In the wet tracks, the within-subject effects were statistically different across weeks, $F(3,33)=23.9, \mathrm{p}<0.05$, but not between individual wet tracks across the growing season, $\mathrm{F}(9,33)=2.02, \mathrm{p}=0.068$ (Table 33). As with SM and AL, the greatest differences were in the western portion of Muskox.

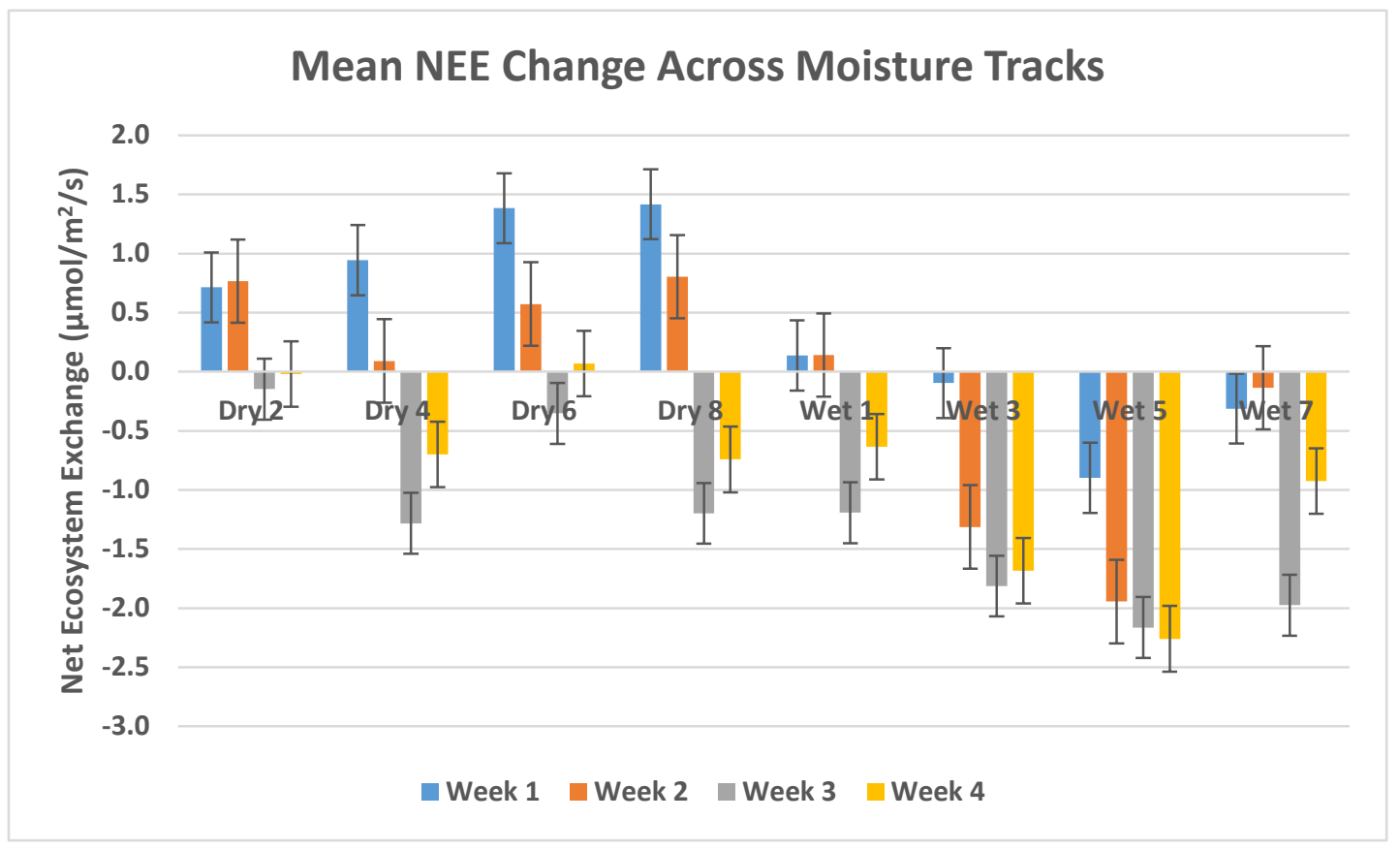

Figure 16: Mean $( \pm 1 \mathrm{SE})$ NEE change across the growing season.

Ecosystem respiration was significantly higher in the wet tracks, $F(1,28)=5.46, \mathrm{p}<0.05$ (Table 3). There was also a statistically significant within-subjects effect between ER across the four-week growing season, $\mathrm{F}(1.42,39.6)=58.5, \mathrm{p}<0.05, \varepsilon=0.472$, and a statistically significant interaction between ER across the moisture tracks over the growing season, $\mathrm{F}(1.42,39.6)=6.70$, $\mathrm{p}<0.05$. When the tracks were investigated individually against each other, the within-subjects 
effects of dry tracks were still statistically significant across weeks, $F(1.79,19.6)=47.4$, $p<$ 0.05, as well as between individual dry tracks across the season, $\mathrm{F}(5.35,19.6)=3.801, \mathrm{p}<0.05$ (Figure 17 and Table 35). Examination of the Tukey's post-hoc test results showed the greatest difference in ER was between Dry 2 and $4(\mathrm{p}<0.05)$. In the wet tracks, the within-subjects effects were statistically significant across weeks, $\mathrm{F}(2.00,22.0)=78.142, \mathrm{p}<0.05$, and between individual wet tracks across the growing season, $\mathrm{F}(6.01,22.0)=8.46, \mathrm{p}<0.05$ (Table 36). The post-hoc results indicated the greatest difference between Wet 1 and Wet $5(\mathrm{p}<0.05)$ as well as Wet 1 and Wet $7(\mathrm{p}<0.05)$.

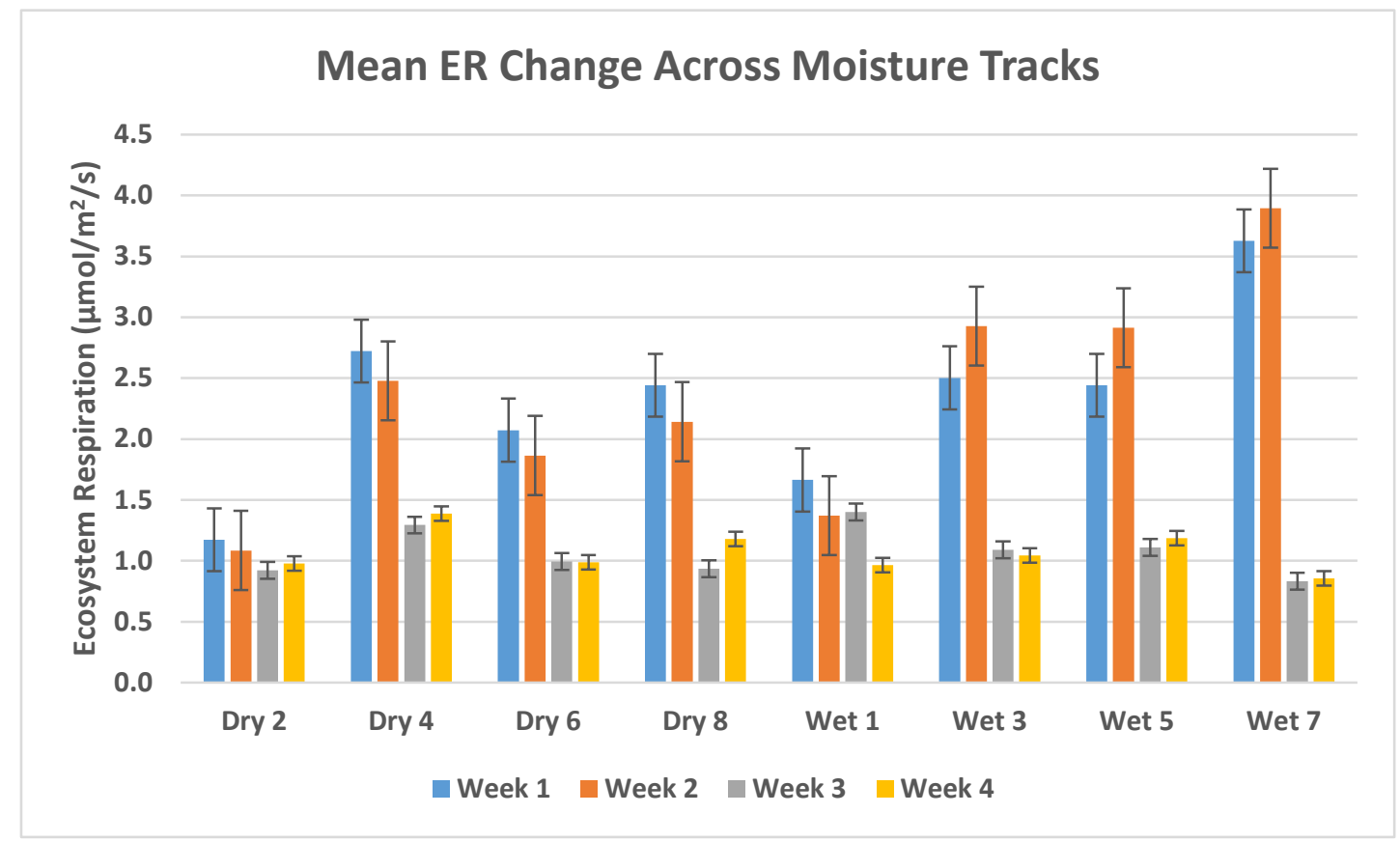

Figure 17: Mean ( \pm 1 SE) ER change across the growing season.

Gross primary production was higher in the wet tracks compared to the dry tracks, $F(1,22)=391, p<0.05$ (Table 3). There was also a statistically significant within-subjects effect of GPP across the four-week growing season, $F(3,84)=8.35, \mathrm{p}<0.05$. A significant interaction existed between GPP across the moisture tracks over the growing season, $\mathrm{F}(1,28)=24.0$, $\mathrm{p}<$ 0.05. As with ER, incoming GPP was greater in the wet tracks than the dry tracks, as shown in 
Figure 18. When the tracks were investigated individually against each other, the within-subjects effects of dry tracks were still statistically different across weeks, $\mathrm{F}(1,12)=51.8$, $\mathrm{p}<0.05$, but not between individual dry tracks across the season, $F(3,12)=1.99 \mathrm{p}=0.169$ (Figure 18 and Table 38). Examination of the Tukey's post-hoc test results showed the greatest difference in GPP was between Dry 2 and 4, although these differences were not statistically significant. In the wet tracks, the within-subjects effects of wet track measurements were statistically different across weeks, $\mathrm{F}(1,12)=514, \mathrm{p}<0.05$, as well as between individual wet tracks across the growing season, $\mathrm{F}(3,12)=11.6, \mathrm{p}<0.05$ (Table 39). The post-hoc results indicated the greatest difference between Wet 1 and Wet $5(\mathrm{p}<0.05)$. Like all other environmental variables, this greatest difference was located in the western portion of the plot.

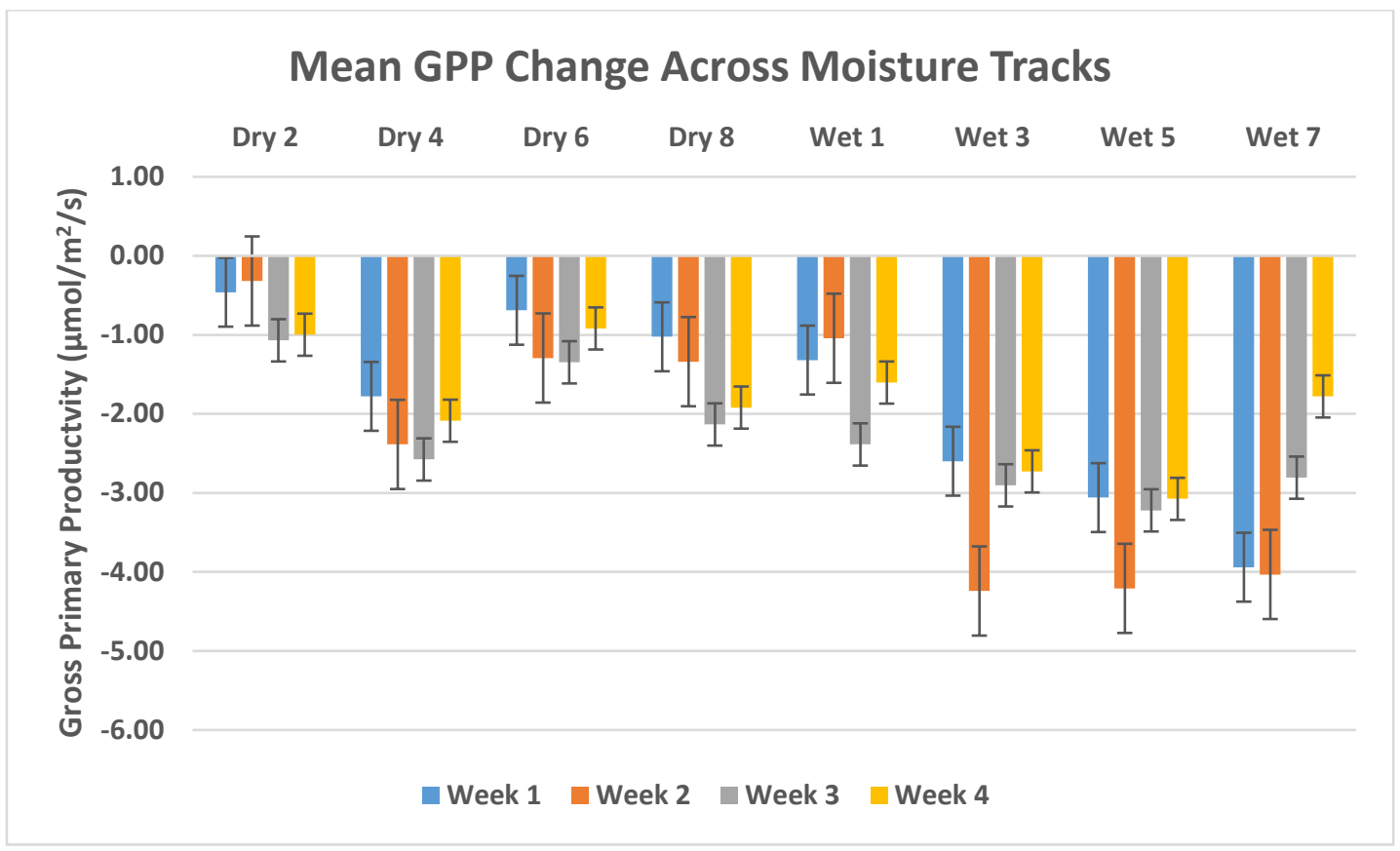

Figure 18: Mean ( $\pm 1 \mathrm{SE}$ ) GPP change across the growing season.

\subsubsection{Quantitative Relationships Between Carbon Flux and Environmental Variables}

Pearson’s bivariate correlation coefficient was environmental variables and C flux against each other to examine the strength and direction of relationships between the environmental 
variables at play in the wet sedge meadow. Total season environmental variables showed statistically significant relationships across all measurements (Table 5Table 5). Strong positive relationships existed between AL and ST as well as NEE and GPP, while strong negative relationships existed between NEE, GPP, and all environmental variables. For example, the relationship between AL and NEE had a moderately high $\mathrm{r}^{2}$ of 0.709 , which is indicative of the role that a deepening active layer can have on the net $\mathrm{C}$ losses.

Table 5: Pearson's bivariate correlation coefficients for carbon flux measurements and environmental variables across the entire growing season. Bolded values indicate significance at $\mathrm{p}<0.05$.

\begin{tabular}{|c|c|c|c|c|c|}
\hline & AL & ST & SM & NEE & ER \\
\hline ST & 0.963 & & & & \\
\hline SM & 0.558 & 0.552 & & & \\
\hline NEE & -0.709 & -0.699 & -0.700 & & \\
\hline ER & 0.604 & 0.603 & 0.554 & -0.366 & \\
\hline GPP & -0.797 & -0.789 & -0.769 & 0.923 & -0.696 \\
\hline
\end{tabular}

As with the entire growing season, AL and ST were also strongly related to one another in the early season. Early season GPP had strong significant negative relationships with all environmental variables and carbon flux measurements (Table 6).

Table 6: Pearson's bivariate correlation coefficients for carbon flux measurements and environmental variables across the early season. Bolded values indicate significance at $\mathrm{p}<0.05$.

\begin{tabular}{|c|c|c|c|c|c|}
\hline & AL & ST & SM & NEE & ER \\
\hline ST & $\mathbf{0 . 9 4 4}$ & & & & \\
\hline SM & $\mathbf{0 . 6 0 1}$ & $\mathbf{0 . 6 0 4}$ & & & \\
\hline NEE & $-\mathbf{0 . 6 3 4}$ & -0.640 & -0.754 & & \\
\hline ER & $\mathbf{0 . 6 4 7}$ & $\mathbf{0 . 6 5 5}$ & $\mathbf{0 . 5 1 2}$ & -0.231 & \\
\hline GPP & $-\mathbf{0 . 8 1 4}$ & $-\mathbf{0 . 8 2 3}$ & -0.819 & $\mathbf{0 . 8 2 5}$ & -0.740 \\
\hline
\end{tabular}

Late season environmental variables and $\mathrm{C}$ fluxes were similar to that observed in the early part of the growing season, with AL and ST having the strongest relationship (Table 7). NEE and GPP also correlated positively. 
Table 7: $\mathrm{r}^{2}$ values for environmental variable regression analysis during the late growing season. Bolded values indicate significance at $\mathrm{p}<0.05$.

\begin{tabular}{|c|c|c|c|c|c|}
\hline & AL & ST & SM & NEE & ER \\
\hline ST & $\mathbf{0 . 9 6 6}$ & & & & \\
\hline SM & $\mathbf{0 . 4 6 4}$ & $\mathbf{0 . 4 5 3}$ & & & \\
\hline NEE & $-\mathbf{0 . 6 6 8}$ & $-\mathbf{0 . 6 7 1}$ & $\mathbf{- 0 . 5 4 2}$ & & \\
\hline ER & -0.061 & -0.138 & 0.064 & -0.126 & \\
\hline GPP & $\mathbf{- 0 . 6 6 0}$ & $\mathbf{- 0 . 6 6 3}$ & $\mathbf{- 0 . 4 9 6}$ & $\mathbf{0 . 9 2 8}$ & -0.276 \\
\hline
\end{tabular}

\subsubsection{Available Soil Nitrogen}

\subsubsection{Seasonal Trends}

A two-way repeated measures ANOVA was conducted for $\mathrm{NO}_{3}{ }^{-}$and $\mathrm{NH}_{4}{ }^{+}$across the growing season, separated into early (June 30 to July 13) and late season (July 13 to 27). When analysing the $\mathrm{N}$ concentration values, studentized residuals were examined for values greater than \pm 3 and any outliers were removed. Early season $\mathrm{N}$ values were normally distributed $(\mathrm{p}<$ 0.05), but late season $\mathrm{N}$ values failed the Shapiro-Wilk's test so concentration values for $\mathrm{NO}_{3}{ }^{-}$ and $\mathrm{NH}_{4}{ }^{+}$(Table 8 ) were logarithmic and square root transformed respectively based on their strongly positive and moderately positive skewed values (Laerd Statistics, 2013).

Table 8: Mean and standard error values for $\mathrm{NO}_{3}{ }^{-}$and $\mathrm{NH}_{4}{ }^{+}$across moisture tracks, expressed as $\mu \mathrm{g}$ of nutrient adsorbed per 10 $\mathrm{cm}^{2}$ per two-week period.

\begin{tabular}{|c|c|c|c|}
\hline Measure & Track & Season & Mean \\
\hline \multirow{6}{*}{$\mathrm{NO}_{3}{ }^{-}$} & \multirow{2}{*}{ Dry } & Early & $2.512 \pm 0.149$ \\
\hline & & Late & $3.448 \pm 0.641$ \\
\hline & \multirow{2}{*}{ Wet } & Early & $2.232 \pm 0.203$ \\
\hline & & Late & $2.452 \pm 0.362$ \\
\hline & \multirow{2}{*}{ SZ } & Early & $2.251 \pm 0.304$ \\
\hline & & Late & $2.478 \pm 0.524$ \\
\hline \multirow{6}{*}{$\mathrm{NH}_{4}^{+}$} & \multirow{2}{*}{ Dry } & Early & $11.728 \pm 0.778$ \\
\hline & & Late & $10.238 \pm 0.130$ \\
\hline & \multirow{2}{*}{ Wet } & Early & $12.487 \pm 1.301$ \\
\hline & & Late & $13.683 \pm 1.049$ \\
\hline & \multirow{2}{*}{ SZ } & Early & $9.795 \pm 0.756$ \\
\hline & & Late & $12.761 \pm 0.580$ \\
\hline
\end{tabular}


There was a statistically significant difference between early and late season $\mathrm{NH}_{4}{ }^{+}$ availability, $\mathrm{F}(1,27)=98.462, \mathrm{p}<0.05$. However, the interaction between seasonality and moisture track was statistically insignificant, $\mathrm{F}(1,27)=0.163, \mathrm{p}=0.689$. Overall, $\mathrm{NH}_{4}^{+}$ availability was greater in the late season than in the early season. The sum of early and late season $\mathrm{NH}_{4}{ }^{+}$adsorption as determined through the ion exchange resins was greater than that of total season resin adsorption, suggesting a potential saturation level reached in the resins and a need to further investigate with soil samples.

Nitrate availability also varied seasonally, $F(1,27)=264.622, \mathrm{p}<0.05$. However, the interaction between seasonality and moisture track was statistically insignificant, $\mathrm{F}(1,27)=$ 0.491, $\mathrm{p}=0.490$. Overall, mean values of $\mathrm{NO}_{3}{ }^{-}$in the tracks increased from early to late season (Resin B2 > Resin B1). The sum of early and late season available $\mathrm{NO}_{3}{ }^{-}$was greater than that of total season resin adsorption, suggesting a potential saturation of the resins and a need for further investigation. The SZ did not exhibit statistically significant differences in nutrient concentrations from the main wet sedge plot in all resin sampling regimes. No clear patterns were exhibited temporally in the SZ.

\subsubsection{Spatial Patterns}

Available $\mathrm{N}$ was looked at for local spatial autocorrelation, shown in Table 9. Local spatial autocorrelations for $\mathrm{N}$ were run and the local indicators of spatial association (LISA) maps were analyzed to determine where areas of high and low $\mathrm{NO}_{3}{ }^{-}$and $\mathrm{NH}_{4}{ }^{+}$tended to gather within Muskox (Figure 19). 
Table 9: Univariate local Moran's I values for $\mathrm{NO}_{3}{ }^{-}$and $\mathrm{NH}_{4}{ }^{+}$

\begin{tabular}{|l|c|}
\hline & Moran's I \\
\hline Resin $\mathrm{A} \mathrm{NO}_{3}{ }^{-}$ & 0.225 \\
\hline Resin $\mathrm{A} \mathrm{NH}_{4}{ }^{+}$ & 0.030 \\
\hline Resin $\mathrm{B}^{-} \mathrm{NO}_{3}{ }^{-}$ & 0.019 \\
\hline Resin $\mathrm{B} 1 \mathrm{NH}_{4}{ }^{+}$ & 0.109 \\
\hline Resin $\mathrm{B2} \mathrm{NO}_{3}^{-}$ & 0.142 \\
\hline Resin $\mathrm{B2} \mathrm{NH}_{4}^{+}$ & -0.142 \\
\hline
\end{tabular}

High-high (red) values of $\mathrm{N}(\mathrm{p}<0.05)$ tended to gather in the southwestern portion of the plot in all resins except late season $\mathrm{NH}_{4}{ }^{+}$, while low-low (blue) values of $\mathrm{N}(\mathrm{p}<0.05)$ clustered in the northeastern corner of the plot for all resin regimes of $\mathrm{NO}_{3}{ }^{-}$and $\mathrm{NH}_{4}{ }^{+}$.
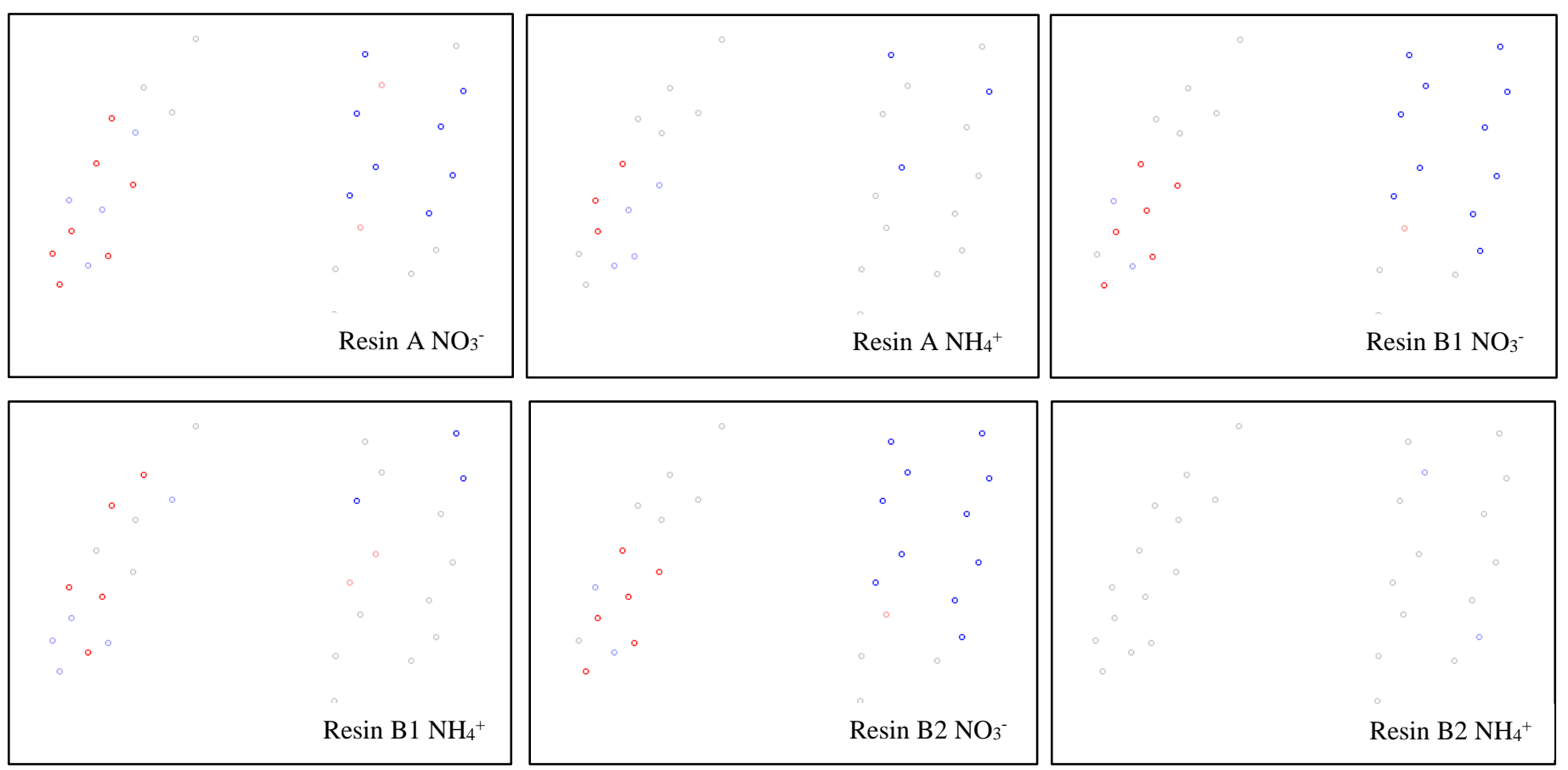

Figure 19: LISA maps of clustered values for $\mathrm{NO}_{3}{ }^{-}$and $\mathrm{NH}_{4}{ }^{+}$

An examination of interpolation maps created through Kriging analysis in ArcGIS showed similar trends in $\mathrm{NO}_{3}{ }^{-}$and $\mathrm{NH}_{4}{ }^{+}$(Figure 20), with higher concentrations of the nutrients in the southwestern corner of the plot and lowest values in the northeastern portion. This pattern followed the gentle sloping of topography in the meadow, where the northeast corner was at the highest elevation, sloping down to the southwest corner at the lowest point. 

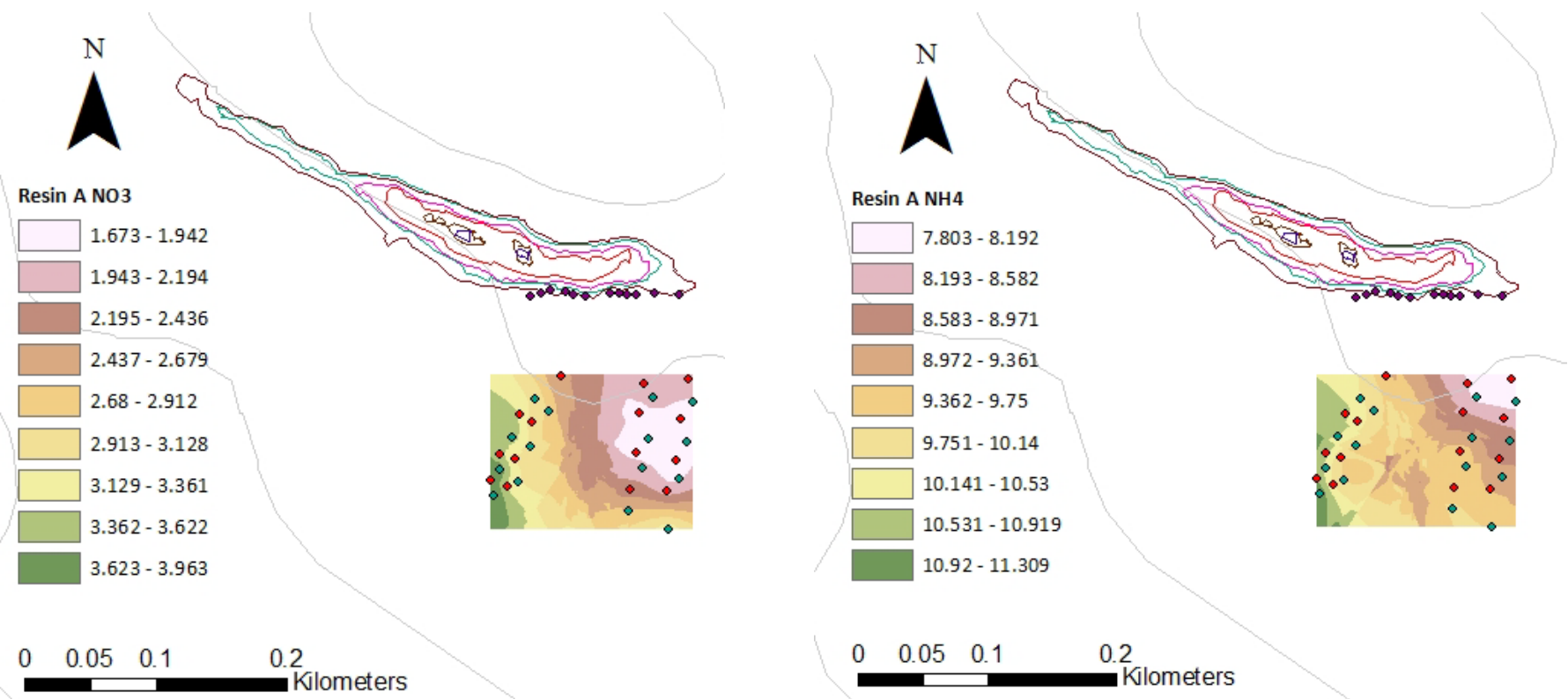

Figure 20: Ordinary kriging maps for total season adsorption of $\mathrm{NO}_{3}{ }^{-}$and $\mathrm{NH}_{4}+$. Red dots represent wet tracks and green dots represent dry tracks.

The early season trend of $\mathrm{NH}_{4}{ }^{+}$was similar to that of total season $\mathrm{NH}_{4}{ }^{+}$, with the highest values being in the western portion of the plot (Figure 21). However, early season $\mathrm{NH}_{4}{ }^{+}$is located more north than the end location of total season $\mathrm{NH}_{4}{ }^{+}$. No clear patterns are discernable from the early season $\mathrm{NO}_{3}{ }^{-}$kriging map, aside from the location of highest values being in the southeastern corner of the plot. 

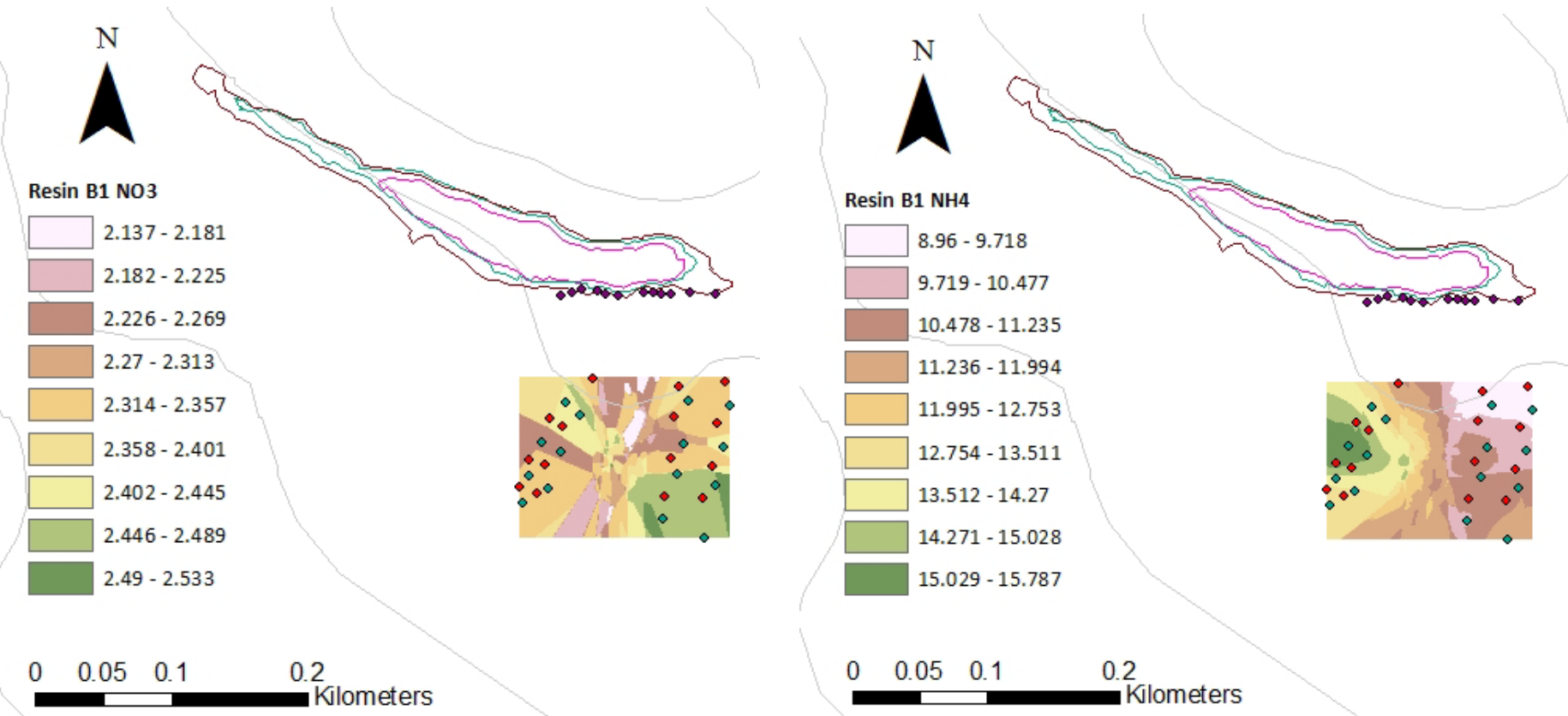

Figure 21: Ordinary kriging maps for early season adsorption of $\mathrm{NO}_{3}{ }^{-}$and $\mathrm{NH}_{4}{ }^{+}$. Red dots represent wet tracks and green dots represent dry tracks.

When looking at late season $\mathrm{N}$, the $\mathrm{NO}_{3}{ }^{-}$and $\mathrm{NH}_{4}{ }^{+}$patterns almost seem like mirror images to those of the early season; late season $\mathrm{NH}_{4}{ }^{+}$matched early season $\mathrm{NO}_{3}{ }^{-}$patterns, while late season $\mathrm{NO}_{3}{ }^{-}$matched early season $\mathrm{NH}_{4}{ }^{+}$patterns (Figure 22). As compared to the early season, late season $\mathrm{NO}_{3}{ }^{-}$had shifted from the southeastern corner to the southwestern corner of the plot. Late season $\mathrm{NH}_{4}{ }^{+}$was highest in the southeastern corner and lower on the western side of the plot. 


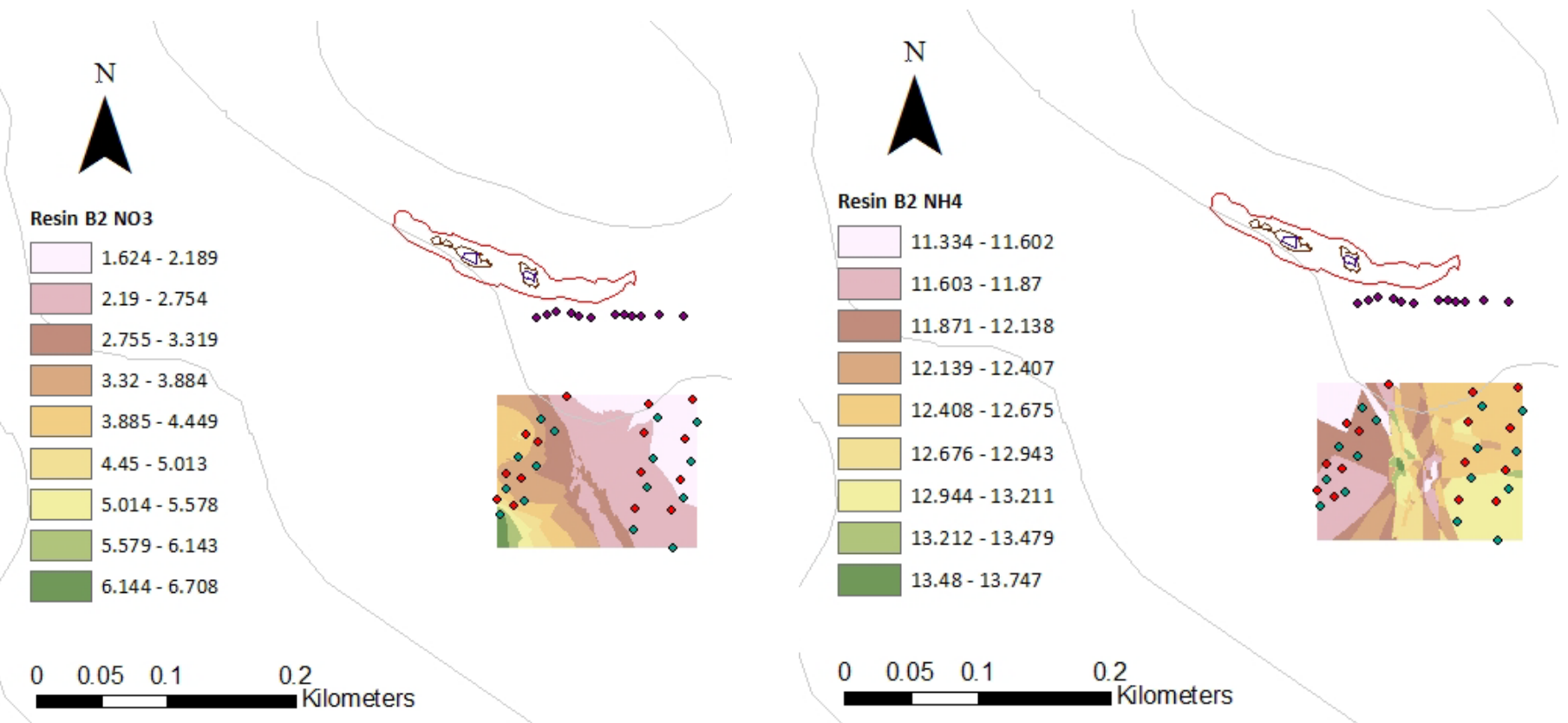

Figure 22: Ordinary kriging maps for late season adsorption of $\mathrm{NO}_{3}{ }^{-}$and $\mathrm{NH}_{4}{ }^{+}$. Red dots represent wet tracks and green dots represent dry tracks.

\subsubsection{Relationships Between Available Nitrogen, Carbon Fluxes, and Environmental Variables}

Linear regression analysis showed that across the dry tracks, $\mathrm{AL}$ and total season $\mathrm{NO}_{3}{ }^{-}$ $\left(\mathrm{R}^{2}=0.707\right), \mathrm{F}(1,12)=28.937, \mathrm{p}<0.05$, and ST and total season $\mathrm{NO}_{3}{ }^{-}\left(\mathrm{R}^{2}=0.598\right), \mathrm{F}(1,12)=$ 17.840, $\mathrm{p}<0.05$ were significantly related (Table 10 ). Total season $\mathrm{NH}_{4}{ }^{+}$in the dry tracks were significant but moderate in their relationships with AL $\left(\mathrm{R}^{2}=0.470\right), \mathrm{F}(1,12)=10.633, \mathrm{p}<0.05$, and ST $\left(\mathrm{R}^{2}=0.456\right), \mathrm{F}(1,12)=10.046, \mathrm{p}<0.05$. Carbon flux measurements also showed significant but moderate relationships between total and late season $\mathrm{NO}_{3}{ }^{-}$and GPP $\left(\mathrm{r}^{2}=0.323\right.$ and $\left.\mathrm{R}^{2}=0.338\right), \mathrm{F}(1,14)=6.64, \mathrm{p}<0.05$ and $\mathrm{F}(1,14)=6.20, \mathrm{p}<0.05$ respectively, as well as moderate relationships with between total season $\mathrm{NH}_{4}{ }^{+}$and ER $\left(\mathrm{R}^{2}=0.359\right)$ and GPP $\left(\mathrm{R}^{2}=\right.$ 0.348), $\mathrm{F}(1,14)=7.27, \mathrm{p}<0.05$ and $\mathrm{F}(1,14)=6.93, \mathrm{p}<0.05$ (Table 11). Early season $\mathrm{NO}_{3}{ }^{-}$and early and late season $\mathrm{NH}_{4}{ }^{+}$were not significant or strong in their relationships to biophysical 
variables and carbon fluxes, suggesting that in a shorter time scale, soil available nitrogen is not a strong predictor of potential ER or GPP.

Table 10: Bivariate regression $\mathrm{R}^{2}$ coefficients for nitrogen (dependent variable) against environmental variables (independent variable) across dry tracks. Bolded values indicate significant values at $\mathrm{p}<0.05$.

\begin{tabular}{|c|c|c|c|c|c|c|}
\hline & Resin $\mathrm{A} \mathrm{NO}_{3}{ }^{-}$ & Resin $\mathrm{A} \mathrm{NH}_{4}{ }^{+}$ & Resin $\mathrm{B} 1 \mathrm{NO}_{3}^{-}$ & Resin B1 $\mathrm{NH}_{4}^{+}$ & Resin $\mathrm{B}^{2} \mathrm{NO}_{3}{ }^{-}$ & Resin $\mathrm{B} 2 \mathrm{NH}_{4}{ }^{+}$ \\
\hline$A L$ & 0.707 & 0.470 & 0.000 & 0.069 & 0.326 & 0.205 \\
\hline ST & 0.598 & 0.456 & 0.009 & 0.037 & 0.342 & 0.161 \\
\hline SM & 0.026 & 0.021 & 0.011 & 0.150 & 0.013 & 0.017 \\
\hline
\end{tabular}

Table 11: Bivariate regression $\mathrm{R}^{2}$ coefficients for nitrogen (independent variable) against environmental variables (dependent variable) across dry tracks. Bolded values indicate significant values at $\mathrm{p}<0.05$.

\begin{tabular}{|l|c|c|c|c|c|c|}
\hline & Resin $\mathrm{A} \mathrm{NO}_{3}{ }^{-}$ & Resin $\mathrm{A} \mathrm{NH}_{4}{ }^{+}$ & Resin B1 $\mathrm{NO}_{3}{ }^{-}$ & Resin B1 $\mathrm{NH}_{4}{ }^{+}$ & Resin $\mathrm{B2} \mathrm{NO}_{3}{ }^{-}$ & Resin B2 $\mathrm{NH}_{4}{ }^{+}$ \\
\hline ER & 0.209 & $\mathbf{0 . 3 5 9}$ & 0.002 & 0.024 & 0.087 & 0.100 \\
\hline GPP & $\mathbf{0 . 3 2 3}$ & $\mathbf{0 . 3 4 8}$ & 0.097 & 0.095 & $\mathbf{0 . 3 3 8}$ & 0.060 \\
\hline
\end{tabular}

In the wet tracks, total season SM had a strong and significant relationship with $\mathrm{NO}_{3}{ }^{-}\left(\mathrm{R}^{2}\right.$ $=0.646), \mathrm{F}(1,13)=23.765, \mathrm{p}<0.05$ (Table 12). Total season $\mathrm{NH}_{4}{ }^{+}$had significant relationships with AL and ST as well. ER and GPP were moderate predictors strong predictors of total season available soil $\mathrm{NO}_{3}{ }^{-}$, while early season $\mathrm{NH}_{4}{ }^{+}$predicted ER (Table 13). Early season $\mathrm{NO}_{3}{ }^{-}$and late season $\mathrm{NH}_{4}{ }^{+}$were not significant or strong in their relationships to biophysical variables and carbon fluxes.

Table 12: Bivariate regression $\mathrm{R}^{2}$ coefficients for nitrogen against environmental variables and carbon flux across wet tracks. Bolded values indicate significant values at $\mathrm{p}<0.05$.

\begin{tabular}{|l|c|c|c|c|c|c|}
\hline & $\begin{array}{c}\text { Total Season } \\
\mathbf{N O}_{3}{ }^{-}\end{array}$ & $\begin{array}{c}\text { Total Season } \\
\mathbf{N H}_{4}{ }^{+}\end{array}$ & $\begin{array}{c}\text { Early Season } \\
\mathbf{N O}_{\mathbf{3}}^{-}\end{array}$ & $\begin{array}{c}\text { Early Season } \\
\mathbf{N H}_{4}{ }^{+}\end{array}$ & $\begin{array}{c}\text { Late Season } \\
\mathbf{N O}_{3}{ }^{-}\end{array}$ & $\begin{array}{c}\text { Late Season } \\
\mathbf{N H}_{4}{ }^{+}\end{array}$ \\
\hline $\mathbf{A L}$ & 0.227 & $\mathbf{0 . 3 7 0}$ & 0.134 & 0.219 & 0.127 & 0.013 \\
\hline ST & $\mathbf{0 . 2 8 9}$ & $\mathbf{0 . 4 2 0}$ & 0.100 & 0.230 & 0.194 & 0.000 \\
\hline SM & $\mathbf{0 . 6 4 6}$ & 0.054 & 0.033 & 0.001 & $\mathbf{0 . 4 4 9}$ & 0.094 \\
\hline
\end{tabular}

Table 13: Bivariate regression $\mathrm{R}^{2}$ coefficients for nitrogen (independent variable) against environmental variables (dependent variable) across wet tracks. Bolded values indicate significant values at $\mathrm{p}<0.05$.

\begin{tabular}{|l|c|c|c|c|c|c|}
\hline & $\begin{array}{c}\text { Total Season } \\
\mathbf{N O}_{3^{-}}{ }^{-}\end{array}$ & $\begin{array}{c}\text { Total Season } \\
\mathbf{N H}_{4}{ }^{+}\end{array}$ & $\begin{array}{c}\text { Early Season } \\
\mathbf{N O}_{3}^{-}\end{array}$ & $\begin{array}{c}\text { Early Season } \\
\mathbf{N H}_{4}{ }^{+}\end{array}$ & $\begin{array}{c}\text { Late Season } \\
\mathbf{N O}_{3}{ }^{-}\end{array}$ & $\begin{array}{c}\text { Late Season } \\
\mathbf{N H}_{4}{ }^{+}\end{array}$ \\
\hline ER & $\mathbf{0 . 3 9 5}$ & 0.112 & 0.008 & $\mathbf{0 . 5 2 8}$ & 0.037 & 0.024 \\
\hline GPP & $\mathbf{0 . 3 8 4}$ & 0.023 & 0.086 & 0.251 & 0.010 & 0.121 \\
\hline
\end{tabular}


Multiple regression models showed to have stronger relationships for environmental variables with total season $\mathrm{N}$ than the bivariate models did, indicating that several variables are at play in determining $\mathrm{N}$ concentration in a wet sedge meadow. The regression model better predicted $\mathrm{N}$ in the wet tracks than the dry tracks, validating the need to separately sample and analyze the plot for moisture tracks that was determined in the original methodology. Two of the multiple regression models statistically significantly predicted total and late season $\mathrm{NO}_{3}{ }^{-}$in the wet tracks $(\mathrm{p}<0.05)$ (Table 17 and Table 19).

Table 14: Multiple regression statistics for total season $\mathrm{NH}_{4}{ }^{+}$across wet and dry tracks. Bolded values indicate significance at $\mathrm{p}<$ 0.05 .

\begin{tabular}{|c|c|c|c|c|c|c|}
\hline & \multicolumn{2}{|c|}{ DRY TRACKS $\left(\mathbf{R}^{2}=\mathbf{0 . 4 8 7}, \mathbf{p}=\mathbf{0 . 0 5 4}\right)$} & \multicolumn{2}{c|}{ WET TRACKS $\left(\mathbf{R}^{2}=\mathbf{4 3 2}, \mathbf{p}=\mathbf{0 . 0 9 0}\right)$} \\
\hline Variable & $\mathbf{B}$ & $\mathbf{S E}$ & $\boldsymbol{B}$ & $\mathbf{B}$ & $\mathrm{SE}_{\mathrm{B}}$ & $\boldsymbol{B}$ \\
\hline $\mathbf{A L}$ & -0.142 & 0.201 & -0.418 & 0.030 & 0.305 & -0.087 \\
\hline ST & -0.751 & 1.59 & -0.278 & -1.51 & 1.87 & -0.712 \\
\hline SM & -0.029 & 0.059 & -0.108 & -0.017 & 0.040 & -0.102 \\
\hline
\end{tabular}

Table 15: Multiple regression statistics for early season $\mathrm{NH}_{4}{ }^{+}$across wet and dry tracks. Bolded values indicate significance at $\mathrm{p}$ $<0.05$.

\begin{tabular}{|c|c|c|c|c|c|c|}
\hline & \multicolumn{2}{|c|}{ DRY TRACKS $\left(\mathbf{R}^{\mathbf{2}}=\mathbf{0 . 2 2 3}, \mathbf{p}=\mathbf{0 . 4 0 9}\right)$} & \multicolumn{2}{c|}{ WET TRACKS $\left(\mathbf{R}^{\mathbf{2}}=\mathbf{0 . 2 7 2}, \mathbf{p}=\mathbf{0 . 3 0 2}\right)$} \\
\hline Variable & $\mathbf{B}$ & $\mathbf{S E} E_{\mathrm{B}}$ & $\boldsymbol{B}$ & $\mathbf{B}$ & $\mathbf{S E}_{\mathrm{B}}$ & $\boldsymbol{B}$ \\
\hline $\mathbf{A L}$ & -0.366 & 0.388 & -0.530 & -0.006 & 0.652 & -0.008 \\
\hline $\mathbf{S T}$ & 1.66 & 2.643 & 0.358 & -2.06 & 3.286 & -0.549 \\
\hline SM & -0.152 & 0.107 & -0.388 & 0.079 & 0.100 & 0.219 \\
\hline
\end{tabular}

Table 16: Multiple regression statistics for late season $\mathrm{NH}_{4}$ across wet and dry tracks. Bolded values indicate significance at $\mathrm{p}<$ 0.05 .

\begin{tabular}{|c|c|c|c|c|c|c|}
\hline & \multicolumn{2}{|c|}{ DRY TRACKS $\left(\mathbf{R}^{2}=\mathbf{0 . 2 1 8}, \mathbf{p}=\mathbf{0 . 4 1 9}\right)$} & \multicolumn{2}{c|}{ WET TRACKS $\left(\mathbf{R}^{2}=\mathbf{0 . 2 9 1}, \mathbf{p}=\mathbf{0 . 2 6 8}\right)$} \\
\hline Variable & $\mathbf{B}$ & $\mathbf{S E}_{\mathrm{B}}$ & $\boldsymbol{B}$ & $\mathbf{B}$ & $\mathbf{S E _ { \mathrm { B } }}$ & $\boldsymbol{B}$ \\
\hline $\mathbf{A L}$ & -0.213 & 0.295 & -0.601 & 0.844 & 0.483 & 1.36 \\
\hline $\mathbf{S T}$ & 0.544 & 2.80 & 0.164 & -6.29 & 3.75 & -1.30 \\
\hline $\mathbf{S M}$ & -0.032 & 0.086 & -0.108 & 0.134 & 0.083 & 0.083 \\
\hline
\end{tabular}


Table 17: Multiple regression statistics for total season $\mathrm{NO}_{3}{ }^{-}$across wet and dry tracks. Bolded values indicate significance at $\mathrm{p}<$ 0.05 .

\begin{tabular}{|c|c|c|c|c|c|c|}
\hline \multirow[b]{2}{*}{ Variable } & \multicolumn{3}{|c|}{ DRY TRACKS $\left(R^{2}=0.533, p<0.05\right)$} & \multicolumn{3}{|c|}{ WET TRACKS $\left(R^{2}=0.803, p<0.05\right)$} \\
\hline & B & $\mathrm{SE}_{\mathrm{B}}$ & ß & B & $\mathrm{SE}_{\mathrm{B}}$ & ß \\
\hline$A L$ & 0.033 & 0.110 & 0.171 & -0.039 & 0.067 & -0.299 \\
\hline ST & -1.34 & 0.874 & -0.864 & -0.081 & 0.409 & -0.103 \\
\hline SM & -0.28 & 0.032 & -0.182 & -0.046 & 0.009 & -0.753 \\
\hline
\end{tabular}

Table 18: Multiple regression statistics for early season $\mathrm{NO}_{3}{ }^{-}$across wet and dry tracks. Bolded values indicate significance at $\mathrm{p}<$ 0.05 .

\begin{tabular}{|c|c|c|c|c|c|c|}
\hline \multirow[b]{2}{*}{ Variable } & \multicolumn{3}{|c|}{ DRY TRACKS $\left(R^{2}=0.068, p=0.847\right)$} & \multicolumn{3}{|c|}{ WET TRACKS $\left(R^{2}=0.157, p=0.581\right)$} \\
\hline & B & $\mathrm{SE}_{\mathrm{B}}$ & ß & B & $\mathrm{SE}_{\mathrm{B}}$ & ß \\
\hline$A L$ & -0.037 & 0.052 & -0.433 & -0.090 & 0.109 & -0.757 \\
\hline ST & 0.293 & 0.357 & 0.512 & 0.262 & 0.551 & 0.447 \\
\hline SM & -0.007 & 0.014 & -0.149 & -0.007 & 0.017 & -0.119 \\
\hline
\end{tabular}

Table 19: Multiple regression statistics for late season $\mathrm{NO}_{3}{ }^{-}$across wet and dry tracks. Bolded values indicate significance at $\mathrm{p}<$ 0.05 .

\begin{tabular}{|c|c|c|c|c|c|c|}
\hline & \multicolumn{2}{|c|}{ DRY TRACKS $\left(\mathbf{R}^{\mathbf{2}}=\mathbf{0 . 3 9 7}, \mathbf{p}=\mathbf{0 . 1 2 2}\right)$} & \multicolumn{2}{c|}{ WET TRACKS $\left(\mathbf{R}^{2}=\mathbf{0 . 6 2 2 ,} \mathbf{p}<0.05\right)$} \\
\hline Variable & $\mathbf{B}$ & $\mathbf{S E} E_{\mathrm{B}}$ & $\boldsymbol{B}$ & $\mathbf{B}$ & $\mathrm{SE}_{\mathrm{B}}$ & $\boldsymbol{B}$ \\
\hline $\mathbf{A L}$ & 0.028 & 0.213 & 0.096 & 0.007 & 0.122 & 0.034 \\
\hline $\mathbf{S T}$ & -1.96 & 2.02 & -0.720 & -0.746 & 0.944 & -0.449 \\
\hline SM & -0.058 & 0.062 & -0.240 & -0.072 & 0.021 & -0.652 \\
\hline
\end{tabular}

Multiple regression models were also explored to predict C fluxes using both soil available $\mathrm{N}$ variables and environmental variables. Three of the models were strongly and significantly predicted for using $\mathrm{AL}, \mathrm{ST}, \mathrm{SM}, \mathrm{NO}_{3}{ }^{-}$, and $\mathrm{NH}_{4}{ }^{+}$: total season GPP in the wet tracks $\left(\mathrm{R}^{2}=0.685\right)$ and early season GPP in both dry $\left(\mathrm{R}^{2}=0.788\right)$ and wet tracks $\left(\mathrm{R}^{2}=0.785\right)($ Table 23 and Table 24). None of the models predicting ER were significant at $\mathrm{p}<0.05$. 
Table 20: Multiple regression statistics for total season ER across wet and dry tracks. Bolded values indicate significance at $\mathrm{p}<$ 0.05 .

\begin{tabular}{|c|c|c|c|c|c|c|}
\hline & \multicolumn{2}{|c|}{ DRY TRACKS $\left(\mathbf{R}^{\mathbf{2}}=\mathbf{0 . 5 0 6}, \mathbf{p}=\mathbf{0 . 2 0 0}\right)$} & \multicolumn{2}{c|}{ WET TRACKS $\left(\mathbf{R}^{\mathbf{2}}=\mathbf{0 . 4 6 7}, \mathbf{p}=\mathbf{0 . 2 5 9}\right)$} \\
\hline Variable & $\mathbf{B}$ & $\mathbf{S E}$ & $\boldsymbol{B}$ & $\mathbf{B}$ & $\mathbf{S} \mathrm{E}_{\mathbf{B}}$ & $\boldsymbol{\beta}$ \\
\hline $\mathbf{A L}$ & 0.024 & 0.0246 & 0.343 & -0.050 & 0.059 & -0.798 \\
\hline $\mathbf{S T}$ & -0.026 & 0.393 & -0.047 & 0.362 & 0.368 & 0.956 \\
\hline $\mathbf{S M}$ & 0.017 & 0.014 & 0.310 & -0.002 & 0.015 & -0.080 \\
\hline $\mathbf{N O}_{\mathbf{3}}{ }^{-}$ & -0.009 & 0.124 & -0.025 & -0.264 & 0.266 & -0.552 \\
\hline $\mathbf{N H}_{4}{ }^{+}$ & -0.069 & 0.068 & -0.336 & -0.003 & 0.058 & -0.018 \\
\hline
\end{tabular}

Table 21: Multiple regression statistics for early season ER across wet and dry tracks. Bolded values indicate significance at $\mathrm{p}<$ 0.05 .

\begin{tabular}{|c|c|c|c|c|c|c|}
\hline & \multicolumn{2}{|c|}{ DRY TRACKS $\left(\mathbf{R}^{\mathbf{2}}=\mathbf{0 . 4 2 6}, \mathbf{p}=\mathbf{0 . 3 3 1}\right)$} & \multicolumn{2}{c|}{ WET TRACKS $\left(\mathbf{R}^{\mathbf{2}}=\mathbf{0 . 6 4 2}, \mathbf{p}=\mathbf{0 . 0 6 0}\right)$} \\
\hline Variable & $\mathbf{B}$ & $\mathbf{S E}$ & $\boldsymbol{B}$ & $\mathbf{B}$ & $\mathbf{S} \mathrm{E}_{\mathrm{B}}$ & $\boldsymbol{B}$ \\
\hline $\mathbf{A L}$ & 0.068 & 0.071 & 0.555 & -0.039 & 0.089 & -0.298 \\
\hline $\mathbf{S T}$ & 0.004 & 0.478 & 0.005 & 0.309 & 0.448 & 0.481 \\
\hline $\mathbf{S M}$ & 0.024 & 0.020 & 0.349 & 0.013 & 0.014 & 0.206 \\
\hline $\mathbf{N O}_{3}{ }^{-}$ & 0.025 & 0.400 & 0.017 & 0.128 & 0.238 & 0.117 \\
\hline $\mathbf{N H}_{4}{ }^{+}$ & 0.023 & 0.054 & 0.129 & $-\mathbf{0 . 1 1 3}$ & 0.040 & -0.662 \\
\hline
\end{tabular}

Table 22: Multiple regression statistics for late season ER across wet and dry tracks. Bolded values indicate significance at $\mathrm{p}<$ 0.05 .

\begin{tabular}{|c|c|c|c|c|c|c|}
\hline & \multicolumn{2}{|c|}{ DRY TRACKS $\left(\mathbf{R}^{\mathbf{2}}=\mathbf{0 . 2 2 4}, \mathbf{p}=\mathbf{0 . 7 5 6}\right)$} & \multicolumn{2}{c|}{ WET TRACKS $\left(\mathbf{R}^{\mathbf{2}}=\mathbf{0 . 5 1 5}, \mathbf{p}=\mathbf{0 . 1 8 8}\right)$} \\
\hline Variable & $\mathbf{B}$ & $\mathbf{S E}$ & $\boldsymbol{B}$ & $\mathbf{B}$ & $\mathbf{S E}$ & $\boldsymbol{B}$ \\
\hline $\mathbf{A L}$ & 0.004 & 0.030 & 0.109 & 0.057 & 0.039 & 1.171 \\
\hline $\mathbf{S T}$ & 0.030 & 0.293 & 0.099 & -0.662 & 0.314 & -1.740 \\
\hline $\mathbf{S M}$ & 0.004 & 0.009 & 0.146 & 0.007 & 0.009 & 0.276 \\
\hline $\mathbf{N O}_{\mathbf{3}}{ }^{-}$ & -0.019 & 0.047 & -0.170 & -0.017 & 0.087 & -0.073 \\
\hline $\mathbf{N H}_{4}{ }^{+}$ & -0.020 & 0.034 & -0.222 & -0.032 & 0.022 & -0.401 \\
\hline
\end{tabular}


Table 23: Multiple regression statistics for total season GPP across wet and dry tracks. Bolded values indicate significance at $\mathrm{p}<$ 0.05 .

\begin{tabular}{|c|c|c|c|c|c|c|}
\hline & \multicolumn{2}{|c|}{ DRY TRACKS $\left(\mathbf{R}^{\mathbf{2}}=\mathbf{0 . 6 2 3}, \mathbf{p}=\mathbf{0 . 0 7 4}\right)$} & \multicolumn{2}{c|}{ WET TRACKS $\left(\mathbf{R}^{2}=\mathbf{0 . 6 8 5 ,} \mathbf{p}<\mathbf{0 . 0 5}\right)$} \\
\hline Variable & $\mathbf{B}$ & $\mathbf{S E}$ & $\boldsymbol{B}$ & $\mathbf{B}$ & $\mathbf{S} \mathrm{E}_{\mathrm{B}}$ & $\boldsymbol{\beta}$ \\
\hline $\mathbf{A L}$ & -0.016 & 0.066 & -0.138 & -0.059 & 0.095 & -0.449 \\
\hline $\mathbf{S T}$ & -0.422 & 0.559 & -0.466 & -0.346 & 0.595 & -0.436 \\
\hline $\mathbf{S M}$ & -0.029 & 0.019 & -0.319 & -0.050 & 0.024 & -0.821 \\
\hline $\mathbf{N O}_{\mathbf{3}}{ }^{-}$ & 0.013 & 0.177 & 0.022 & -0.316 & 0.431 & -0.314 \\
\hline $\mathbf{N H}_{4}{ }^{+}$ & 0.042 & 0.097 & 0.125 & -0.180 & 0.094 & -0.482 \\
\hline
\end{tabular}

Table 24: Multiple regression statistics for early season GPP across wet and dry tracks. Bolded values indicate significance at $\mathrm{p}<$ 0.05 .

\begin{tabular}{|c|c|c|c|c|c|c|}
\hline \multirow[b]{2}{*}{ Variable } & \multicolumn{3}{|c|}{ DRY TRACKS $\left(R^{2}=0.788, p<0.05\right)$} & \multicolumn{3}{|c|}{ WET TRACKS $\left(R^{2}=0.785, p<0.05\right)$} \\
\hline & B & $\mathrm{SE}_{\mathrm{B}}$ & ß & B & $\mathrm{SE}_{\mathrm{B}}$ & ß \\
\hline$A L$ & -0.011 & 0.055 & -0.071 & 0.067 & 0.091 & 0.390 \\
\hline ST & -0.639 & 0.371 & -0.607 & -0.618 & 0.458 & -0.728 \\
\hline SM & -0.026 & 0.016 & -0.289 & -0.041 & 0.014 & -0.505 \\
\hline $\mathrm{NO}_{3}^{-}$ & 0.685 & 0.310 & 0.372 & 0.072 & 0.244 & 0.050 \\
\hline $\mathrm{NH}_{4}{ }^{+}$ & 0.032 & 0.042 & 0.142 & 0.076 & 0.041 & 0.336 \\
\hline
\end{tabular}

Table 25: Multiple regression statistics for late season GPP across wet and dry tracks. Bolded values indicate significance at $\mathrm{p}<$ 0.05 .

\begin{tabular}{|c|c|c|c|c|c|c|}
\hline & \multicolumn{2}{|c|}{ DRY TRACKS $\left(\mathbf{R}^{\mathbf{2}}=\mathbf{0 . 5 2 8}, \mathbf{p}=\mathbf{0 . 1 7 1}\right)$} & \multicolumn{2}{c|}{ WET TRACKS $\left(\mathbf{R}^{\mathbf{2}}=\mathbf{0 . 2 2 0}, \mathbf{p}=\mathbf{0 . 7 6 5}\right)$} \\
\hline Variable & $\mathbf{B}$ & $\mathbf{S E}$ & $\boldsymbol{B}$ & $\mathbf{B}$ & $\mathbf{S} \mathrm{E}_{\mathrm{B}}$ & $\boldsymbol{B}$ \\
\hline $\mathbf{A L}$ & 0.018 & 0.037 & 0.349 & -0.003 & 0.051 & -0.051 \\
\hline $\mathbf{S T}$ & -0.313 & 0.362 & -0.657 & -0.069 & 0.406 & -0.178 \\
\hline $\mathbf{S M}$ & 0.004 & 0.011 & 0.092 & -0.012 & 0.012 & -0.454 \\
\hline $\mathbf{N O}_{3}{ }^{-}$ & 0.073 & 0.058 & 0.416 & -0.088 & 0.112 & -0.379 \\
\hline $\mathbf{N H}_{\mathbf{4}}{ }^{+}$ & 0.027 & 0.042 & 0.186 & -0.024 & 0.028 & -0.301 \\
\hline
\end{tabular}

\subsection{Discussion}

\subsubsection{Carbon Flux and Environmental Trends}

As expected with the progression of the growing season, ST and SM values increased while AL deepened $(\mathrm{p}<0.05)$; this matched results of environmental trends from previous studies by Blaser and Luce in Cape Bounty wet sedge plant communities (Blaser, 2016; Luce, 
2016). The local spatial differences of wet and dry tracks for $C$ exchange and environmental variables were all significant; generally, wet tracks had warmer, wetter, and deeper values than dry tracks for ST, SM, and AL. Perhaps the most notable difference between SM in the wet and dry tracks is the consistent increase of SM across the season, while there is a decrease in SM in dry tracks between weeks 3 and 4 . This finding is an indication of the start of drying out and return to fall conditions. This difference between the moisture tracks indicative of the need to account for small-scale individuality of ecosystems when sampling in these environments.

Examinations of 2014 and 2015 C fluxes in the wet sedge determined that these wetland communities were a net C sink (Blaser, 2016; Luce, 2016). In examining 2016 C flux data, the wet sedge meadow was an early season source with ER dominant with a net efflux of C, turning into a late season sink as GPP took over with a net C influx. There was spatial variability between the moisture regimes of the wet sedge meadow, with GPP and ER rates higher in wet tracks than dry tracks, which Blaser found in the static chamber measurement sites as well in her 2014 field season (Blaser, 2016). Over the growing season, dry tracks averaged $1.513 \mu \mathrm{mol} / \mathrm{m}^{2} / \mathrm{s}$ in ER while mean ER in the wet tracks was $1.899 \mu \mathrm{mol} / \mathrm{m}^{2} / \mathrm{s}$. GPP calculated using NEE and ER measurements averaged $-1.34 \mu \mathrm{mol} / \mathrm{m}^{2} / \mathrm{s}$ and $-3.01 \mu \mathrm{mol} / \mathrm{m}^{2} / \mathrm{s}$ in the dry and wet tracks respectively. Overall, dry tracks yielded a $0.171 \mu \mathrm{mol} / \mathrm{m}^{2} / \mathrm{s}$ seasonal NEE average, while wet tracks had an NEE seasonal average of $-1.112 \mu \mathrm{mol} / \mathrm{m}^{2} / \mathrm{s}$. These numbers are indicative of the Muskox wet sedge meadow being an overall sink in the 2016 growing season. ER was the driving process for $\mathrm{C}$ fluxes in the early season dry tracks, switching over to GPP being the dominant force in the late season, as shown in Figure 23. However, GPP was the dominant factor throughout the entire season in the wet tracks, suggesting the importance of the role that SM has in photosynthetic processes in the High Arctic wetlands. 


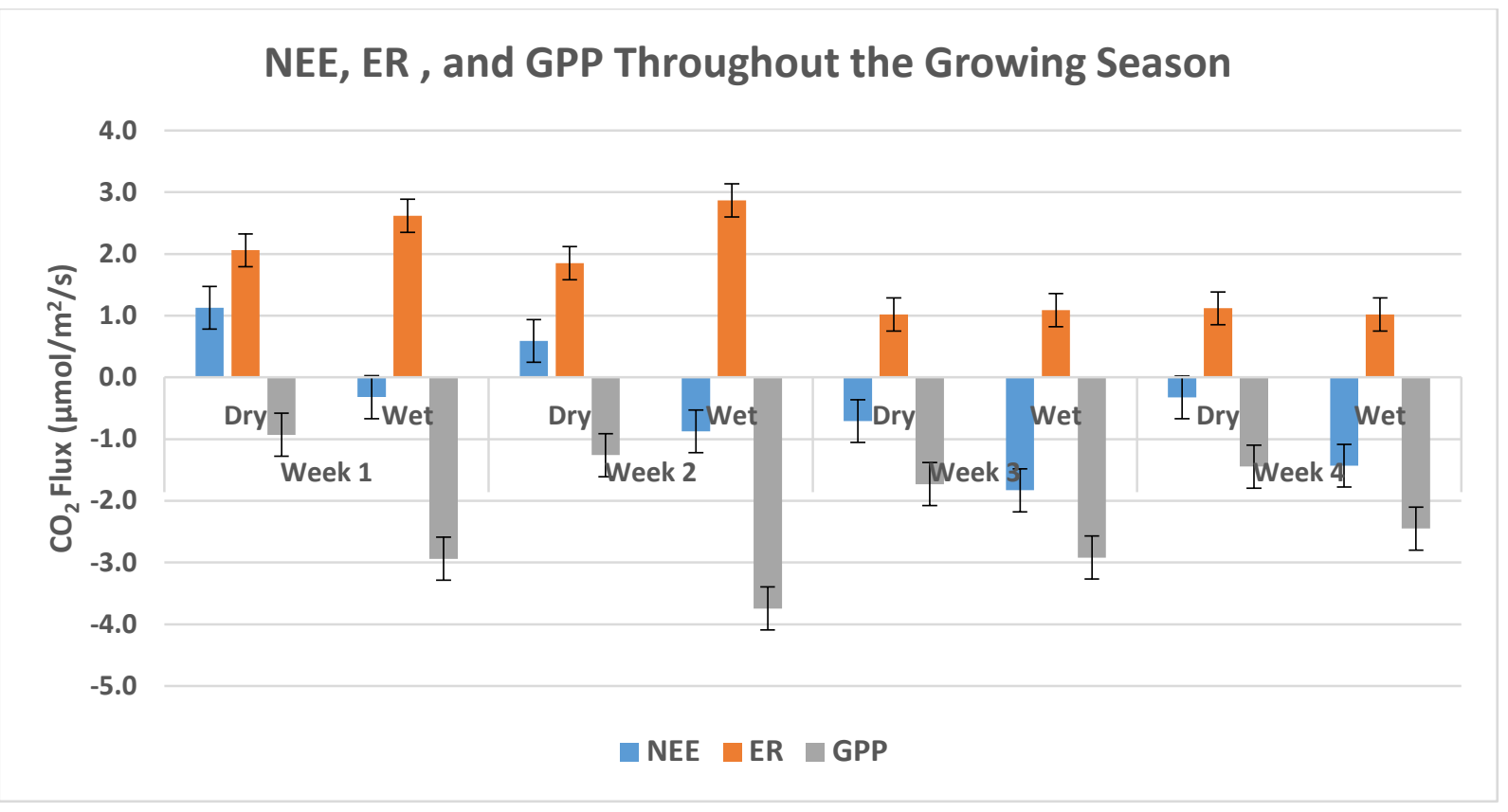

Figure 23: NEE, ER, and GPP change throughout the growing season across moisture tracks. Errors bars indicate \pm 1 standard error.

Across the entire season, increases in ST strongly corresponded with a deepening active layer. All other variables were also moderately related, except for SM and AL. Early season GPP and NEE had moderate negative relationships with AL, ST, and SM, while increased ST and SM and deeper AL corresponded to higher ER. ST increases across the growing season corresponded a net $\mathrm{C}$ release with decreasing NEE. In the early season, ST governed ER, but the transition into the late season saw a shift of ST influencing GPP. Slowing rates of ER in the latter parts of the season corresponded with deepening active layers and higher ST, evidence of increased decomposition with increased temperatures and lowering water table as shown in literature (Schuur et al., 2009; Guicharnaud et al., 2010). As the season progressed all C flux relationships with AL, ST, and SM became negative. Wet and dry tracks exhibited the similar temporal patterns. 


\subsubsection{Nitrogen Trends}

$\mathrm{NO}_{3}{ }^{-}$and $\mathrm{NH}_{4}{ }^{+}$were significantly different across wet and dry tracks, again reinforcing the need to explore spatial variability that can exist within a generally homogenous ecosystem. Across most tracks, it was determined that wet tracks generally had higher levels of $\mathrm{NH}_{4}{ }^{+}$than dry tracks, while $\mathrm{NO}_{3}^{-}$concentrations were similar across both moisture gradients. Raw concentrations of $\mathrm{NH}_{4}{ }^{+}$were always higher than concentrations of $\mathrm{NO}_{3}{ }^{-}$, which is to be expected because of their relative positions and roles in the $\mathrm{N}$ cycle and is in accordance with results from prior research (Nadelhoffer et al., 1991; Clein and Schimel, 1995; Gregory, 2011). Within the N cycle, there needs to be a surplus of $\mathrm{NH}_{4}{ }^{+}$before microbes can convert it to $\mathrm{NO}_{3}{ }^{-}$. Furthermore, in an anoxic environment like Arctic wetlands, aerobic processes like nitrification are generally limited or absent (Giblin et al., 1991; Nadelhoffer et al., 1991; Clein and Schimel, 1995; Stark, 2007; Beermann, 2016). On average, $\mathrm{N}$ adsorption was higher in the later season (July 13 to 27) than the earlier part of the season (June 30 to July 13). This is contrary to findings from 2008 wet sedge nutrient measurements where early season adsorption was higher than the late season (Gregory, 2011); however, the prior study only deployed one PRS measurement in each wet sedge site (for a total of 4), as such the spatial variability is not accounted for. Compared to the polar desert and mesic tundra N PRS probe measurements from 2008 (Gregory, 2011), the values measured in the wet sedge meadow are generally two to three times higher. The later season nutrient release and subsequent adsorption can be explained by a combination of early season snowmelt, increasing ST, and a deepening AL that allowed for water flow, promoting nutrient availability and the release of inorganic N. A lag period follows late in the early season after which organic $\mathrm{N}$ is then available for microbes to mineralize into $\mathrm{NH}_{4}{ }^{+}$and then $\mathrm{NO}_{3}{ }^{-}$. 
The bivariate regression statistics showed that AL and ST have strong positive relationships with $\mathrm{NO}_{3}{ }^{-}$and $\mathrm{NH}_{4}{ }^{+}$in the dry tracks. The seasonal $\mathrm{NO}_{3}{ }^{-}$and $\mathrm{NH}_{4}{ }^{+}$measurements could not be predicted significantly or strongly by a single variable. SM in the wet tracks was able to predict total and late season $\mathrm{NO}_{3}{ }^{-}$, which could be indicative of the role of water in nitrification processes. Multivariate regression analyses showed much stronger relationships between environmental variables and $\mathrm{NO}_{3}{ }^{-}$and $\mathrm{NH}_{4}{ }^{+}$concentrations in predicting GPP, which is indicative of the collaborative role that different environmental variables and soil available nitrogen play in promoting photosynthetic activity in wet sedge. While dry track models were not significant, the multivariate regression models favoured wet tracks, strengthening the argument of the importance of water in the processes in wet sedge meadows. In the wet tracks, the multivariate regression model suggests that total season GPP is most affected by ST and $\mathrm{NO}_{3}{ }^{-}$. Increases in $\mathrm{NO}_{3}{ }^{-}$would also have a greater effect on GPP decrease than $\mathrm{NH}_{4}{ }^{+}$would. Early season GPP is most affected by ST, and the soil available N impacts on GPP are similar.

The results from the regression models point to increases in ST having the greatest effect on mineralization and nitrification as compared to other environmental variables. Furthermore, in the dry tracks, the effect of ST was greater on nitrification than mineralization, while the opposite effect was seen in the wet tracks. This was consistent with results from tundra studies in Toolik Lake, Alaska which found that experimentally elevated temperatures triggered increased $\mathrm{N}$ mineralization, while light attenuation resulted in decreased $\mathrm{NH}_{4}{ }^{+}$levels (Shaver and Chapin., 1995). Subsequent experiments with temperature-driven greenhouse incubations found consistent increases in $\mathrm{N}$ mineralization (Shaver et al., 1998) at magnitudes of $40-200 \%$. At CBAWO, increases in SM promoted nitrification towards to the latter part of the season, as reflected in the higher late and total season $\mathrm{NO}_{3}{ }^{-}$. Nitrification was always secondary to 
mineralization and absent in some plots; this is a change from previous research where nitrification was often completely absent in wet sedge tundra (Giblin et al., 1991; Stark, 2007).

The southern portion of the meadow generally had higher $\mathrm{NO}_{3}{ }^{-}$and $\mathrm{NH}_{4}{ }^{+}$than the north and the west had higher $\mathrm{N}$ than the east; this can be attributed to the downslope of the topography promoting water flow, which is a transport method of nutrients down the meadow into lower lying areas (Woo and Young, 2006). This is consistent with research conducted by Stewart et al. (2014), where $\mathrm{N}$ mineralization rates, and consequently $\mathrm{NH}_{4}{ }^{+}$levels, were higher in lower lying areas. The increase of nutrient concentrations from east to west also follows the east to west retreat of the snowpack as the melt season progressed, which ties back to the importance of this perennial snowpack to the wetland in this environment (Woo and Young, 2014).

Contrary to original hypotheses that the SZ would have significantly higher inorganic N levels due to the direct accessibility to water from snowmelt, the $\mathrm{NO}_{3}{ }^{-}$and $\mathrm{NH}_{4}{ }^{+}$levels were not significantly different from the rest of the plot. Previous research in literature would have led us to believe that the $\mathrm{N}$ levels would be significantly lower than that of vegetated wetland areas due to premature wetland development and frequent surface erosion (Woo and Young, 2006). However, at Muskox, this could have been countered by a constant and significant water input from the snowpack, bringing in nutrients from upslope under the snowpack, which was the case discovered at Toolik Lake during spring melt by Bilbrough et al. (2000).

\subsubsection{Implications of Lack of Statistical Significance}

While the lack of statistical significance provides some answers towards the research questions posed, we cannot rule out the proven facts of ecological significance that environmental variables have on nutrient distribution. Statistical significance simply implies 90- 
95\% confidence that the measured variables were not simply due to chance, the lack of the statistical significance in this case does not necessarily mean that interactions do not exist between the environmental variables and soil available $\mathrm{N}$.

The lack of statistical significance may also be pointing to the fact that research questions underestimated the role of water in the wet sedge meadow. The nature of the dependence of the wet sedge meadow on water is such that ion exchange resin membranes may not have been the most robust methodology for measuring nutrient concentrations in this environment. Diffusion is the driving process in the ion exchange resin membrane adsorption (Western Ag, 2012); as such, with the nature of the wetland, the $\mathrm{N}$ adsorbed might not represent just nutrient adsorbed from soil, but potentially also nutrients adsorbed through water flow during snowmelt. The general down-slope movement of water is often not included in assessments of terrestrial dynamics in Arctic ecosystems (Shaver et al., 1991; Rastetter et al., 2004), but is an important transport mechanism because dissolved nutrients for soil uptake are often located near the surface due to permafrost (Shaver et al., 1991; Rastetter et al., 2004). Oftentimes, the movement of water downslope carries nutrients that are taken back up and cycled within the system's soils and vegetation through the nutrient-spiraling concept (Newbold et al., 1981; Rastetter et al., 2004). Analysis of soil samples will provide the answer to whether inorganic $\mathrm{N}$ in water in the meadow was adsorbed or whether measurements acquired through the ion exchange resin membrane technique was solely from soil adsorption. 


\section{Chapter 4: Summary}

Table 26 summarizes the measurements of $\mathrm{C}$ flux and environmental variables across the 2016 growing season:

Table 26: Summary of environmental variables and carbon flux trends across the growing season. Bolded cells indicate

\begin{tabular}{|c|c|c|c|c|}
\hline Variable & Time & Track & $\begin{array}{c}\text { Time } x \text { Moisture } \\
\text { track }\end{array}$ & Between Tracks \\
\hline Soil temperature & Increased & Wet $>$ dry & Insignificant & West $\neq$ east \\
\hline Soil moisture & Increased & Wet > dry & Significant & West $>$ east \\
\hline Active layer depth & Deepened & Wet > dry & Significant & West $>$ east \\
\hline $\begin{array}{l}\text { Ecosystem } \\
\text { respiration }\end{array}$ & $\begin{array}{l}\text { More negative } \\
\left(\mathrm{CO}_{2} \text { moving from }\right. \\
\text { atmosphere into } \\
\text { ecosystem) }\end{array}$ & Wet $>$ dry & Significant & West > east \\
\hline $\begin{array}{l}\text { Gross primary } \\
\text { production }\end{array}$ & $\begin{array}{l}\text { More negative } \\
\left(\mathrm{CO}_{2} \text { moving from }\right. \\
\text { atmosphere into } \\
\text { ecosystem) }\end{array}$ & Wet > dry & Significant & West > east \\
\hline $\begin{array}{l}\text { Net ecosystem } \\
\text { exchange }\end{array}$ & $\begin{array}{l}\text { More negative } \\
\left(\mathrm{CO}_{2} \text { moving from }\right. \\
\text { atmosphere into } \\
\text { ecosystem) }\end{array}$ & Wet > dry & Insignificant & West > east \\
\hline
\end{tabular}

Overall, both $\mathrm{NH}_{4}{ }^{+}$and $\mathrm{NO}_{3}{ }^{-}$were higher in the latter part of the growing season. Wet tracks generally had higher levels of $\mathrm{NH}_{4}{ }^{+}$than dry tracks, while $\mathrm{NO}_{3}{ }^{-}$concentrations were similar across both moisture gradients.

In revisiting the three research questions, the following conclusions can be drawn from this study:

1. How do active layer depth, soil moisture, and soil temperature affect nitrogen availability of a High Arctic wetland throughout the growing season?

The 2016 growing season saw increased ST and AL as the season progressed, resulting in higher $\mathrm{NH}_{4}{ }^{+}$and $\mathrm{NO}_{3}{ }^{-}$in the latter part of the season. Mineralization was the dominant portion of 
the N cycle over nitrification, which is consistent with previous Arctic N studies (Giblin et al., 1991; Stark, 2007). Nitrification was present throughout the growing season, as evidenced by the increasing presence of $\mathrm{NO}_{3}{ }^{-}$from the early season to late season. This is a change from previous studies where nitrification was generally absent from wet sedge meadows (Giblin et al., 1991; Stark, 2007). SM played a role in nitrification, but only in the latter half of the growing season.

With the sampling methodology that was employed, it was qualitatively demonstrated that water availability plays an important role in controlling the rates of the different environmental processes in this wet sedge meadow. The multivariate regression models had high goodness of fit for all wet tracks, implying that in the presence of higher soil water content, the quantitative relationship between soil $\mathrm{N}$ and environmental variables can be better predicted.

2. What relationships exist between carbon flux and the concentration of soil nitrogen in a High Arctic wetland throughout the growing season?

In the 2016 growing season, the wet sedge meadow was an early season source and late season sink; overall, the system was a net sink. GPP increases throughout the first three weeks of the growing season corresponded with increases in $\mathrm{NH}_{4}^{+}$, suggesting that $\mathrm{N}$ mineralization promotes and light promotes photosynthetic activity. Higher $\mathrm{N}$ adsorption in the latter part of the season corresponded with increased decomposition and C release in the atmosphere through respiration. Billings et al. (1984) found that that an increase in soil $\mathrm{N}$ significantly increased $\mathrm{CO}_{2}$ uptake; this relationship was also found in the wet sedge of CBAWO, as regression models suggested $\mathrm{NH}_{4}{ }^{+}$and $\mathrm{NO}_{3}{ }^{-}$were drivers of GPP.

3. What effect does proximity to the perennial snowpacks have on nitrogen availability of a High Arctic wetland as the growing season progresses? 
Proximity to the perennial snowpack had an indirect effect on $\mathrm{N}$ availability in the High Arctic wetland. Distance to the snowpack had no direct effect, but the snowpack's function as a water source was evident as the melt season progressed. The north to south and east to west downslopes of the wetland acted as mechanisms for water flow from snowmelt, which was a transport method of inorganic $\mathrm{N}$. As such, higher levels of $\mathrm{NH}_{4}{ }^{+}$and $\mathrm{NO}_{3}{ }^{-}$were found in lowerlying areas of the wetland. However, further work is needed to examine the role the nutrientspiraling concept may have played in $\mathrm{N}$ distribution of this downsloping wetland.

The overarching goal of this study was to examine the relationships between processes and physical characteristics that are present in High Arctic vegetation environments. The main findings of this study can be summarized into three main points:

1. Multiple environmental variables contribute to determining nitrogen concentrations in wet sedge meadows.

This confirms previous findings that no single variable directly explains nutrient availability, and soil $\mathrm{N}$ availability does not show a straightforward response to increases in temperature (Robinson, 2002). Multivariate regression models of environmental variables versus inorganic $\mathrm{N}$ performed significantly better than bivariate regression models of individual environmental measures against $\mathrm{NO}_{3}{ }^{-}$and $\mathrm{NH}_{4}{ }^{+}$. This is indicative of the important of multiple environmental variables in controlling the nutrient dynamics of a High Arctic wetland; similar results have been found in other High Arctic wet sedge studies (Shaver et al., 1998).

2. ST is a driver of $\mathrm{N}$ mineralization; in this study, increased ST coincided with higher $\mathrm{NH}_{4}{ }^{+}$ concentrations, promoting GPP.

These findings conform with previous investigations of drivers of Arctic $\mathrm{N}$ cycling that $\mathrm{N}$ mineralization is highly temperature dependent (Biederbeck and Campbell, 1973; Billings et al., 
1982; Nadelhoffer et al., 1991; Shaver et al., 1998; Rustad et al., 2001; Robinson, 2002), as the coupling of light and ST as light is a contributing factor to warmth. Increased $\mathrm{NH}_{4}{ }^{+}$to plants can be incorporated directly into their $\mathrm{NH}_{4}{ }^{+}$assimilation pathways, which will then allow them to harness $\mathrm{CO}_{2}$ and water to produce glucose, which is what gross primary production encompasses.

3. The inorganic nitrogen dynamics cannot be fully analyzed separately from the hydrological dynamics in High Arctic wetlands, particularly when there is an elevation gradient present.

The transport and distribution of inorganic $\mathrm{N}$ in this High Arctic wetland is highly dependent on the movement of water, as the wet sedge meadow is located on a downslope. Research has suggested that spatial vegetation patterns are highly dependent on underlying hydrology for the distribution of nutrients necessary for growth (Oberbauer et al., 1989; Rastetter et al., 2004), and as such the nutrient-spiraling models can be applied in these types of terrestrial environments. Using the knowledge gathered from this study and the hillslope-nutrient model developed by Rastetter et al. (2004), the movement of $\mathrm{N}$ downslope is a slow process, and downslope additions of plant-available $\mathrm{N}$ will result in increased photosynthetic rates (Oberbauer et al., 1989).

In summary, the spatial and temporal dynamics of a High Arctic wet sedge meadow exhibit variances within the ecosystem itself and investigations into the processes operating in the wetlands cannot simply be scaled up to the biome level (Rustad et al., 2001). This study found that seasonally, plant-available $\mathrm{N}$ was highest in the latter part of the growing season, with the largest concentrations of these inorganic $\mathrm{N}$ forms in lower-lying areas. Increases in GPP corresponded to increases in $\mathrm{NH}_{4}{ }^{+}$, demonstrating a link between light and photosynthetic 
activity with mineralization rates. Nitrification, although muted, was present in this environment in the 2016 growing season. Within the plot, significant differences were found between moisture tracks: the patterns were the same between the tracks, but the rates at which these patterns occurred were higher in wet tracks than dry tracks. This finding is indicative of the importance of water availability and moisture in driving the abiotic processes that occur in wet sedge meadows; the next step in this finding would be to determine the magnitude of the role water plays in controlling each of these variables. The underlying hydrology and movement of water was a large factor in determining the spatial pattern of $\mathrm{NH}_{4}{ }^{+}$and $\mathrm{NO}_{3}{ }^{-}$in the meadow. The melt of the north-adjacent perennial snowpack as the growing season progressed was the source of water that controlled C flux processes in the meadow. The downslope nature of the Muskox wet sedge meadow allowed for the formation of subsurface preferential flow pathways, transporting and cycling nutrients through the plot (Rastetter et al., 2004).

Historically, Arctic wetlands have been a strong C sink (Mikan et al., 2005), and with projected increases in air temperature affecting soil temperature, increases in soil respiration have the possibility of creating direct positive feedback loops (Post et al., 1982; Elberling et al., 2008; Chae et al., 2015; Christiansen, 2016; Euskirchen et al., 2016). In this study, the 2016 growing season saw the wetland plot shift from being an early season source to a late season sink. Wet tracks were generally sinks throughout the entire season, while the dry tracks saw the shift from source to sink, and again the magnitude of the flux processes in wet tracks were always greater than in the dry tracks. This conforms with research from Welker et al. (2004) where the differences between land cover $\mathrm{C}$ exchange responses had a strong dependence on hydrologic conditions and that wet sedge productivity is strongly linked to moisture (Reynolds and Tenhunen, 1996). The predicted future increases in air temperature will promote earlier and 
deeper thaw, allowing for microbial activity to be active and for movement and transfer of nutrients (Biederbeck and Campbell, 1973; Jonasson and Shaver, 1999; Shaver et al., 2000). The spatial and temporal dynamics of these nutrients will dictate future shifts in biotic and abiotic conditions.

\subsection{Future Work}

With the nature of the dynamic changes that are occurring in the High Arctic regions, continual work should be conducted in these environments as the ecosystems continue to evolve and change. The analysis of soil samples for early season, late season, and total season $\mathrm{NO}_{3}{ }^{-}$and $\mathrm{NH}_{4}{ }^{+}$will allow us to definitively determine how well the ion exchange resin membranes performed in this wet sedge environment. It will also help definitively decide whether $\mathrm{N}$ adsorbed was from the soil or subterraneous water flow. The knowledge gathered from the 2016 field season at Muskox points to the fact that the hydrological regime of the Muskox wet sedge meadow at Cape Bounty needs to be further sampled to understand the role that water plays in nutrient transport and distribution, particularly after spring melt.

Early spring and late fall measurements would be useful to add for a more robust and comprehensive study. Research through snow manipulation has shown that previous seasons' winter and spring climatic events play a role in summer and year-long growth (Robinson, 2002; Aerts et al., 2005; Edwards et al., 2006). Edwards et al. (2006) found peak nutrient availability to be early in the freeze-thaw period when soil temperatures were between -7 and $0^{\circ} \mathrm{C}$; as such, solely measuring growing season nutrient availability does not encompass the period when soilavailable nutrients may be at their peak. Furthermore, research has found microbial nutrient cycling to be present in Arctic snowpacks (Larose et al, 2013), and the release of these snowpack nutrients during melt can affect vegetation cover and productivity in the following growing 
season. Understanding the role that winter freeze and spring thaw has on Arctic ecosystems can help determine and project future shifts in plant cover and soil composition that are anticipated results of climate change (Aerts et al.,2005).

The distribution and role of $\mathrm{N}$-fixing cyanobacteria needs to be investigated in tandem with belowground inorganic $\mathrm{N}$ to get the full spectrum of High Arctic $\mathrm{N}$ cycling in wetlands. Quantifying the N fixation of Nostoc using stable isotope and chemical analysis would allow for the determination of the contribution of the cyanobacteria in $\mathrm{N}$ cycling in an environment like High Arctic wet sedge (Skrzypek et al., 2015). High $\mathrm{N}_{2} \mathrm{O}$ concentrations have been linked to higher $\mathrm{NH}_{4}{ }^{+}$levels belowground (Stewart et al., 2014), which could be explored through the analysis of trace gas samples in tandem with nutrient adsorption (trace gas samples were taken of the 2016 growing season in Muskox but not included in this manuscript).

Lastly, improving our understanding of $\mathrm{N}$ dynamics within a complex ecosystem like a High Arctic wetland, requires other contributing nutrients with $\mathrm{C}$ and $\mathrm{P}$ to be examined for their roles in promoting or limiting different processes within the $\mathrm{N}$ cycle. P has long been known to be a limiting nutrient in Arctic plant growth (Nadelhoffer et al., 1992; Shaver and Chapin, 1995; Shaver et al., 1998; Shaver et al., 2000; Chapin et al., 2002; Stark, 2007), and in some experiments, has been shown to be the dominant limiting nutrient in Arctic wet sedge (Shaver et al., 1998; Gough and Hobbie, 2003). The balance between N and P in these environments can have effects on the rates and shifts in microbial activity (Shaver et al., 1998), and future nutrient cycling studies need to incorporate both limiting nutrients in examining Arctic wetlands. The importance of the role of C in High Arctic N cycling has also been presented in literature (Stark, 2007). C to $\mathrm{N}$ ratios have been shown in literature to be an important proxy of mineralization rates (Janssen, 1996), and the ratio of mineralized C to mineralized $\mathrm{N}$ is overall affected by soil 
temperature (Robinson, 2002). Regardless of the environment and temperature, the important interactions between $\mathrm{C}$ and $\mathrm{N}$ need to be considered in future studies of $\mathrm{N}$ cycling. 


\section{Appendices}

\section{Appendix A - Sampling locations}

Table 27: UTM coordinates (WGS 84, Zone 12N) of all sampling sites in the Muskox wet sedge meadow at the Cape Bounty Arctic Watershed Observatory

\begin{tabular}{|l|l|r|r|}
\hline \multicolumn{1}{|c|}{ Site Name } & \multicolumn{1}{|c|}{ Track } & Easting & Northing \\
\hline NE-A6 & Dry & 541878.0 & 8314208.8 \\
\hline NE-A8 & Dry & 541908.0 & 8314213.5 \\
\hline NE-B6 & Dry & 541877.1 & 8314199.4 \\
\hline NE-B8 & Dry & 541907.5 & 8314196.9 \\
\hline NE-C6 & Dry & 541875.8 & 8314186.5 \\
\hline NE-C8 & Dry & 541906.7 & 8314180.1 \\
\hline NE-D6 & Dry & 541874.6 & 8314168.8 \\
\hline NE-D8 & Dry & 541903.7 & 8314165.6 \\
\hline NW-A2 & Dry & 541793.1 & 8314217.0 \\
\hline NW-A4 & Dry & 541812.6 & 8314208.5 \\
\hline NW-B2 & Dry & 541787.6 & 8314198.6 \\
\hline NW-B4 & Dry & 541798.3 & 8314189.0 \\
\hline NW-C2 & Dry & 541779.5 & 8314183.2 \\
\hline NW-C4 & Dry & 541791.8 & 8314175.4 \\
\hline NW-D2 & Dry & 541770.1 & 8314169.9 \\
\hline NW-D4 & Dry & 541783.7 & 8314161.9 \\
\hline SE-E6 & Dry & 541873.4 & 8314157.5 \\
\hline SE-E8 & Dry & 541900.6 & 8314149.9 \\
\hline SE-F6 & Dry & 541869.2 & 8314146.1 \\
\hline SE-F8 & Dry & 541897.6 & 8314137.4 \\
\hline SE-G6 & Dry & 541865.4 & 8314131.1 \\
\hline SE-G8 & Dry & 541893.3 & 8314124.7 \\
\hline SE-H6 & Dry & 541859.2 & 8314113.4 \\
\hline SE-H8 & Dry & 541889.5 & 8314099.2 \\
\hline SW-E2 & Dry & 541765.0 & 8314157.3 \\
\hline SW-E4 & Dry & 541778.8 & 8314146.5 \\
\hline SW-F2 & Dry & 541760.8 & 8314144.5 \\
\hline SW-F4 & Dry & 541774.4 & 8314135.5 \\
\hline SW-G2 & Dry & 541759.1 & 8314136.0 \\
\hline SW-G4 & Dry & 541772.4 & 8314127.1 \\
\hline SW-H2 & Dry & 541756.1 & 8314124.6 \\
\hline SW-H4 & Dry & 8314118.8 \\
\hline SZ1 & & 8314276.9 \\
\hline SZ10 & & 8314278.7 \\
\hline SZ11 & & & \\
\hline & & 5414280.0 \\
\hline
\end{tabular}




\begin{tabular}{|c|c|c|c|}
\hline SZ12 & SZ & 541897.6 & 8314278.5 \\
\hline $\mathrm{SZ2}$ & SZ & 541792.6 & 8314280.1 \\
\hline SZ3 & $S Z$ & 541798.6 & 8314281.6 \\
\hline SZ4 & $S Z$ & 541810.6 & 8314281.1 \\
\hline SZ5 & $\mathrm{SZ}$ & 541817.0 & 8314278.7 \\
\hline SZ6 & $S Z$ & 541826.4 & 8314277.2 \\
\hline SZ7 & SZ & 541845.2 & 8314279.4 \\
\hline SZ8 & $S Z$ & 541852.1 & 8314279.4 \\
\hline SZ9 & SZ & 541857.1 & 8314278.6 \\
\hline NE-A5 & Wet & 541870.9 & 8314210.8 \\
\hline NE-A7 & Wet & 541905.0 & 8314213.7 \\
\hline NE-B5 & Wet & 541868.3 & 8314197.5 \\
\hline NE-B7 & Wet & 541902.2 & 8314198.0 \\
\hline $\mathrm{NE}-\mathrm{C} 5$ & Wet & 541867.5 & 8314188.6 \\
\hline $\mathrm{NE}-\mathrm{C} 7$ & Wet & 541899.0 & 8314183.6 \\
\hline NE-D5 & Wet & 541868.4 & 8314170.3 \\
\hline NE-D7 & Wet & 541896.3 & 8314168.8 \\
\hline NW-A1 & Wet & 541787.3 & 8314219.3 \\
\hline NW-A3 & Wet & 541807.4 & 8314216.8 \\
\hline NW-B1 & Wet & 541781.5 & 8314201.3 \\
\hline NW-B3 & Wet & 541796.5 & 8314196.7 \\
\hline NW-C1 & Wet & 541775.9 & 8314186.7 \\
\hline NW-C3 & Wet & 541784.8 & 8314181.3 \\
\hline NW-D1 & Wet & 541767.5 & 8314173.2 \\
\hline NW-D3 & Wet & 541778.4 & 8314167.4 \\
\hline SE-E5 & Wet & 541865.0 & 8314158.1 \\
\hline SE-E7 & Wet & 541894.6 & 8314151.4 \\
\hline SE-F5 & Wet & 541864.5 & 8314144.0 \\
\hline SE-F7 & Wet & 541890.2 & 8314142.3 \\
\hline SE-G5 & Wet & 541859.5 & 8314130.3 \\
\hline SE-G7 & Wet & 541888.0 & 8314128.7 \\
\hline SE-H5 & Wet & 541853.9 & 8314114.6 \\
\hline SE-H7 & Wet & 541878.8 & 8314103.2 \\
\hline SW-E1 & Wet & 541759.9 & 8314156.1 \\
\hline SW-E3 & Wet & 541772.1 & 8314152.8 \\
\hline SW-F1 & Wet & 541755.1 & 8314145.6 \\
\hline SW-F3 & Wet & 541769.0 & 8314138.3 \\
\hline SW-G1 & Wet & 541753.7 & 8314136.4 \\
\hline SW-G3 & Wet & 541766.8 & 8314131.9 \\
\hline $\mathrm{SW}-\mathrm{H} 1$ & Wet & 541749.2 & 8314124.3 \\
\hline SW-H3 & Wet & 541764.2 & 8314121.3 \\
\hline
\end{tabular}




\section{Appendix B - Soil nitrogen data}

Table 28: Resin A (June 30 to July 27) $\mathrm{NO}_{3}{ }^{-}$(orange) and $\mathrm{NH}_{4}{ }^{+}$(green) adsorbed using ion exchange membranes, expressed as $\mu \mathrm{g}$ of nutrient adsorbed per 10 cm² over a fourweek period

\begin{tabular}{|c|c|c|c|c|c|c|c|c|c|c|c|c|}
\hline \multirow{3}{*}{$\begin{array}{c}\text { Saturation } \\
\text { Zone }\end{array}$} & SZ1 & SZ2 & SZ3 & SZ4 & SZ5 & SZ6 & SZ7 & SZ8 & SZ9 & SZ10 & SZ11 & SZ12 \\
\hline & 0.593 & 1.694 & 1.566 & 2.193 & 2.185 & 2.602 & 2.341 & 1.850 & 2.989 & 2.318 & 4.189 & 5.979 \\
\hline & 4.803 & 7.857 & 5.191 & 6.036 & 7.069 & 6.561 & 4.620 & 7.034 & 7.525 & 6.690 & 12.176 & 7.141 \\
\hline & \multirow{24}{*}{ 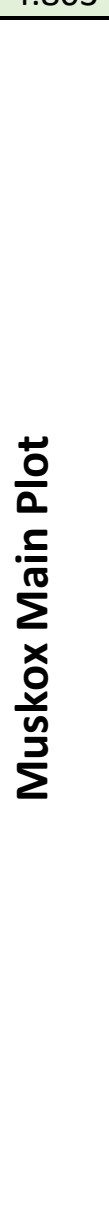 } & & NW-A1 & NW-A2 & NW-A3 & NW-A4 & & NE-A5 & NE-A6 & NE-A7 & NE-A8 & \\
\hline & & & 7.009 & 2.664 & 2.131 & 2.409 & & 1.936 & 3.231 & 2.193 & 2.315 & \\
\hline & & & 14.441 & 9.942 & 8.887 & 8.350 & & 8.660 & 5.270 & 7.014 & 7.101 & \\
\hline & & & NW-B1 & NW-B2 & NW-B3 & NW-B4 & & NE-B5 & NE-B6 & NE-B7 & NE-B8 & \\
\hline & & & 2.880 & 3.060 & 1.608 & 3.091 & & 1.022 & 3.044 & 1.920 & 1.904 & \\
\hline & & & 16.770 & 9.766 & 13.344 & 9.669 & & 11.402 & 6.214 & 5.358 & 7.597 & \\
\hline & & & NW-C1 & NW-C2 & NW-C3 & NW-C4 & & NE-C5 & NE-C6 & NE-C7 & NE-C8 & \\
\hline & & & 4.207 & 2.942 & 1.881 & 2.883 & & 1.233 & 2.638 & 1.124 & 2.396 & \\
\hline & & & 11.532 & 9.679 & 11.936 & 2.956 & & 8.475 & 6.019 & 8.175 & 8.690 & \\
\hline & & & NW-D1 & NW-D2 & NW-D3 & NW-D4 & & NE-D5 & NE-D6 & NE-D7 & NE-D8 & \\
\hline & & & 2.849 & 4.797 & 1.748 & 3.049 & & 2.451 & 1.662 & 1.259 & 2.646 & \\
\hline & & & 12.709 & 12.951 & 5.692 & 9.369 & & 9.269 & 9.541 & 6.737 & 10.353 & \\
\hline & & & SW-E1 & SW-E2 & SW-E3 & SW-E4 & & SE-E5 & SE-E6 & SE-E7 & SE-E8 & \\
\hline & & & 2.201 & 5.128 & 1.865 & 2.084 & & 1.366 & 1.249 & 1.218 & 2.708 & \\
\hline & & & 12.877 & 15.003 & 5.062 & 8.022 & & 11.780 & 6.844 & 7.618 & 9.399 & \\
\hline & & & SW-F1 & SW-F2 & SW-F3 & SW-F4 & & SE-F5 & SE-F6 & SE-F7 & SE-F8 & \\
\hline & & & 2.362 & 6.439 & 0.911 & 2.872 & & 1.584 & 2.810 & 1.420 & 1.631 & \\
\hline & & & 9.070 & 10.197 & 6.957 & 7.587 & & 7.645 & 10.239 & 6.378 & 8.685 & \\
\hline & & & SW-G1 & SW-G2 & SW-G3 & SW-G4 & & SE-G5 & SE-G6 & SE-G7 & SE-G8 & \\
\hline & & & 3.356 & 5.370 & 1.709 & 1.967 & & 2.102 & 1.975 & 1.145 & 2.380 & \\
\hline & & & 11.203 & 13.410 & 7.244 & 11.569 & & 6.833 & 11.275 & 9.116 & 8.153 & \\
\hline & & & SW-H1 & SW-H2 & SW-H3 & SW-H4 & & SE-H5 & SE-H6 & SE-H7 & SE-H8 & \\
\hline & & & 2.849 & 5.370 & 1.264 & 8.601 & & 1.530 & 2.911 & 2.295 & 4.589 & \\
\hline & & & 13.280 & 16.369 & 9.256 & 10.152 & & 8.980 & 11.696 & 4.923 & 10.218 & \\
\hline
\end{tabular}


Table 29: Resin $\mathrm{B} 1$ (June 30 to July 13) $\mathrm{NO}_{3}^{-}$(orange) and $\mathrm{NH}_{4}^{+}$(green) adsorbed using ion exchange membranes, expressed as $\mu$ g of nutrient adsorbed per 10 cm² over a twoweek period

\begin{tabular}{|c|c|c|c|c|c|c|c|c|c|c|c|c|}
\hline \multirow{3}{*}{$\begin{array}{c}\text { Saturation } \\
\text { Zone }\end{array}$} & SZ1 & SZ2 & SZ3 & SZ4 & SZ5 & SZ6 & SZ7 & SZ8 & SZ9 & SZ10 & SZ11 & SZ12 \\
\hline & 1.936 & 0.856 & 1.845 & 1.384 & 2.856 & 1.880 & 1.704 & 1.732 & 2.776 & 1.656 & 4.136 & 4.256 \\
\hline & 12.738 & 12.464 & 13.362 & 11.957 & 11.020 & 10.349 & 5.136 & 7.422 & 9.912 & 8.055 & 7.376 & 7.750 \\
\hline & \multirow{24}{*}{ 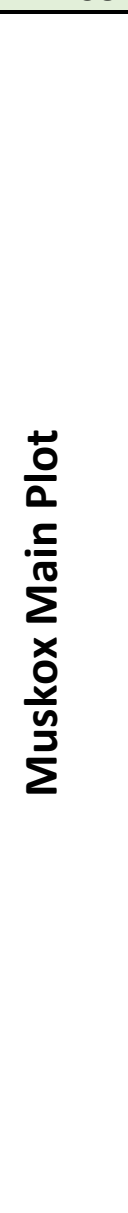 } & & NW-A1 & NW-A2 & NW-A3 & NW-A4 & & NE-A5 & NE-A6 & NE-A7 & NE-A8 & \\
\hline & & & 5.909 & 1.192 & 3.054 & 2.443 & & 1.352 & 1.692 & 3.000 & 2.376 & \\
\hline & & & 2.824 & 10.004 & 8.788 & 7.135 & & 8.351 & 6.080 & 9.361 & 10.664 & \\
\hline & & & NW-B1 & NW-B2 & NW-B3 & NW-B4 & & NE-B5 & NE-B6 & NE-B7 & NE-B8 & \\
\hline & & & 3.974 & 1.544 & 1.605 & 2.496 & & 2.384 & 1.951 & 2.544 & 2.600 & \\
\hline & & & 9.190 & 12.648 & 13.740 & 9.171 & & 16.234 & 7.727 & 12.698 & 6.419 & \\
\hline & & & NW-C1 & NW-C2 & NW-C3 & NW-C4 & & NE-C5 & NE-C6 & NE-C7 & NE-C8 & \\
\hline & & & 3.899 & 1.504 & 2.376 & 2.928 & & 2.096 & 2.357 & 2.544 & 2.176 & \\
\hline & & & 20.012 & 6.616 & 13.467 & 8.876 & & 8.851 & 11.465 & 13.179 & 5.762 & \\
\hline & & & NW-D1 & NW-D2 & NW-D3 & NW-D4 & & NE-D5 & NE-D6 & NE-D7 & NE-D8 & \\
\hline & & & 3.096 & 2.688 & 1.004 & 1.656 & & 1.728 & 2.364 & 1.952 & 2.360 & \\
\hline & & & 19.297 & 17.053 & 14.433 & 19.449 & & 17.655 & 12.066 & 14.638 & 8.310 & \\
\hline & & & SW-E1 & SW-E2 & SW-E3 & SW-E4 & & SE-E5 & SE-E6 & SE-E7 & SE-E8 & \\
\hline & & & 2.864 & 1.792 & 2.001 & 1.631 & & 1.400 & 2.690 & 2.824 & 2.456 & \\
\hline & & & 23.547 & 12.322 & 14.589 & 7.994 & & 17.140 & 16.999 & 5.400 & 17.891 & \\
\hline & & & SW-F1 & SW-F2 & SW-F3 & SW-F4 & & SE-F5 & SE-F6 & SE-F7 & SE-F8 & \\
\hline & & & 2.096 & 2.424 & 1.122 & 2.600 & & 2.488 & 3.686 & 2.136 & 2.640 & \\
\hline & & & 7.471 & 10.959 & 10.601 & 8.437 & & 21.510 & 8.187 & 12.270 & 16.350 & \\
\hline & & & SW-G1 & SW-G2 & SW-G3 & SW-G4 & & SE-G5 & SE-G6 & SE-G7 & SE-G8 & \\
\hline & & & 1.048 & 2.248 & 1.491 & 0.000 & & 2.112 & 2.014 & 2.296 & 2.352 & \\
\hline & & & 9.269 & 16.241 & 15.721 & 18.618 & & 12.043 & 13.589 & 7.583 & 5.268 & \\
\hline & & & SW-H1 & SW-H2 & SW-H3 & SW-H4 & & SE-H5 & SE-H6 & SE-H7 & SE-H8 & \\
\hline & & & 1.264 & 2.560 & 1.941 & 5.072 & & 2.017 & 2.840 & 2.704 & 3.184 & \\
\hline & & & 10.672 & 10.751 & 10.542 & 20.954 & & 14.915 & 5.255 & 11.362 & 17.108 & \\
\hline
\end{tabular}


Table 30: Resin B2 (July 13 to July 27) $\mathrm{NO}_{3}{ }^{-}$(orange) and $\mathrm{NH}_{4}{ }^{+}$(green) adsorbed using ion exchange membranes, expressed as $\mu \mathrm{g}$ of nutrient adsorbed per 10 cm ${ }^{2}$ over a twoweek period

\begin{tabular}{|c|c|c|c|c|c|c|c|c|c|c|c|c|}
\hline \multirow{3}{*}{$\begin{array}{c}\text { Saturation } \\
\text { Zone }\end{array}$} & SZ1 & SZ2 & SZ3 & SZ4 & SZ5 & SZ6 & SZ7 & SZ8 & SZ9 & SZ10 & SZ11 & SZ12 \\
\hline & 1.038 & 1.577 & 1.647 & 1.155 & 1.660 & 2.139 & 1.701 & 1.631 & 4.222 & 1.803 & 3.848 & 7.313 \\
\hline & 8.878 & 14.189 & 12.572 & 16.140 & 10.573 & 14.080 & 11.044 & 12.433 & 13.089 & 11.582 & 14.533 & 14.018 \\
\hline & \multirow{24}{*}{ 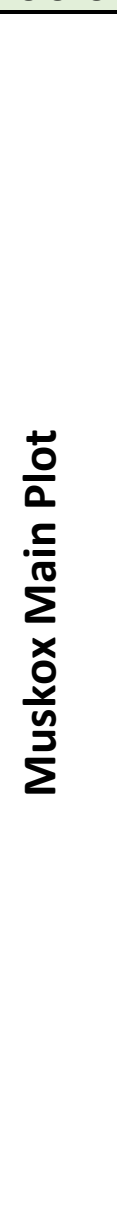 } & & NW-A1 & NW-A2 & NW-A3 & NW-A4 & & NE-A5 & NE-A6 & NE-A7 & NE-A8 & \\
\hline & & & 20.168 & 2.412 & 1.545 & 1.545 & & 1.858 & 2.857 & 2.100 & 1.561 & \\
\hline & & & 18.747 & 8.414 & 10.622 & 8.804 & & 11.237 & 4.561 & 13.053 & 10.172 & \\
\hline & & & NW-B1 & NW-B2 & NW-B3 & NW-B4 & & NE-B5 & NE-B6 & NE-B7 & NE-B8 & \\
\hline & & & 5.440 & 2.935 & 2.295 & 3.112 & & 1.904 & 2.412 & 2.599 & 1.597 & \\
\hline & & & 10.388 & 12.886 & 13.487 & 8.999 & & 15.379 & 6.572 & 9.019 & 12.087 & \\
\hline & & & NW-C1 & NW-C2 & NW-C3 & NW-C4 & & NE-C5 & NE-C6 & NE-C7 & NE-C8 & \\
\hline & & & 7.001 & 3.200 & 2.237 & 2.955 & & 2.539 & 11.465 & 1.233 & 1.842 & \\
\hline & & & 12.121 & 8.695 & 13.357 & 10.224 & & 10.928 & 6.934 & 15.227 & 14.371 & \\
\hline & & & NW-D1 & NW-D2 & NW-D3 & NW-D4 & & NE-D5 & NE-D6 & NE-D7 & NE-D8 & \\
\hline & & & 3.575 & 4.898 & 2.076 & 3.278 & & 2.602 & 2.217 & 1.975 & 1.514 & \\
\hline & & & 10.779 & 15.391 & 17.725 & 9.140 & & 11.951 & 10.112 & 17.417 & 14.293 & \\
\hline & & & SW-E1 & SW-E2 & SW-E3 & SW-E4 & & SE-E5 & SE-E6 & SE-E7 & SE-E8 & \\
\hline & & & 2.037 & 3.236 & 3.007 & 2.857 & & 1.727 & 3.013 & 2.165 & 2.712 & \\
\hline & & & 15.173 & 7.711 & 14.642 & 10.287 & & 25.783 & 11.091 & 9.806 & 14.423 & \\
\hline & & & SW-F1 & SW-F2 & SW-F3 & SW-F4 & & SE-F5 & SE-F6 & SE-F7 & SE-F8 & \\
\hline & & & 3.707 & 4.129 & 1.920 & 4.007 & & 1.826 & 3.403 & 1.675 & 2.006 & \\
\hline & & & 10.459 & 9.600 & 11.645 & 4.974 & & 29.921 & 12.027 & 12.860 & 9.495 & \\
\hline & & & SW-G1 & SW-G2 & SW-G3 & SW-G4 & & SE-G5 & SE-G6 & SE-G7 & SE-G8 & \\
\hline & & & 3.602 & 4.503 & 1.264 & 1.842 & & 2.253 & 2.490 & 2.205 & 2.420 & \\
\hline & & & 10.439 & 10.919 & 17.522 & 8.429 & & 14.981 & 12.979 & 10.356 & 10.529 & \\
\hline & & & SW-H1 & SW-H2 & SW-H3 & SW-H4 & & SE-H5 & SE-H6 & SE-H7 & SE-H8 & \\
\hline & & & 3.286 & 11.153 & 2.576 & 5.510 & & 1.462 & 2.685 & 1.436 & 3.052 & \\
\hline & & & 11.192 & 10.170 & 9.616 & 11.145 & & 15.813 & 10.273 & 11.780 & 13.775 & \\
\hline
\end{tabular}




\section{Appendix C - Carbon dioxide exchange data}

Table 31: Net ecosystem exchange (NEE) throughout the growing season expressed as $\mu \mathrm{mol} / \mathrm{m}^{2} / \mathrm{s}$

\begin{tabular}{|c|c|c|c|c|c|c|c|c|}
\hline Date & NW-A1 & & NW-A3 & & NE-A5 & & NE-A7 & \\
\hline July 5 & 1.089 & & 0.623 & & -0.303 & & 0.422 & \\
\hline July 10 & 0.831 & & -1.252 & & -1.348 & & -0.653 & \\
\hline July 17 & -1.000 & & -1.625 & & -2.120 & & -1.575 & \\
\hline July 24 & -0.898 & & -2.283 & & -2.041 & & -0.955 & \\
\hline & & NW-B2 & & NW-B4 & & NE-B6 & & NE-B8 \\
\hline July 5 & & 1.033 & & 0.578 & & 1.332 & & 0.763 \\
\hline July 10 & & 1.333 & & 0.154 & & 0.602 & & 0.539 \\
\hline July 17 & & -0.516 & & -0.853 & & -0.319 & & -1.117 \\
\hline July 24 & & -0.518 & & -0.765 & & -0.931 & & -0.811 \\
\hline & NW-C1 & & NW-C3 & & NE-C5 & & NE-C7 & \\
\hline July 5 & -0.554 & & -0.716 & & -0.819 & & -0.741 & \\
\hline July 10 & -0.476 & & -0.938 & & -2.322 & & -0.254 & \\
\hline July 17 & -1.654 & & -2.176 & & -2.301 & & -2.831 & \\
\hline July 24 & -0.681 & & -1.968 & & -2.161 & & -0.765 & \\
\hline & & NW-D2 & & NW-D4 & & NE-D6 & & NE-D8 \\
\hline July 5 & & 0.814 & & 1.881 & & 0.692 & & 0.774 \\
\hline July 10 & & 0.255 & & 0.702 & & -1.060 & & 0.287 \\
\hline July 17 & & -0.412 & & -1.113 & & -0.361 & & -1.468 \\
\hline July 24 & & -0.278 & & -0.833 & & -0.478 & & -0.817 \\
\hline & SW-E1 & & SW-E3 & & SE-E5 & & SE-E7 & \\
\hline July 5 & 0.542 & & 1.074 & & -1.375 & & -0.283 & \\
\hline July 10 & 0.378 & & -0.922 & & -2.523 & & 0.778 & \\
\hline July 17 & -0.470 & & -1.018 & & -2.986 & & -2.274 & \\
\hline July 24 & -0.716 & & -0.970 & & -3.645 & & -1.205 & \\
\hline & & SW-F2 & & SW-F4 & & SE-F6 & & SE-F8 \\
\hline July 5 & & 0.888 & & 0.373 & & 2.116 & & 0.416 \\
\hline July 10 & & 0.744 & & -0.583 & & 1.968 & & 0.348 \\
\hline July 17 & & -0.336 & & -1.882 & & 0.621 & & -1.147 \\
\hline July 24 & & 0.198 & & -0.502 & & 2.162 & & -0.963 \\
\hline & SW-G1 & & SW-G3 & & SE-G5 & & SE-G7 & \\
\hline July 5 & 0.425 & & -1.364 & & -1.094 & & -0.645 & \\
\hline July 10 & 0.522 & & -2.143 & & -1.582 & & -0.414 & \\
\hline July 17 & -1.455 & & -2.436 & & -1.246 & & -1.219 & \\
\hline July 24 & -0.510 & & -1.510 & & -1.189 & & -0.770 & \\
\hline & & SW-H2 & & SW-H4 & & SE-H6 & & SE-H8 \\
\hline July 5 & & 0.121 & & 0.713 & & 1.396 & & 3.714 \\
\hline July 10 & & 0.733 & & 0.207 & & 0.780 & & 2.043 \\
\hline July 17 & & 0.674 & & -0.270 & & -1.349 & & -1.062 \\
\hline July 24 & & 0.520 & & -0.275 & & -0.475 & & -0.376 \\
\hline
\end{tabular}


Table 32: Mean NEE measurements standard deviation across the dry tracks over the growing season

\begin{tabular}{|l|c|c|c|c|c|c|c|c|}
\hline \multirow{2}{*}{} & \multicolumn{2}{|c|}{ Dry 2 } & \multicolumn{2}{c|}{ Dry 4 } & \multicolumn{2}{c|}{ Dry 6 } & \multicolumn{2}{c|}{ Dry 8 } \\
\cline { 2 - 9 } & Mean & SD & Mean & SD & Mean & SD & Mean & SD \\
\hline Week 1 & 0.714 & 0.405 & 0.944 & 0.818 & 1.384 & 0.582 & 1.417 & 1.540 \\
\hline Week 2 & 0.766 & 0.441 & 0.091 & 0.645 & 0.573 & 1.246 & 0.804 & 0.833 \\
\hline Week 3 & -0.147 & 0.553 & -1.283 & 0.535 & -0.352 & 0.804 & -1.198 & 0.183 \\
\hline Week 4 & -0.019 & 0.467 & -0.700 & 0.175 & 0.070 & 1.411 & -0.742 & 0.254 \\
\hline
\end{tabular}

Table 33: Mean NEE measurements standard deviation across the wet tracks over the growing season

\begin{tabular}{|l|c|c|c|c|c|c|c|c|}
\hline \multirow{2}{*}{} & \multicolumn{2}{|c|}{ Wet 1 } & \multicolumn{2}{c|}{ Wet 3 } & \multicolumn{2}{c|}{ Wet 5 } & \multicolumn{2}{c|}{ Wet 7 } \\
\cline { 2 - 9 } & Mean & SD & Mean & SD & Mean & SD & Mean & SD \\
\hline Week 1 & 0.138 & 0.602 & -0.096 & 1.137 & -0.898 & 0.457 & -0.312 & 0.528 \\
\hline Week 2 & 0.141 & 0.539 & -1.313 & 0.573 & -1.944 & 0.567 & -0.136 & 0.631 \\
\hline Week 3 & -1.193 & 0.634 & -1.814 & 0.629 & -2.163 & 0.716 & -1.975 & 0.720 \\
\hline Week 4 & -0.636 & 0.110 & -1.683 & 0.571 & -2.259 & 1.020 & -0.924 & 0.207 \\
\hline
\end{tabular}


Table 34: Ecosystem respiration (ER) throughout the growing season expressed as $\mu \mathrm{mol} / \mathrm{m}^{2} / \mathrm{s}$

\begin{tabular}{|c|c|c|c|c|c|c|c|c|}
\hline Date & NW-A1 & & NW-A3 & & NE-A5 & & NE-A7 & \\
\hline July 5 & 1.676 & & 3.043 & & 3.140 & & 3.476 & \\
\hline July 10 & 1.221 & & 3.258 & & 3.736 & & 3.309 & \\
\hline July 17 & 1.741 & & 1.485 & & 0.738 & & 1.086 & \\
\hline July 24 & 1.316 & & 1.786 & & 0.752 & & 0.669 & \\
\hline & & NW-B2 & & NW-B4 & & NE-B6 & & NE-B8 \\
\hline July 5 & & 1.487 & & 2.417 & & 2.186 & & 3.599 \\
\hline July 10 & & 1.416 & & 2.044 & & 1.971 & & 3.624 \\
\hline July 17 & & 0.987 & & 1.092 & & 1.112 & & 1.169 \\
\hline July 24 & & 1.188 & & 1.110 & & 1.421 & & 1.622 \\
\hline & NW-C1 & & NW-C3 & & NE-C5 & & NE-C7 & \\
\hline July 5 & 1.387 & & 2.636 & & 1.844 & & 3.164 & \\
\hline July 10 & 1.126 & & 2.951 & & 3.106 & & 4.326 & \\
\hline July 17 & 1.355 & & 1.195 & & 1.378 & & 0.517 & \\
\hline July 24 & 0.910 & & 1.223 & & 1.466 & & 0.562 & \\
\hline & & NW-D2 & & NW-D4 & & NE-D6 & & NE-D8 \\
\hline July 5 & & 0.919 & & 3.395 & & 1.547 & & 2.006 \\
\hline July 10 & & 1.065 & & 3.358 & & 1.197 & & 1.849 \\
\hline July 17 & & 0.986 & & 1.561 & & 0.855 & & 0.940 \\
\hline July 24 & & 0.948 & & 1.615 & & 0.368 & & 1.082 \\
\hline & SW-E1 & & SW-E3 & & SE-E5 & & SE-E7 & \\
\hline July 5 & 1.728 & & 2.458 & & 2.408 & & 3.827 & \\
\hline July 10 & 1.321 & & 2.532 & & 2.545 & & 4.764 & \\
\hline July 17 & 1.329 & & 0.886 & & 1.196 & & 0.792 & \\
\hline July 24 & 0.578 & & 0.411 & & 1.274 & & 0.814 & \\
\hline & & SW-F2 & & SW-F4 & & SE-F6 & & SE-F8 \\
\hline July 5 & & 1.387 & & 2.355 & & 2.282 & & 1.657 \\
\hline July 10 & & 1.076 & & 2.030 & & 2.392 & & 1.745 \\
\hline July 17 & & 0.992 & & 1.229 & & 1.060 & & 0.900 \\
\hline July 24 & & 1.019 & & 1.435 & & 1.325 & & 1.050 \\
\hline & SW-G1 & & SW-G3 & & SE-G5 & & SE-G7 & \\
\hline July 5 & 1.877 & & 1.875 & & 2.371 & & 4.045 & \\
\hline July 10 & 1.664 & & 2.970 & & 2.275 & & 3.185 & \\
\hline July 17 & 1.520 & & 0.795 & & 1.128 & & 0.934 & \\
\hline July 24 & 1.403 & & 0.759 & & 1.258 & & 1.377 & \\
\hline & & SW-H2 & & SW-H4 & & SE-H6 & & SE-H8 \\
\hline July 5 & & 0.902 & & 0.998 & & 2.279 & & 2.503 \\
\hline July 10 & & 0.783 & & 0.703 & & 1.901 & & 1.353 \\
\hline July 17 & & 0.723 & & 0.848 & & 0.955 & & 0.733 \\
\hline July 24 & & 0.760 & & 0.728 & & 0.839 & & 0.960 \\
\hline
\end{tabular}


Table 35: Mean ER measurements standard deviation across the dry tracks over the growing season

\begin{tabular}{|l|c|c|c|c|c|c|c|c|}
\hline \multirow{2}{*}{} & \multicolumn{2}{|c|}{ Dry 2 } & \multicolumn{2}{c|}{ Dry 4 } & \multicolumn{2}{c|}{ Dry 6 } & \multicolumn{2}{c|}{ Dry 8 } \\
\cline { 2 - 9 } & Mean & SD & Mean & SD & Mean & SD & Mean & SD \\
\hline Week 1 & 1.174 & 0.307 & 2.722 & 0.584 & 2.073 & 0.354 & 2.441 & 0.846 \\
\hline Week 2 & 1.085 & 0.259 & 2.478 & 0.763 & 1.865 & 0.496 & 2.143 & 1.010 \\
\hline Week 3 & 0.922 & 0.133 & 1.294 & 0.241 & 0.995 & 0.114 & 0.935 & 0.180 \\
\hline Week 4 & 0.979 & 0.177 & 1.386 & 0.256 & 0.988 & 0.486 & 1.178 & 0.300 \\
\hline
\end{tabular}

Table 36: Mean ER measurements standard deviation across the wet tracks over the growing season

\begin{tabular}{|l|c|c|c|c|c|c|c|c|}
\hline \multirow{2}{*}{} & \multicolumn{2}{|c|}{ Wet 1 } & \multicolumn{2}{c|}{ Wet 3 } & \multicolumn{2}{c|}{ Wet 5 } & \multicolumn{2}{c|}{ Wet 7 } \\
\cline { 2 - 9 } & Mean & SD & Mean & SD & Mean & SD & Mean & SD \\
\hline Week 1 & 1.664 & 0.251 & 2.503 & 0.485 & 2.441 & 0.533 & 3.628 & 0.388 \\
\hline Week 2 & 1.370 & 0.273 & 2.928 & 0.299 & 2.915 & 0.647 & 3.896 & 0.772 \\
\hline Week 3 & 1.401 & 0.104 & 1.090 & 0.314 & 1.110 & 0.269 & 0.832 & 0.242 \\
\hline Week 4 & 0.964 & 0.415 & 1.045 & 0.596 & 1.187 & 0.305 & 0.855 & 0.363 \\
\hline
\end{tabular}


Table 37: Gross primary production (GPP) throughout the growing season expressed as $\mu \mathrm{mol} / \mathrm{m}^{2} / \mathrm{s}$

\begin{tabular}{|c|c|c|c|c|c|c|c|c|}
\hline Date & NW-A1 & & NW-A3 & & NE-A5 & & NE-A7 & \\
\hline July 5 & -0.586 & & -2.419 & & -3.443 & & -3.053 & \\
\hline July 10 & -0.390 & & -4.510 & & -5.084 & & -3.962 & \\
\hline July 17 & -2.741 & & -3.110 & & -2.859 & & -2.661 & \\
\hline July 24 & -2.213 & & -4.068 & & -2.792 & & -1.623 & \\
\hline & & NW-B2 & & NW-B4 & & NE-B6 & & NE-B8 \\
\hline July 5 & & -0.454 & & -1.839 & & -0.854 & & -2.837 \\
\hline July 10 & & -0.083 & & -1.890 & & -1.369 & & -3.086 \\
\hline July 17 & & -1.502 & & -1.945 & & -1.431 & & -2.286 \\
\hline July 24 & & -1.705 & & -1.874 & & -2.352 & & -2.433 \\
\hline & NW-C1 & & NW-C3 & & NE-C5 & & NE-C7 & \\
\hline July 5 & -1.941 & & -3.352 & & -2.664 & & -3.906 & \\
\hline July 10 & -1.602 & & -3.889 & & -5.428 & & -4.580 & \\
\hline July 17 & -3.009 & & -3.371 & & -3.680 & & -3.348 & \\
\hline July 24 & -1.591 & & -3.191 & & -3.626 & & -1.327 & \\
\hline & & NW-D2 & & NW-D4 & & NE-D6 & & NE-D8 \\
\hline July 5 & & -0.106 & & -1.514 & & -0.855 & & -1.232 \\
\hline July 10 & & -0.810 & & -2.656 & & -2.257 & & -1.562 \\
\hline July 17 & & -1.397 & & -2.674 & & -1.216 & & -2.408 \\
\hline July 24 & & -1.226 & & -2.448 & & -0.846 & & -1.899 \\
\hline & SW-E1 & & SW-E3 & & SE-E5 & & SE-E7 & \\
\hline July 5 & -1.186 & & -1.385 & & -3.783 & & -4.110 & \\
\hline July 10 & -0.943 & & -3.453 & & -5.068 & & -3.986 & \\
\hline July 17 & -1.799 & & -1.905 & & -4.182 & & -3.066 & \\
\hline July 24 & -1.294 & & -1.381 & & -4.919 & & -2.019 & \\
\hline & & SW-F2 & & SW-F4 & & SE-F6 & & SE-F8 \\
\hline July 5 & & -0.500 & & -1.982 & & -0.166 & & -1.242 \\
\hline July 10 & & -0.332 & & -2.613 & & -0.424 & & -1.397 \\
\hline July 17 & & -1.328 & & -3.112 & & -0.439 & & -2.046 \\
\hline July 24 & & -0.821 & & -1.937 & & 0.837 & & -2.013 \\
\hline & SW-G1 & & SW-G3 & & SE-G5 & & SE-G7 & \\
\hline July 5 & -1.452 & & -3.239 & & -3.465 & & -4.690 & \\
\hline July 10 & -1.142 & & -5.113 & & -3.857 & & -3.599 & \\
\hline July 17 & -2.975 & & -3.231 & & -2.374 & & -2.153 & \\
\hline July 24 & -1.913 & & -2.269 & & -2.447 & & -2.146 & \\
\hline & & SW-H2 & & SW-H4 & & SE-H6 & & SE-H8 \\
\hline July 5 & & -0.781 & & -0.285 & & -0.883 & & 1.211 \\
\hline July 10 & & -0.049 & & -0.496 & & -1.121 & & 0.690 \\
\hline July 17 & & -0.049 & & -1.118 & & -2.304 & & -1.794 \\
\hline July 24 & & -0.241 & & -1.003 & & -1.314 & & -1.336 \\
\hline
\end{tabular}


Table 38: Mean GPP measurements standard deviation across the dry tracks over the growing season

\begin{tabular}{|l|c|c|c|c|c|c|c|c|}
\hline & \multicolumn{2}{|c|}{ Dry 2 } & \multicolumn{2}{c|}{ Dry 4 } & \multicolumn{2}{c|}{ Dry 6 } & \multicolumn{2}{c|}{ Dry 8 } \\
\cline { 2 - 9 } & Mean & SD & Mean & SD & Mean & SD & Mean & SD \\
\hline Week 1 & -0.460 & 0.277 & -1.78 & 0.772 & -0.689 & 0.349 & -1.03 & 1.67 \\
\hline Week 2 & -0.318 & 0.351 & -2.39 & 1.01 & -1.29 & 0.757 & -1.34 & 1.55 \\
\hline Week 3 & -1.07 & 0.684 & -2.58 & 0.874 & -1.35 & 0.767 & -2.13 & 0.272 \\
\hline Week 4 & -0.998 & 0.621 & -2.09 & 0.600 & -0.919 & 1.33 & -1.92 & 0.452 \\
\hline
\end{tabular}

Table 39: Mean GPP measurements standard deviation across the wet tracks over the growing season

\begin{tabular}{|l|c|c|c|c|c|c|c|c|}
\hline \multirow{2}{*}{} & \multicolumn{2}{|c|}{ Wet 1 } & \multicolumn{2}{c|}{ Wet 3 } & \multicolumn{2}{c|}{ Wet 5 } & \multicolumn{2}{c|}{ Wet 7 } \\
\cline { 2 - 9 } & Mean & SD & Mean & SD & Mean & SD & Mean & SD \\
\hline Week 1 & -1.32 & 0.565 & -2.60 & 0.910 & -3.06 & 0.476 & -3.94 & 0.678 \\
\hline Week 2 & -1.04 & 0.502 & -4.24 & 0.725 & -4.21 & 0.688 & -4.03 & 0.406 \\
\hline Week 3 & -2.39 & 0.567 & -2.90 & 0.675 & -3.22 & 0.811 & -2.81 & 0.519 \\
\hline Week 4 & -1.60 & 0.397 & -2.73 & 1.16 & -3.08 & 1.10 & -1.78 & 0.375 \\
\hline
\end{tabular}




\section{Appendix D - Soil moisture, soil temperature, and active layer depth data}

Table 40: Soil temperature data collected throughout the growing season, expressed in Celsius

\begin{tabular}{|c|c|c|c|c|c|c|c|c|c|c|}
\hline \multirow{2}{*}{ Sample Location } & \multicolumn{10}{|c|}{ Date } \\
\hline & June 29-30 & 04-Jul & 05-Jul & 10-Jul & 15-Jul & 17-Jul & 20-Jul & 24-Jul & 25-Jul & 26-Jul \\
\hline NW-A1 & -1.5 & 0.6 & 1.4 & 3.0 & 1.9 & 1.4 & 1.6 & 1.8 & 3.1 & 2.5 \\
\hline NW-C1 & 0.0 & 1.3 & 2.3 & 3.6 & 1.4 & 1.8 & 1.9 & 2.2 & 3.6 & 2.8 \\
\hline SW-E1 & -0.2 & 0.4 & 1.1 & 1.8 & 1.0 & 1.3 & 1.5 & 1.8 & 3.3 & 2.6 \\
\hline SW-G1 & 0.2 & 0.5 & 1.1 & 2.0 & 1.4 & 1.4 & 1.2 & 1.3 & 3.2 & 2.1 \\
\hline SW-H2 & -0.3 & -0.5 & -0.2 & 0.6 & 0.2 & 0.0 & -0.1 & 0.4 & 1.0 & 0.3 \\
\hline SW-F2 & -0.2 & 0.2 & 0.9 & 1.8 & 0.4 & 0.5 & 0.9 & 1.4 & 2.4 & 1.8 \\
\hline NW-D2 & -0.4 & -0.1 & 0.7 & 1.5 & 0.5 & 0.6 & 0.1 & 0.5 & 1.6 & 0.5 \\
\hline NW-B2 & -0.3 & -0.1 & 1.2 & 0.9 & 0.6 & 0.5 & 0.4 & 0.8 & 1.9 & 1.3 \\
\hline NW-A3 & 0.0 & 1.1 & 3.2 & 4.0 & 2.4 & 2.7 & 2.2 & 2.9 & 4.0 & 3.2 \\
\hline NW-C3 & 0.1 & 0.4 & 1.6 & 3.3 & 1.8 & 2.1 & 1.9 & 2.1 & 3.5 & 2.7 \\
\hline SW-E3 & 0.7 & 2.2 & 4.4 & 5.5 & 3.5 & 3.6 & 3.4 & 3.4 & 4.6 & 4.0 \\
\hline SW-G3 & 0.8 & 1.8 & 3.8 & 4.8 & 3.5 & 3.4 & 3.3 & 3.1 & 4.2 & 4.0 \\
\hline SW-H4 & -0.2 & 0.6 & 1.9 & 2.0 & 1.2 & 0.8 & 1.0 & 1.6 & 2.2 & 1.6 \\
\hline SW-F4 & 0.5 & 2.3 & 3.6 & 4.8 & 3.0 & 2.9 & 2.6 & 3.1 & 4.1 & 3.5 \\
\hline NW-D4 & 0.3 & 0.2 & 1.0 & 2.8 & 1.7 & 1.5 & 1.3 & 1.8 & 2.9 & 2.1 \\
\hline NW-B4 & -0.2 & 0.6 & 1.3 & 2.0 & 1.2 & 1.0 & 0.8 & 1.2 & 1.6 & 1.4 \\
\hline NE-A5 & 2.0 & 6.2 & 8.4 & 8.3 & 4.8 & 4.9 & 4.1 & 4.5 & 5.4 & 5.2 \\
\hline NE-C5 & 1.6 & 3.7 & 5.5 & 5.9 & 4.1 & 3.4 & 3.3 & 3.2 & 4.3 & 3.9 \\
\hline SE-E5 & 0.9 & 3.4 & 4.5 & 4.6 & 3.3 & 2.8 & 3.0 & 3.0 & 3.8 & 3.5 \\
\hline SE-G5 & 1.0 & 3.7 & 3.7 & 4.9 & 3.5 & 3.0 & 2.7 & 2.9 & 3.7 & 3.4 \\
\hline SE-H6 & -0.2 & 0.8 & 0.8 & 2.3 & 1.7 & 1.6 & 1.4 & 1.4 & 1.8 & 2.1 \\
\hline SE-F6 & -0.2 & 1.3 & 0.8 & 2.1 & 1.7 & 1.1 & 1.2 & 1.6 & 2.3 & 2.1 \\
\hline NE-D6 & 0.2 & 1.7 & 2.3 & 2.9 & 2.2 & 2.0 & 1.6 & 2.2 & 2.7 & 2.4 \\
\hline NE-B6 & 0.1 & 0.9 & 1.0 & 1.8 & 1.2 & 1.1 & 1.4 & 1.4 & 2.0 & 1.9 \\
\hline SE-G7 & 1.4 & 2.9 & 4.2 & 4.4 & 4.0 & 3.7 & 2.9 & 3.5 & 3.8 & 4.3 \\
\hline SE-E7 & 1.1 & 2.7 & 3.6 & 3.6 & 3.9 & 3.2 & 3.2 & 3.6 & 4.1 & 4.8 \\
\hline NE-C7 & 1.2 & 2.9 & 4.5 & 4.6 & 3.7 & 4.3 & 3.9 & 3.9 & 4.4 & 4.6 \\
\hline NE-A7 & 1.6 & 4.0 & 5.0 & 5.7 & 3.8 & 4.0 & 3.0 & 3.4 & 4.3 & 5.0 \\
\hline SE-H8 & 0.1 & 0.3 & 1.1 & 1.3 & 1.2 & 1.2 & 0.8 & 1.8 & 1.9 & 1.9 \\
\hline SE-F8 & 1.2 & 2.3 & 3.2 & 4.0 & 3.1 & 2.9 & 2.3 & 3.2 & 3.6 & 3.7 \\
\hline NE-D8 & 0.6 & 1.5 & 1.8 & 2.8 & 1.3 & 1.6 & 1.3 & 2.2 & 2.7 & 2.5 \\
\hline NE-B8 & 1.2 & 2.7 & 3.2 & 4.0 & 3.5 & 2.9 & 2.4 & 2.5 & 3.3 & 3.4 \\
\hline
\end{tabular}


Table 41: Mean ST measurements standard deviation across the dry tracks over the growing season

\begin{tabular}{|l|c|c|c|c|c|c|c|c|}
\hline & \multicolumn{2}{|c|}{ Dry 2 } & \multicolumn{2}{c|}{ Dry 4 } & \multicolumn{2}{c|}{ Dry 6 } & \multicolumn{2}{c|}{ Dry 8 } \\
\cline { 2 - 9 } & Mean & SD & Mean & SD & Mean & SD & Mean & SD \\
\hline Week 1 & 0.069 & 0.288 & 1.056 & 0.915 & 0.797 & 0.404 & 1.592 & 0.865 \\
\hline Week 2 & 0.825 & 0.296 & 2.572 & 1.188 & 1.979 & 0.447 & 2.658 & 1.209 \\
\hline Week 3 & 0.346 & 0.299 & 1.681 & 0.974 & 1.413 & 0.279 & 1.933 & 0.820 \\
\hline Week 4 & 1.150 & 0.552 & 2.430 & 1.098 & 1.989 & 0.297 & 2.722 & 0.704 \\
\hline
\end{tabular}

Table 42: Mean ST measurements standard deviation across the wet tracks over the growing season

\begin{tabular}{|l|c|c|c|c|c|c|c|c|}
\hline \multirow{2}{*}{} & \multicolumn{2}{|c|}{ Wet 1 } & \multicolumn{2}{c|}{ Wet 3 } & \multicolumn{2}{c|}{ Wet 5 } & \multicolumn{2}{c|}{ Wet 7 } \\
\cline { 2 - 9 } & Mean & SD & Mean & SD & Mean & SD & Mean & SD \\
\hline Week 1 & 0.730 & 0.408 & 1.675 & 0.782 & 3.722 & 1.263 & 2.931 & 0.448 \\
\hline Week 2 & 1.867 & 0.569 & 3.596 & 0.892 & 4.938 & 1.183 & 4.221 & 0.424 \\
\hline Week 3 & 1.517 & 0.277 & 2.821 & 0.728 & 3.396 & 0.779 & 3.508 & 0.414 \\
\hline Week 4 & 2.544 & 0.340 & 3.467 & 0.543 & 3.900 & 0.797 & 4.142 & 0.203 \\
\hline
\end{tabular}


Table 43: Soil moisture data collected throughout the growing season, expressed as a percentage

\begin{tabular}{|c|c|c|c|c|c|c|c|c|c|c|}
\hline \multirow{2}{*}{ Sample Location } & \multicolumn{10}{|c|}{ Date } \\
\hline & June $29-30$ & 04-Jul & 05-Jul & 10-Jul & 15-Jul & 17-Jul & 20-Jul & 24-Jul & 25-Jul & 26-Jul \\
\hline NW-A1 & 34.5 & 25.7 & 23.4 & 19.0 & 51.6 & 58.4 & 39.4 & 38.7 & 32.0 & 46.5 \\
\hline NW-C1 & 68.7 & 51.9 & 52.3 & 45.4 & 79.6 & 62.3 & 56.5 & 59.9 & 56.4 & 66.3 \\
\hline SW-E1 & 43.5 & 79.6 & 79.2 & 63.7 & 91.7 & 94.9 & 89.5 & 100.0 & 94.6 & 89.2 \\
\hline SW-G1 & 39.9 & 45.9 & 53.8 & 45.3 & 63.5 & 71.1 & 73.0 & 81.4 & 72.2 & 84.4 \\
\hline SW-H2 & 30.6 & 45.5 & 34.3 & 38.8 & 82.0 & 76.4 & 71.9 & 64.9 & 47.5 & 73.6 \\
\hline SW-F2 & 28.6 & 43.5 & 35.9 & 45.0 & 72.7 & 72.5 & 55.1 & 70.5 & 66.3 & 54.1 \\
\hline NW-D2 & 35.3 & 33.3 & 32.9 & 46.9 & 49.7 & 54.1 & 48.3 & 46.3 & 36.1 & 55.2 \\
\hline NW-B2 & 32.5 & 28.8 & 41.4 & 29.3 & 60.7 & 70.4 & 80.1 & 65.8 & 51.5 & 77.7 \\
\hline NW-A3 & 79.1 & 86.7 & 89.7 & 90.7 & 89.1 & 88.0 & 88.9 & 97.2 & 90.8 & 88.6 \\
\hline NW-C3 & 71.6 & 61.9 & 78.4 & 49.4 & 96.6 & 92.9 & 94.5 & 99.1 & 96.7 & 98.2 \\
\hline SW-E3 & 87.5 & 84.1 & 82.3 & 74.3 & 74.0 & 72.3 & 80.7 & 77.5 & 85.2 & 82.4 \\
\hline SW-G3 & 100.0 & 90.2 & 93.5 & 94.3 & 94.8 & 93.3 & 97.3 & 88.1 & 101.0 & 91.8 \\
\hline SW-H4 & 53.4 & 47.2 & 42.6 & 38.7 & 51.0 & 59.5 & 58.1 & 55.6 & 54.9 & 56.4 \\
\hline SW-F4 & 47.6 & 50.6 & 46.0 & 44.1 & 59.0 & 49.4 & 54.7 & 50.1 & 47.8 & 53.3 \\
\hline NW-D4 & 48.1 & 47.0 & 49.6 & 38.8 & 72.3 & 79.4 & 85.2 & 39.4 & 51.6 & 68.4 \\
\hline NW-B4 & 66.4 & 65.9 & 72.4 & 67.7 & 86.4 & 73.4 & 74.0 & 77.5 & 73.6 & 71.4 \\
\hline NE-A5 & 86.7 & 62.9 & 69.5 & 50.6 & 70.9 & 64.1 & 69.9 & 61.1 & 66.9 & 59.2 \\
\hline NE-C5 & 101.1 & 95.9 & 98.8 & 94.2 & 100.8 & 100.6 & 104.0 & 96.5 & 100.2 & 100.7 \\
\hline SE-E5 & 99.3 & 101.2 & 101.9 & 96.6 & 99.7 & 99.5 & 99.9 & 98.7 & 98.7 & 100.5 \\
\hline SE-G5 & 88.3 & 92.2 & 89.8 & 83.3 & 75.1 & 86.2 & 76.6 & 91.4 & 82.4 & 99.7 \\
\hline SE-H6 & 63.5 & 73.1 & 77.0 & 61.9 & 79.9 & 71.6 & 82.5 & 78.2 & 78.6 & 78.0 \\
\hline SE-F6 & 39.0 & 26.0 & 25.3 & 23.9 & 41.3 & 67.8 & 76.8 & 73.3 & 46.2 & 68.1 \\
\hline NE-D6 & 53.9 & 57.7 & 48.1 & 42.1 & 60.0 & 63.7 & 64.5 & 64.8 & 60.8 & 60.1 \\
\hline NE-B6 & 55.5 & 40.1 & 25.7 & 32.5 & 81.3 & 91.2 & 91.4 & 76.5 & 45.8 & 77.9 \\
\hline SE-G7 & 95.6 & 69.2 & 84.2 & 54.9 & 67.8 & 91.1 & 98.8 & 93.1 & 96.9 & 97.5 \\
\hline SE-E7 & 100.1 & 73.6 & 82.6 & 61.1 & 82.1 & 95.0 & 98.5 & 98.3 & 97.0 & 340.4 \\
\hline NE-C7 & 99.1 & 97.5 & 99.5 & 73.3 & 92.1 & 100.3 & 100.7 & 99.7 & 94.7 & 98.8 \\
\hline NE-A7 & 90.9 & 64.3 & 68.1 & 66.1 & 83.0 & 76.7 & 77.6 & 83.5 & 80.8 & 87.5 \\
\hline SE-H8 & 41.5 & 35.3 & 44.1 & 43.0 & 67.1 & 67.4 & 66.6 & 71.7 & 62.6 & 76.1 \\
\hline SE-F8 & 42.7 & 43.1 & 46.5 & 37.7 & 52.3 & 51.5 & 53.2 & 54.7 & 54.9 & 62.4 \\
\hline NE-D8 & 42.5 & 44.0 & 48.0 & 40.1 & 62.9 & 51.1 & 70.6 & 61.2 & 39.2 & 65.4 \\
\hline NE-B8 & 47.9 & 56.4 & 65.5 & 71.5 & 69.6 & 76.9 & 92.5 & 89.4 & 53.7 & 79.4 \\
\hline
\end{tabular}


Table 44: Mean SM measurements standard deviation across the dry tracks over the growing season

\begin{tabular}{|l|c|c|c|c|c|c|c|c|}
\hline \multirow{2}{*}{} & \multicolumn{2}{|c|}{ Dry 2 } & \multicolumn{2}{c|}{ Dry 4 } & \multicolumn{2}{c|}{ Dry 6 } & \multicolumn{2}{c|}{ Dry 8 } \\
\cline { 2 - 9 } & Mean & SD & Mean & SD & Mean & SD & Mean & SD \\
\hline Week 1 & 35.207 & 1.418 & 54.826 & 11.611 & 48.750 & 17.714 & 46.467 & 7.044 \\
\hline Week 2 & 53.129 & 7.643 & 61.411 & 13.720 & 52.858 & 15.876 & 55.529 & 10.848 \\
\hline Week 3 & 66.113 & 11.189 & 69.350 & 15.587 & 76.192 & 11.421 & 66.217 & 13.705 \\
\hline Week 4 & 59.114 & 8.936 & 59.233 & 12.996 & 67.356 & 7.583 & 64.214 & 9.334 \\
\hline
\end{tabular}

Table 45: Mean SM measurements standard deviation across the wet tracks over the growing season

\begin{tabular}{|l|c|c|c|c|c|c|c|c|}
\hline \multirow{2}{*}{} & \multicolumn{2}{|c|}{ Wet 1 } & \multicolumn{2}{c|}{ Wet 3 } & \multicolumn{2}{c|}{ Wet 5 } & \multicolumn{2}{c|}{ Wet 7 } \\
\cline { 2 - 9 } & Mean & SD & Mean & SD & Mean & SD & Mean & SD \\
\hline Week 1 & 57.204 & 10.473 & 83.761 & 9.856 & 90.642 & 12.606 & 85.400 & 10.054 \\
\hline Week 2 & 64.872 & 11.844 & 82.908 & 10.942 & 83.879 & 17.771 & 72.550 & 8.825 \\
\hline Week 3 & 74.556 & 16.541 & 88.483 & 8.518 & 87.617 & 16.574 & 92.325 & 10.390 \\
\hline Week 4 & 78.263 & 16.915 & 91.367 & 6.915 & 88.008 & 17.487 & 93.289 & 6.312 \\
\hline
\end{tabular}


Table 46: Active layer depth collected throughout the growing season, expressed in centimetres

\begin{tabular}{|c|c|c|c|c|}
\hline \multirow{2}{*}{ Sample Location } & \multicolumn{4}{|c|}{ Date } \\
\hline & 06-Jul & 11-Jul & 18-Jul & 25-Jul \\
\hline NW-A1 & 30.0 & 36.0 & 41.7 & 40.7 \\
\hline NW-B1 & 29.0 & 27.0 & 25.7 & 26.0 \\
\hline NW-C1 & 25.0 & 37.7 & 37.3 & 40.0 \\
\hline NW-D1 & 20.0 & 32.0 & 33.0 & 37.7 \\
\hline SW-E1 & 22.0 & 30.0 & 33.7 & 36.0 \\
\hline SW-F1 & 26.0 & 32.3 & 36.7 & 41.0 \\
\hline SW-G1 & 30.0 & 32.0 & 31.7 & 32.0 \\
\hline SW-H1 & 32.0 & 38.3 & 40.7 & 41.7 \\
\hline SW-H2 & 15.0 & 16.0 & 18.0 & 18.3 \\
\hline SW-G2 & 28.0 & 26.0 & 29.0 & 32.3 \\
\hline SW-F2 & 31.0 & 27.7 & 29.3 & 28.3 \\
\hline SW-E2 & 20.0 & 25.0 & 26.3 & 26.3 \\
\hline NW-D2 & 16.0 & 23.0 & 17.0 & 19.3 \\
\hline NW-C2 & 20.0 & 19.3 & 20.0 & 22.7 \\
\hline NW-B2 & 22.0 & 21.3 & 20.0 & 24.3 \\
\hline NW-A2 & 20.0 & 24.3 & 26.0 & 28.0 \\
\hline NW-A3 & 29.0 & 40.3 & 40.3 & 42.3 \\
\hline NW-B3 & 27.0 & 33.0 & 33.7 & 37.7 \\
\hline NW-C3 & 27.0 & 33.3 & 35.7 & 38.3 \\
\hline NW-D3 & 38.0 & 45.3 & 45.7 & 50.0 \\
\hline SW-E3 & 41.0 & 45.3 & 49.3 & 49.0 \\
\hline SW-F3 & 43.0 & 44.0 & 49.0 & 48.0 \\
\hline SW-G3 & 36.0 & 43.7 & 48.3 & 46.7 \\
\hline SW-H3 & 36.0 & 37.0 & 43.3 & 47.7 \\
\hline SW-H4 & 22.0 & 24.0 & 25.7 & 26.0 \\
\hline SW-G4 & 30.0 & 30.3 & 30.0 & 30.0 \\
\hline SW-F4 & 33.0 & 38.7 & 41.0 & 43.3 \\
\hline SW-E4 & 36.0 & 39.3 & 44.0 & 43.0 \\
\hline NW-D4 & 25.0 & 35.0 & 35.0 & 32.0 \\
\hline NW-C4 & 25.0 & 30.7 & 27.3 & 30.0 \\
\hline NW-B4 & 22.0 & 20.3 & 22.3 & 27.0 \\
\hline NW-A4 & 32.0 & 35.7 & 40.3 & 38.0 \\
\hline NE-A5 & 48.0 & 54.3 & 57.7 & 57.3 \\
\hline NE-B5 & 40.0 & 48.3 & 51.7 & 50.3 \\
\hline NE-C5 & 38.0 & 47.0 & 49.3 & 45.0 \\
\hline NE-D5 & 38.0 & 43.0 & 47.0 & 46.0 \\
\hline SE-E5 & 35.0 & 46.3 & 48.0 & 45.0 \\
\hline SE-F5 & 33.0 & 40.3 & 44.0 & 44.0 \\
\hline SE-G5 & 33.0 & 40.0 & 41.3 & 39.0 \\
\hline
\end{tabular}




\begin{tabular}{|c|c|c|c|c|}
\hline SE-H5 & 30.0 & 35.0 & 38.0 & 35.7 \\
\hline SE-H6 & 29.0 & 28.7 & 33.7 & 30.3 \\
\hline SE-G6 & 29.0 & 33.7 & 40.0 & 40.0 \\
\hline SE-F6 & 28.0 & 28.7 & 30.0 & 31.0 \\
\hline SE-E6 & 18.0 & 19.7 & 27.3 & 28.3 \\
\hline NE-D6 & 25.0 & 32.7 & 38.3 & 36.3 \\
\hline NE-C6 & 30.0 & 33.0 & 39.7 & 37.3 \\
\hline NE-B6 & 24.0 & 29.0 & 30.3 & 31.0 \\
\hline NE-A6 & 33.0 & 40.3 & 45.7 & 42.7 \\
\hline NE-A7 & 42.0 & 48.3 & 47.0 & 48.0 \\
\hline NE-B7 & 47.0 & 48.7 & 49.7 & 53.0 \\
\hline NE-C7 & 32.0 & 43.0 & 46.7 & 47.0 \\
\hline NE-D7 & 38.0 & 46.7 & 45.7 & 48.7 \\
\hline SE-E7 & 31.0 & 40.0 & 41.0 & 44.7 \\
\hline SE-F7 & 40.0 & 40.0 & 42.0 & 42.0 \\
\hline SE-G7 & 39.0 & 43.7 & 47.0 & 47.7 \\
\hline SE-H7 & 43.0 & 49.3 & 53.3 & 56.3 \\
\hline SE-H8 & 17.0 & 21.7 & 21.7 & 22.3 \\
\hline SE-G8 & 30.0 & 37.3 & 39.7 & 45.7 \\
\hline SE-F8 & 31.0 & 38.3 & 37.7 & 37.7 \\
\hline SE-E8 & 21.0 & 29.3 & 29.7 & 26.3 \\
\hline NE-D8 & 27.0 & 30.3 & 31.7 & 36.7 \\
\hline NE-C8 & 18.0 & 30.3 & 32.3 & 33.3 \\
\hline NE-B8 & 34.0 & 38.7 & 41.0 & 44.0 \\
\hline NE-A8 & 31.0 & 41.0 & 44.7 & 44.3 \\
\hline SZ12 & 28.0 & 44.0 & 55.0 & 61.7 \\
\hline SZ11 & 33.0 & 39.0 & 64.7 & 58.0 \\
\hline SZ10 & 44.0 & 56.7 & 63.3 & 63.7 \\
\hline SZ9 & 42.0 & 56.0 & 68.0 & 70.7 \\
\hline SZ8 & 40.0 & 53.3 & 61.0 & 62.7 \\
\hline SZ7 & 36.0 & 52.0 & 57.3 & 57.3 \\
\hline SZ6 & 36.0 & 53.0 & 59.0 & 60.3 \\
\hline SZ5 & 33.0 & 53.3 & 60.7 & 62.3 \\
\hline SZ4 & 22.0 & 50.3 & 59.0 & 58.3 \\
\hline SZ3 & 28.0 & 55.3 & 63.3 & 59.0 \\
\hline SZ2 & 41.0 & 56.7 & 63.0 & 64.3 \\
\hline SZ1 & 41.0 & 53.7 & 64.7 & 64.7 \\
\hline
\end{tabular}


Table 47: Mean AL measurements standard deviation across the dry tracks over the growing season

\begin{tabular}{|l|c|c|c|c|c|c|c|c|}
\hline & \multicolumn{2}{|c|}{ Dry 2 } & \multicolumn{2}{c|}{ Dry 4 } & \multicolumn{2}{c|}{ Dry 6 } & \multicolumn{2}{c|}{ Dry 8 } \\
\cline { 2 - 9 } & Mean & SD & Mean & SD & Mean & SD & Mean & SD \\
\hline Week 1 & 21.000 & 7.348 & 26.667 & 5.686 & 26.500 & 2.380 & 27.250 & 7.411 \\
\hline Week 2 & 22.000 & 4.815 & 31.333 & 9.701 & 29.750 & 1.951 & 32.250 & 8.039 \\
\hline Week 3 & 21.083 & 5.640 & 32.778 & 9.530 & 33.083 & 3.872 & 33.000 & 8.485 \\
\hline Week 4 & 22.583 & 4.646 & 34.111 & 8.369 & 32.167 & 2.795 & 35.167 & 9.151 \\
\hline
\end{tabular}

Table 48: Mean AL measurements standard deviation across the wet tracks over the growing season

\begin{tabular}{|l|c|c|c|c|c|c|c|c|}
\hline \multirow{2}{*}{} & \multicolumn{2}{|c|}{ Wet 1 } & \multicolumn{2}{c|}{ Wet 3 } & \multicolumn{2}{c|}{ Wet 5 } & \multicolumn{2}{c|}{ Wet 7 } \\
\cline { 2 - 9 } & Mean & SD & Mean & SD & Mean & SD & Mean & SD \\
\hline Week 1 & 25.667 & 4.041 & 33.250 & 6.449 & 38.500 & 6.658 & 36.000 & 5.354 \\
\hline Week 2 & 33.222 & 3.977 & 40.667 & 5.312 & 46.917 & 5.865 & 43.750 & 3.447 \\
\hline Week 3 & 34.222 & 2.874 & 43.417 & 6.551 & 49.083 & 6.708 & 45.417 & 2.949 \\
\hline Week 4 & 36.000 & 4.000 & 44.083 & 4.725 & 46.583 & 7.705 & 46.833 & 1.503 \\
\hline
\end{tabular}




\section{References}

Arctic Climate Impact Assessment [ACIA]. (2005). Arctic Tundra and Polar Desert Ecosystems, in Arctic Climate Impact Assessment - Scientific Report (Chapter 7). Cambridge, UK: Cambridge University Press

Aerts, R., Cornelissen, J.H.C., and Dorrepaal, E. (2005). Plant performance in a warmer world: General responses of plants from cold, northern biomes and the importance of winter and spring events. Plant Ecology, 182(1): 65-77.

Aren, S.J.T., Sullivan, P.F., and Welker, J.M. (2008). Nonlinear responses to nitrogen and strong interaction with nitrogen and phosphorus additions drastically alter the structure and function of a High Arctic ecosystem. Journal of Geophysical Research, 113, G03S09.

Astoria Pacific. (2011). What is micro seg flow? Astoria Pacific. Retrieved May 12, 2017 from http://www.astoria-pacific.com/industrial/technology-industrial/what-is-micro-seg-flow/.

Atkinson, D.M. (2012). Modelling biophysical variables and carbon dioxide exchange in Arctic tundra landscapes using high spatial resolution remote sensing data. Doctoral dissertation. Retrieved from Queen’s Theses \& Dissertations. (http://hdl.handle.net/1974/7709).

Atkinson, D.M. and Treitz, P. (2012). Arctic ecological classifications derived from vegetation community and satellite spectral data. Remote Sensing, 4: 3948-3971.

Atkinson, D.M. and Treitz, P. (2013). Modeling biophysical variables across an Arctic latitudinal gradient using high spatial resolution remote sensing data. Arctic, Antarctic, and Alpine Research, 45(2): 161-178.

Atkinson, D.M. (2016). Personal communication. Department of Geography and Environmental Studies, Ryerson University. Toronto, Canada.

Avis, C.A., Weaver, A.J., and Meissner, K.J. (2011). Reduction in areal extent of high-latitude wetlands in response to permafrost thaw. Nature Geoscience, 4: 444-448. doi: 10.1038/ngeo1160.

Beamish, A., Neil, A., Wagner, I., and Scott, N.A. (2014). Short-term impacts of active layer detachments on carbon exchange in a High Arctic ecosystem, Cape Bounty, Nunavut, Canada. Polar Biology, 37: 1459-1468.

Beermann, F. (2016). Nutrient availability and limitation within soils of polygonal tundra in the Sakha Republic, Russian Federation. Doctoral dissertation. Retrieved from Max Planck Society

Public

Repository (http://pubman.mpdl.mpg.de/pubman/item/escidoc:2296827/component/escidoc:2296826 /Dissertation_Beermann.pdf) 
Bell, T.H., Callender, K.L., Whyte, L.G., and Greer, C.W. (2013). Microbial competition in polar soils: A review of an understudied but potentially important control on productivity. Biology (Basel), 2(2): 533-554.

Biederbeck, V.O. and Campbell, C.A. (1973). Soil microbial activity as influenced by temperature trends and fluctuations. Canadian Journal of Soil Science, 53: 363-376.

Bilbrough, C., Welker, J., and Bowman, W.D. (2000). Early spring nitrogen uptake by snowcovered plants: a comparison of arctic and alpine plant function under the snowpack. Arctic, Antarctic and Alpine Research, 32: 404-411.

Billings, W.D., Luken, J.O., Mortensen, D.A., and Peterson, K.M. (1982). Arctic tundra: a source or sink for atmospheric carbon dioxide in a changing environment? Oecologia, 53(1): 7-11.

Billings, W.D., Peterson, K.M., Luken, J.O., and Mortensen, D.A. (1984). Interaction of increasing atmospheric carbon dioxide and soil nitrogen on the carbon balance of tundra microcosms. Oecologia, 65(1): 26-29.

Binkley, P. and Matson, P. (1983). Ion exchange resin bag method for assessing available forest soil nitrogen. Soil Science Society of America Journal, 47: 1050-1052.

Bintanja, R. and Andry, O. (2017). Towards a rainfall-driven Arctic. Nature Climate Change, 7: 263-268.

Blaser, A. (2016). Spatial and temporal patterns of carbon dioxide exchange for a wet sedge plant community, Melville Island, NU. Master’s thesis. Retrieved from Queen's Theses \& Dissertations. (http://hdl.handle.net/1974/13987).

Bunnell, F.L., Tait, D.E.N., Flanagan, P.W., and Van Cleve, K. (1977). Microbial respiration and substrate weight loss - I: A general model of the influences of abiotic variables. Soil Biology and Biochemistry, 9: 33-40.

Callaghan, T.V., Johansson, M., Brown, R.D., Groisman, P.Y., Labba, N., Radionov, V., Barry, R.G., Bulygina, O.N., Essery, R.L.H., Frolov, D.M., Golubev, V.N., Grenfell, T.C., Petrushina, M.N., Razuvaev, V.N., Robinson, D.A., Romanov, P., Shindell D., Shmakin, A.B., Sokratov, S.A., Warren, S., and Yang, D.Q. (2011). The changing face of Arctic snow cover: A synthesis of observed and projected changes. Ambio, 40: 17-31.

Callaghan, T.V., Johansson, M., Brown, R.D., Groisman, P.Y., Labba, N., Radionov, V., Bradley, R.S., Blangy, S., Bulygina, O.N., Christensen, T.R., Colman, J.E., Essery, R.L.H., Forbes, B.C., Forchhammer, M.C., Golubev, V.N., Honrath, R.E., Juday, G.P., Meshcherskaya, A.V., Phoenix, G.K., Pomeroy, J., Rautio, A., Robinson, D.A., Schmidt, N.M., Serreze, M.C., Shevchenko, V.P., Shiklomanov, A.I., Shmakin, A.B., Sköld, P., Sturm, M., Woo, M.K., and Wood, E.F. (2011). Multiple effects of changes in Arctic snow cover. Ambio, 40(1): 32-45. 
Canadian Network of Northern Research Operators [CNNRO]. (2015). Cape Bounty Arctic Watershed Observatory. Retrieved June 2, 2016 from http://cnnro.ca/cape-bounty-arcticwatershed-observatory/.

Chae, Y., Kang, S.M., Jeong, S.J., Kim, B., and Frierson, D.M.W. (2015). Arctic greening can cause earlier seasonality of Arctic amplification. Geophysical Research Letters, 42. doi:10.1002/2014GL061841.

Chapin, D.M. and Bledsoe, C.S. (1992) Nitrogen fixation in Arctic plant communities. In Chapin, F.S. III, Jefferies, R.L., Reynolds, J.F., Shaver, G.R., Svoboda, J., and Chu, E. (Eds). Arctic ecosystems in a changing climate (301-319). New York: Elsevier Science.

Chapin, F.S. III, Shaver, G.R., Giblin, A.E., Nadelhoffer, K.J., and Laundre, J.A. (1995). Responses of Arctic tundra to experimental and observed changes in climate. Ecology, 76(3): 694-711. doi: 10.2307/1939337.

Chapin, F.S. III, Matson, P.A., and Mooney, H.A. (2002). Principles of terrestrial ecosystem ecology. New York: Springer.

Chen, Z., Ding, W., Xu, Y., Müller, C., Yu, H., and Fan, J. (2016). Increased $\mathrm{N}_{2} \mathrm{O}$ emissions during soil drying after waterlogging and spring thaw in a record wet year. Soil Biology and Biogeochemistry, 101: 152-164.

Christiansen, C.T. (2016). Seasonal controls on litter and soil carbon and nutrient cycling in Arctic tundra ecosystems and potential impacts of climate change. Doctoral dissertation. Retrieved from Queen’s Theses \& Dissertations. (http://hdl.handle.net/1974/13988).

Childs, C. (2004). Interpolating surfaces in ArcGIS Spatial Analyst. Retrieved April 17, 2017 from https://www.esri.com/news/arcuser/0704/files/interpolating.pdf

Clein, J.S. and Schimel, J.P. (1995). Microbial activity of tundra and taiga soils at sub-zero temperatures. Soil Biology and Biochemistry, 27(9): 1231-1234.

Commane, R., Lindaas, J., Benmerqui, J., Luus, K.A., Chang, R.Y.W., Daube, B.C., Euskirchen, E.S., Henderson, J.M., Karion, A., Miller, J.B., Miller, S.M., Parazoo, N.C., Randerson, J.T., Sweeney, C., Tans, P., Thoning, K., Veraverbeke, S., Miller, C.E., and Wofsy, S.C. (2017). Carbon dioxide sources from Alaska driven by increasing early winter respiration from Arctic tundra. Proceedings of the National Academy of Sciences of the United States of America. doi: 10.1073/pnas.1618567114.

Del Grosso, S.J., Parton, W.J., Mosier, A.R., Ojima, D.S., Kulmala, A.E., and Phongpan, S. (2000). General model for $\mathrm{N}_{2} \mathrm{O}$ and $\mathrm{N}_{2}$ gas emissions from soils due to denitrification. Global Biogeochemical Cycles, 14(4): 1045-1060. 
Edwards, K.A., McCulloch, J., Kershaw, P.G., and Jefferies, R.L. (2006). Soil microbial and nutrient dynamics in a wet arctic sedge meadow in late winter and early spring. Soil Biology and Biochemistry, 38(9): 2843-2851. doi: 10.1016/j.soilbio.2006.04.042.

Elberling, B., Christiansen, H.H., and Hansen, B.U. (2010). High nitrous oxide production from thawing permafrost. Nature Geoscience, 3: 332-325. doi:10.1038/ngeo803.

Elberling, B., Nordstrøm, C., Grøndahl, L., Søgaard, H., Friborg, T., Christensen, T.R., Ström, L., Marchand, F., and Nijs, I. (2008). High-Arctic soil $\mathrm{CO}_{2}$ and $\mathrm{CH}_{4}$ production controlled by temperature, water, freezing, and snow. In Meltofte, H., Christensen, T.R., Elberling, B., Forchhamer, M.C., and Rasch, M. (Eds.). Advances in ecological research: High-Arctic ecosystem dynamics in a changing climate (Vol. 40, 441-472). Oxford: Elsevier.

Environment and Climate Change Canada. (2016). Canadian Environmental Sustainability Indicators: Extent of Canada's Wetlands. Retrieved April 30, 2017 from http://www.ec.gc.ca/indicateurs-indicators/default.asp?lang=en\&n=69E2D25B-1.

Euskirchen, E.S., Bret-Harte, M.S., Shaver, G.R., Edgar, C.W., and Romanovsky, V.E. (2016). Long-term release of carbon dioxide from Arctic tundra ecosystems in Alaska. Ecosystems: 1-15. doi: 10.1007/s10021-016-0085-9.

Fortier, D., Allard, M., and Shur, Y. (2007). Observations of rapid drainage system development by thermal erosion of ice wedges on Bylot Island, Canadian Arctic Archipelago. Permafrost and Periglacial Processes, 18: 229-243.

Gebauer, R.L.E., Reynolds, J.F., and Tenhunen, J.D. (1995). Growth and allocation of the Arctic sedges Eriophorum angustifolium and E. vaginatum: effects of variable soil oxygen and nutrient availability. Oecologia, 104: 330-339.

Giblin, A.E., Nadelhoffer, K.J. Shaver, G.R., Laundre, J.A., and McKerrow, A.J. (1991). Biogeochemical diversity along a riverside toposequence in Arctic Alaska. Ecological Monographs, 61(4): 415-435.

Gorham, E. (1991). Northern peatlands: role in the carbon cycle and probably response to climatic warming. Ecological Applications, 1(2): 182-195.

Gough, L. and Hobbie, S.E. (2003). Responses of moist non-acidic Arctic tundra to altered environment: productivity, biomass, and species richness. OIKOS, 103(1): 204-216.

Gregory, F.M. (2011). Biophysical remote sensing and terrestrial $\mathrm{CO}_{2}$ exchange at Cape Bounty, Melville Island. Master's thesis. Retrieved from Queen's Theses \& Dissertations. (http://hdl.handle.net/1974/6953). 
Griffith, D.A. (2014). Nitrogen fixation by the cyanobacterium Nostoc punctiforme in response to variation in nitrogen availability, temperature, and atmospheric $\mathrm{CO}_{2}$ concentrations. Electronic Thesis and Dissertation Repository. Paper 2309.

Grogan, P. and Chapin, F.S. III. (2000). Initial effects of experimental warming on above- and belowground component of net ecosystem $\mathrm{CO}_{2}$ exchange in arctic tundra. Oecologia, 125: 512-520. doi: 10.1007/s004420000490

Grogan, P. and Jonasson, S. (2005). Temperature and substrate controls on intra-annual variation in ecosystem respiration in two subarctic vegetation types. Global Change Biology, 11: 465-475. doi: 10.1111/j.1365-2486.2005.00912.x.

Grosse, G., Romanovsky, V.E., Jorgenson, T., Anthony, K.W., Brown, J., and Overduin, P.P. (2011). Vulnerability and feedbacks of permafrost to climate change. Eos, 92(9): 73-80.

Guicharnaud, R., Arnalds, O., and Paton, G.I. (2010). Short term changes of microbial processes in Icelandic soils to increasing temperatures. Biogeosciences, 7: 671-682.

Gunther, A.J. (1989). Nitrogen fixation by lichens in a subarctic Alaskan watershed. The Bryologist, 92: 202-208.

Henry, G.H.R. (1998). Environmental influences on the structure of sedge meadows in the Canadian High Arctic. Plant Ecology, 134: 119-129.

Henry, G.H.R., Svoboda, J., and Freedman, B. (1990). Standing crop and net production of ungrazed sedge meadows of a polar desert oasis. Canadian Journal of Botany, 68: 26602667.

Hill, G.B. and Henry, G.H.R. (2011). Responses of High Arctic wet sedge tundra to climate warming since 1980. Global Change Biology, 17: 276-287.

Hobbie, S.E. and Chapin, F.S. III. (1996). Regulation of tundra litter carbon and nitrogen dynamics. Biogeochemistry, 35(2): 327-338.

Hodgson, D.A., Vincent, J.S., and Fyles, J.G. (1984). Quaternary Geology of Central Melville Island, Northwest Territories. Ottawa: Geological Survey of Canada, Paper 83-16.

Hodson, A.J., Mumford, P.N., Kohler, J., and Wynn, P.M. (2005). The high Arctic glacial ecosystem: new insights from nutrient budgets. Biogeochemistry, 72: 233-256.

Intergovernmental Panel on Climate Change [IPCC]. (2013). The Physical Basis. Contribution of Working Group I to the Fifth Assessment Report of the Intergovernmental Panel on Climate Change. 
Isaksen, K., Benestad, R.E., Harris, C., and Sollid, J.L. (2007). Recent extreme near-surface permafrost temperatures on Svalbard in relation to future climate scenarios. Geophysical Research Letters, 34. doi: 10.1029/2007GL031002.

Janssen, B.H. (1996). Nitrogen mineralization in relation to C:N ratio and decomposability of organic materials. Plant and Soil, 181: 39-45.

Jasrotia, P. and McSwiney, C. (2009). Ion Exchange Resin Strips to Estimate Nitrogen Availability. Retrieved June 9, 2016 from http://ter.kbs.msu.edu/protocols/105.

Johnson, L.C., Shaver, G.R., Cades, D.H., Rastetter, E., Nadelhoffer, K., Giblin, A.E., Laundre, J., and Stanley, A. (2000). Plant carbon-nutrient interactions control $\mathrm{CO}_{2}$ exchange in Alaskan wet sedge tundra ecosystems. Ecology, 81(2): 453-469.

Jonasson, S. and Shaver, G.R. (1999). Within-stand nutrient cycling in Arctic and boreal wetlands. Ecology, 80(7): 2139-2150.

Jones, A., Stolbovoy, V., Tarnocai, C., Broll, G., Spargaren, O., and Montanarella, L. (Eds.). (2010). Soil atlas of the northern circumpolar region. Luxembourg: European Commission.

Jorgenson, M.T., Shur, Y.L., and Pullman, E.R. (2006). Abrupt increase in permafrost degradation in Arctic Alaska. Geophysical Research Letters, 33. doi: 10.1029/2005GL024960.

Kahn, B. (2016). The world passes $400 \mathrm{ppm}$ threshold. Permanently. Climate Central. Retrieved March 20, 2017 from http://www.climatecentral.org/news/world-passes-400-ppmthreshold-permanently-20738.

Laerd Statistics. (2013). Mixed ANOVA using SPSS Statistics. Retrieved from https://statistics.laerd.com/spss-tutorials/mixed-anova-using-spss-statistics.php

Lafleur, P.M., Humphreys, E.R., St. Louis, V.L., Myklebust, M.C., Papakyriakou, T., Poissant, L., Barker, J., Pilote, M., and Swystun, K.A. (2012). Variation in peak growing season net ecosystem production across the Canadian Arctic. Environmental Science and Technology, 46: 7971-7977.

Lafrenière, M.J., Laurin, E., and Lamoureux, S.F. (2013). The impact of snow accumulation on the active layer thermal regime in High Arctic soils. Vadose Zone Journal, 12: 1-13. doi: 10.2136/vzj2012.0058.

Lagerström, A., Nilsson, M.C., Zackrisson, O., and Wardle, D.A. (2007). Ecosystem input of nitrogen through biological fixation in feather mosses during ecosystem retrogression. Functional Ecology, 21: 1027-1033 
Lajtha, K. (1988). The use of ion-exchange resin bags for measuring nutrient availability in an arid ecosystem. Plant and Soil, 105(1): 105-111.

Lamoureux, S.F. and Lafrenière, M.J. (2009). Fluvial impact of extensive active layer detachments, Cape Bounty, Melville Island, Canada. Arctic, Antarctic, and Alpine Research, 41(1): 59-68.

Larose, C., Dommergue, A., and Vogel, T.M. (2013). Microbial nitrogen cycling in Arctic snopacks. Environmental Research Letters, 8: 1-9.

Lavoie, M., Mack, M.C., and Schuur, E.A.G. (2011). Effects of elevation nitrogen and temperature on carbon and nitrogen dynamics in Alaskan Arctic and boreal soils. Journal of Geophysical Research, 116, G03013.

Lennihan, R., Chapin, D.M., and Dickson, L.G. (1994). Nitrogen fixation and photosynthesis in High Arctic forms of Nostoc commune. Canadian Journal of Botany, 72: 940-945.

Leppänen, S.M., Rissanen, A.J., and Tiirola, M. (2015). Nitrogen fixation in Sphagnum mosses is affected by moss species and water table level. Plant Soil, 389: 185-196. doi: 10.1007/s11104-014-2356-6.

Luce, S.J. (2016). Spatial and temporal patterns of biophysical variables and their influence on $\mathrm{CO}_{2}$ flux in a High Arctic wetland. Master's thesis. Retrieved from Ryerson University Digital Repository.

Mack, M.C., Schuur, E.A.G., Shaver, G.R., and Chapin, F.S. III. (2004). Ecosystem carbon storage in Arctic tundra reduced by long-term nutrient fertilization. Nature, 431: 440-443. doi:10.1038/nature02887.

Maxwell, S.E. and Delaney, H.D. (2004). Designing experiments and analyzing data: A model comparison perspective ( $2^{\text {nd }}$ ed). New York, NY: Psychology Press.

McGuire, A.D., Christensen, T.R., Hayes, D., Heroult, A., Euskirchen, E., Kimball, J.S., Koven, C., Lafleur, P.M., Miller, P.A., Oechel, W., Peylin, P., Williams, M., and Yi, Y. (2012). An assessment of the carbon balance of Arctic tundra: comparisons among observations, process models, and atmospheric inversions. Biogeosciences, 9(8): 3185-3204.

Mellinger, M.V. and McNaughton, S.J. (1975). Structure and function of successional vascular plant communities in Central New York. Ecological Monographs, 45: 161-182.

Mikan, C.J., Schimel, J.P., and Doyle, A.P. (2002). Temperature controls of microbial respiration in Arctic tundra soils above and below freezing. Soil Biology and Biochemistry, 34: 1785-1795.

Milligan, P. (2010). PRS-Probe: Not Just a Soil Test. Grainews. Retrieved May 20, 2016 from http://www.grainews.ca/2010/03/08/prsprobe-not-just-a-soil-test/. 
Nadelhoffer, K.J., Giblin, A.E., Shaver, G.R., and Laundre, J.A. (1991). Effects of temperature and substrate quality on element mineralization in 6 Arctic soils. Ecology, 72: 242-253.

Nadelhoffer, K.J., Giblin, A.E., Shaver, G.R., and Linkins, A.E. (1992). Microbial processes and plant nutrient availability in arctic soils. In Chapin, F.S. III, Jefferies, R.L., Reynold, J.F., Shaver, G.R., and Svoboda, J. (Eds.). Arctic ecosystems in a changing climate, an ecophysiological perspective. San Diego: Academic Press. pp. 281-300

Natali, S.M., Schuur, E.A.G., Trucco, C., Hicks Pries, C.E., Crummer, K.G., and Baron Lopez, A.F. (2011). Effects of experimental warming of air, soil, and permafrost on carbon balance in Alaskan tundra. Global Change Biology, 17: 1394-1407. doi: 10.1111/j.13652486.2010.02303.x.

National Atmospheric Deposition Program [NADP]. (2002). National Atmospheric Deposition Program 2001 Summary, NADP Report. Champaign, IL: Illinois State Water Survey.

National Aeronautics and Space Administration [NASA]. (2017). NOAA/NASA Annual Global Analysis for 2016 - 2016 was third successive record-warm year [Powerpoint slides]. Retrieved from https://www.giss.nasa.gov/research/news/20170118/NOAANASA_Global_Analysis-2016-FINAL.pdf.

National Oceanic and Atmospheric Administration [NOAA]. (2015). National Ocean Service. $\begin{array}{llll}\text { Retrieved } & \text { September } & 20, & \text { from }\end{array}$ http://oceanservice.noaa.gov/facts/remotesensing.html.

National Wetlands Working Group. (1988). Wetlands of Canada, Volume 24. Montreal: Environment Canada and Polysciences Publications Inc., Ecological Land Classification Series.

Newbold, J.D., Elwood, J.W., O’Neill, R.V., and Van Winkle, W. (1981). Measuring nutrient spiraling in streams. Canadian Journal of Fisheries and Aquatic Science, 38: 860-863.

Nobrega, S. and Grogan, P. (2008) Landscape and ecosystem-level controls on net carbon dioxide exchange along a natural moisture gradient in Canadian Low Arctic tundra. Ecosystems, 11: 377-396. doi: 10.1007/s10021-008-9128-1.

Oberbauer, S.F., Hastings, S.J., Beyers, J.L., and Oechel, W.C. (1989). Comparative effects of downslope water and nutrient movement on plant nutrition, photosynthesis, and growth in Alaskan tundra. Holarctic Ecology, 12: 324-334.

Oechel, W.C., Hastings, S.J., Vourlitis, G., Jenkins, M., Riechers, G., and Grulke, N. (1993). Recent change of arctic tundra ecosystems from a net carbon dioxide sink to a source. Nature, 361: 520-523. 
Pansu, M. and Gautheyrou, J. (2006). Handbook of Soil Analysis: Mineralogical, Organic and Inorganic Methods. Springer: Berlin/Heidelberg, Germany.

Post, W.M., Emmanuel, W.R., Zinke, P.J. Strangenburger, A.G. (1982). Soil carbon pools and world life zones. Nature, 298: 156-159.

Qian, P. and Schoenau, J.J. (2005). Use of ion-exchange membrane to assess nitrogen-supply power of soils. Journal of Plant Nutrition, 28: 2193-2200.

Ramsay, G. (2015). Spatial and temporal modelling of biophysical variables within a High Arctic wetland. Master’s thesis. Retrieved from Ryerson University Digital Repository.

Rastetter, E.B., Kwiatkowski, B.L., Le Dizès, S., and Hobbie, J.E. (2004). The role of downslope water and nutrient fluxes in the response of Arctic hill slopes to climate change. Biogeochemistry, 69: 37-62.

Reynolds, J.F. and Tenhunen, J.D. (1996). Landscape function and disturbance in Arctic tundra. Berlin: Springer.

Robinson, C.H. and Wookey, P.A. (1997). Microbial ecology, decomposition, and nutrient cycling. In Woodin, S.J. and Marquiss, M. (Eds.). Ecology of Arctic Environments (4167). Oxford: Blackwell.

Robinson, C.H. (2002). Controls on decomposition and soil nitrogen availability at high latitudes. Plant and Soil, 242(1): 65-81.

Rustad, L.E., Campbell, J.L., Marion, G.M., Norby, R.J., Mitchell, M.J., Hartley, A.E., Cornelissen, J.H.C., Gurevitch, J. (2000). A meta-analysis of the response of soil respiration, net nitrogen mineralization, and aboveground plant growth to experimental ecosystem warming. Oecologia, 126: 543-562. doi: 10.1007/s004420000544.

Schmidt, I.K., Michelsen, A., and Jonasson, S. (1997). Effect on plant production after addition of labile carbon to Arctic/alpine soils. Oecologia, 112: 305-313.

Schmidt, I.K., Jonasson, S., and Michelsen, A. (1999). Mineralization and microbial immobilization of $\mathrm{N}$ and $\mathrm{P}$ in Arctic soils in relation to season, temperature, and nutrient amendment. Applied Soil Ecology, 11: 147-160.

Schmidt, I.K., Jonasson, S., Shaver, G.R., Michelsen, A., and Nordin, A. (2002). Mineralization and distribution of nutrients in plants and microbes in four Arctic ecosystems: responses to warming. Plant and Soil, 242(1): 93-106.

Schmidt, S.K. and Lipson, D.A. (2004). Microbial growth under the snow: Implications for nutrient and allelochemical availability in temperature soils. Plant and Soil, 259: 1-7. 
Schuur, E.A.G., Vogel, J., Crummer, K., Lee, H., Sickman, J., and Osterkamp, T. (2009) The effect of permafrost thaw on old carbon release and net carbon exchange from tundra. Nature, 459: 556-559.

Shaver, G.R., Billings, W.D., Chapin, F.S. III, Giblin, A.E., Nadelhoffer, K.J., Oechel, W.C., and Rastetter, E.B. (1992). Global change and the carbon balance of Arctic ecosystems. Bioscience, 42: 433-441

Shaver, G.R., Canadell, J., Chapin, F.S. III, Gurevitch, J., Harte, J., Henry, G.H.R., Ineson, P., Jonasson, S., Mellilo, J., Pitelka, L., and Rustad, L.E. (2000). Global warming and terrestrial ecosystems: A conceptual framework for analysis. BioScience, 50(10): 871882.

Shaver, G.R., and Chapin, F.S. III. (1991). Production: biomass relationships and element cycling in contrasting Arctic vegetation types. Ecological Monographs, 61(1): 1-31.

Shaver, G.R., and Chapin, F.S. III. (1995). Long-term responses to factorial, NPK fertilizer treatment by Alaskan wet and moist tundra sedge species. Ecography, 18(3): 259-275.

Siska, P.P. and Hung, I-K. (2001). Assessment of Kriging Accuracy in the GIS Environment. Faculty Presentations. Paper 7. In 21st Annual ESRI International Conference, San Diego, CA.

Skrzypek, G., Wojtuń, B., Richter, D., Jakubas, D., Wojczulanis-Jakubas, K., and SameckaCymerman, A. (2015). Diversity of nitrogen sources in various tundra vegetation types in the High Arctic. PLoS One, 10(9).

Stark, S. (2007). Nutrient cycling in the tundra. In Marschner, P. and Rengel, Z. (Eds.), Soil biology: Nutrient cycling in terrestrial ecosystems (Vol. 10, 309-331). Berlin: Springer.

Stewart, K.J., Brummel, M.E., Coxson, D.S., and Siciliano, S.D. (2012). How is nitrogen fixation in the High Arctic linked to greenhouse gas emissions? Plant and Soil, 362(1): 215-229. doi: 10.1007/s11104-012-1282-8.

Stewart, K.J., Grogan, P., Coxson, D.S., and Siciliano, S.D. (2014). Topography as a key factor driving atmospheric nitrogen exchanges in Arctic terrestrial ecosystems. Soil Biology and Biochemistry, 70: 96-112. doi: 10.1016/j.soilbio.2013.12.005.

Stocker, T.F., Qin, D., Plattner, G.-K., Alexander, L.V., Allen, S.K., Bindoff, N.L., Bréon, F.-M., Church, J.A., Cubasch, U., Emori, S., Forster, P., Friedlingstein, P., Gillett, N., Gregory, J.M., Hartmann, D.L., Jansen, E., Kirtman, B., Knutti, R., Krishna Kumar, K., Lemke, P., Marotzke, J., Masson-Delmotte, V., Meehl, G.A., Mokhov, I.I., Piao, S., Ramaswamy, V., Randall, D., Rhein, M., Rojas, M., Sabine, C., Shindell, D., Talley, L.D., Vaughan, D.G., and Xie, S.-P. (2013). 2013: Technical Summary. Climate Change 2013: The Physical Science Basis. Contribution of Working Group I to the Fifth Assessment Report 
of the Intergovernmental Panel on Climate Change. Cambridge, U.K. and New York, NY: Cambridge University Press.

Sullivan, P.F., Arens, S.J.T., Chimner, R.A., and Welker, J.M. (2008). Temperature and microtopography interact to control carbon cycling in a High Arctic fen. Ecosystems, 11: 61-76.

Tarnocai, C., Canadell, J.G., Schuur, E.A.G., Kuhry, P., Mazhitova, G., and Zimov, S. (2009). Soil organic carbon pools in the northern circumpolar permafrost region. Global Biogeochemical Cycles, 23. doi:10.1029/2008GB003327.

Thompson, D.K. and Woo, M.K. (2009). Seasonal hydrochemistry of a High Arctic wetland complex. Hydrological Processes, 23: 1397-1407. doi: 10.1002/hyp.7271.

Tilman, D. (1982). Resource competition and community structure. Princeton University Press, Princeton, New Jersey: Princeton University Press.

United States Environmental Protection Agency [US EPA]. (2017). Understanding global warming potentials. Retrieved April 30, 2017 from https://www.epa.gov/ghgemissions/understanding-global-warming-potentials.

Van Cleve, K. and Alexander, V. (1981). Nitrogen cycling in tundra and boreal systems. In Clark, F.E. and Rosswall, T. (Eds.), Terrestrial nitrogen cycles (Vol. 33, 375-404). Stockholm: Ecological Bulletins.

Verhoeven, J.T.A., Maltby, E., and Schmitz, M.B. (1990). Nitrogen and phosphorus mineralization in fens and bogs. Journal of Ecology, 78: 713-726.

Voigt, C., Lamprecht, R.E., Marushchak, M.E., Lind, S.E., Novakovskiy, A., Aurela, M., Martikainen, P.J., and Biasi, C. (2016). Warming of subarctic tundra increases emissions of all three important greenhouse gases - carbon dioxide, methane, and nitrous oxide. Global Change Biology, 22(12). doi: 10.1111/gcb.13563.

Walker, D.A., Raynolds, M.K., Daniels, F.J.A., Einarsson, E., Elvebakk, A., Gould, W.A., Katenin, A.E., Kholod, S.S., Markon, C.J., Melnikov, E.S., Moskalenko, N.G., Talbot, S.S., Yurtsev, B.A., Bliss, L.C., Edlund, S.A., Zoltai, S.C., Wilhelm, M., Bay, C., Gudjónsson, G., Moskalenko, N.G., Ananjeva, G.V., Drozdov, D.S., Konchenko, L.A., Korostelev, Y.V., Melnikov, E.S., Ponomareva, O.E., Matveyeva, N.V., Safranova, I.N., Shelkunova, R., Polezhaev, A.N., Johansen, B.E., Maier, H.A., Murray, D.F., Fleming, M.D., Trahan, N.G., Charron, T.M., Lauritzen, S.M., and Vairin, B.A. (2005). The circumpolar Arctic vegetation map. Journal of Vegetation Science, 16: 267-282.

Welker, J.M., Fahnestock, J.T., Henry, G.H.R., O’Dea, K.W., and Chimners. R.A. (2004). $\mathrm{CO}_{2}$ exchange in three Canadian High Arctic ecosystems: Response to long-term experimental warming. Global Change Biology, 10(12): 1981-1995. 
Weller, G., Chapin, F.S., Everett, K.R., Hobbie, J.E., Kane, D., Oechel, W.C., Ping, C.L., Reeburgh, W.S., Walker, D., and Walsh, J. (1995). The Arctic flux study: a regional view of trace gas release. Journal of Biogeography, 22: 365-374.

Western Ag. (2012). PRS Technology. Retrieved June 8, 2016 from https://www.westernag.ca/innovations/technology/basics.

Woo, M.K. (2011). Northern wetlands. In: Woo, M.K. (Ed). Permafrost Hydrology. Berlin: Springer-Verlag Berlin Heidelberg.

Woo, M.K. and Young, K.L. (2006). High Arctic wetlands: their occurrence, hydrological characteristics and sustainability. Journal of Hydrology, 320(3-4): 432-450. doi: 10.1016/j.jhydrol.2005.07.025.

Woo, M.K. and Young, K.L. (2012). Wetlands of the Canadian Arctic. In: Bengtsson, L., Herschy, R.W., and Fairbridge, R.W. (Eds.). Encyclopedia of Lakes and Reservoirs. Dordrecht, Netherlands: Springer Netherlands.

Woo, M.K. and Young, K.L. (2014). Disappearance of semi-permanent snow in the High Arctic and its consequences. Journal of Glaciology, 60(219): 192-200. doi: 10.3189/2014JoG13J150.

Woo, M.K., Young, K.L., and Brown, L. (2013). High Arctic patchy wetlands: Hydrologic variability and their sustainability. Physical Geography, 27(4): 297-307.

Woodin, S.J. (1997). Effects of acid deposition on arctic vegetation. In: Wooding, S.J. and Marquiss, M. (Eds.). Ecology of Arctic Environments. Oxford: Blackwell Science.

Yang, Z., Ouyang, H., Zhang, X., Xu, X., Zhou, X., and Yang, W. (2011). Spatial variability of soil moisture at typical alpine meadow and steppe sites in the Qinghai-Tibetan Plateau permafrost region. Environmental Earth Sciences, 63:477-488.

Young, K.L. (2006). Assessment of snow storage and ground ice melt in High Arctic environments. Hydrological Processes, 20: 2643-2645. doi: 10.1002/hyp.6348.

Zoltai, S.C. and Martikainen, P.J. (1996). The role of forested peatlands in the global carbon cycle. NATO ASI Ser I, 40: 47-58. 